DEPARTAMENTO DE ANATOMÍA E HISTOLOGÍA HUMANA FACULTAD DE MEDICINA UNIVERSIDAD DE SALAMANCA

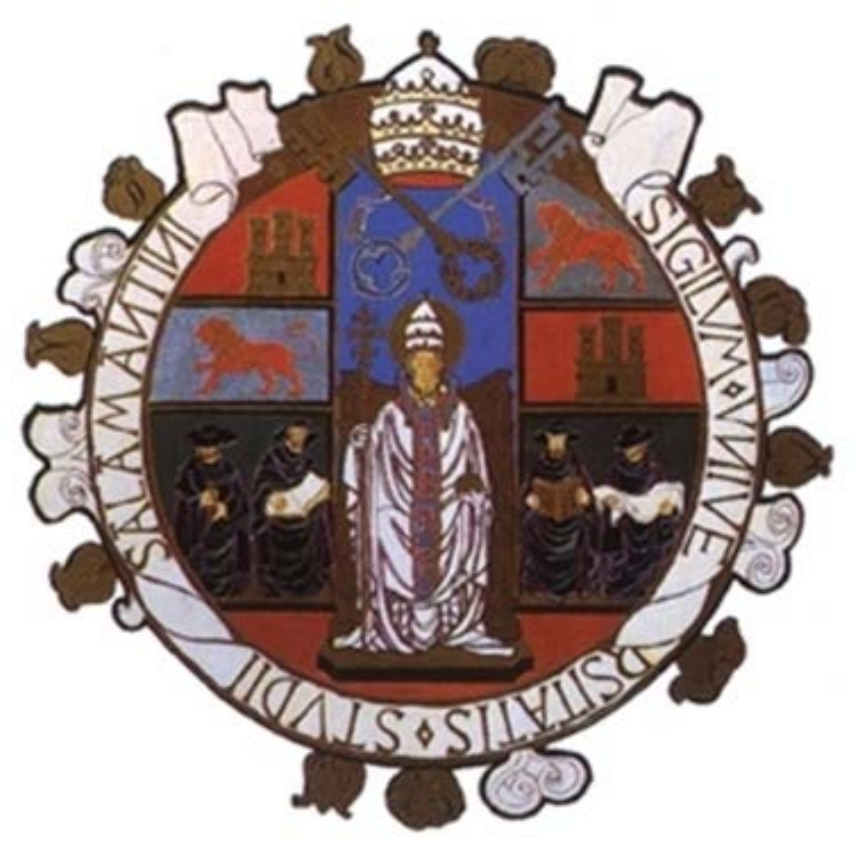

\title{
ALTERACIONES MORFO-FUNCIONALES DEL CORPÚSCULO RENAL EN UN MODELO EXPERIMENTAL DE OBSTRUCCIÓN URETERAL UNILATERAL
}

TESIS DOCTORAL

Marta Ortiz Aranda

DIRECTOR

Miguel A. Arévalo Gómez

Salamanca, 2015 
"La paciencia es la más heroica de las virtudes, precisamente porque carece de toda apariencia heroica"

Giacomo Leopardi

A mi binomio, Fran 


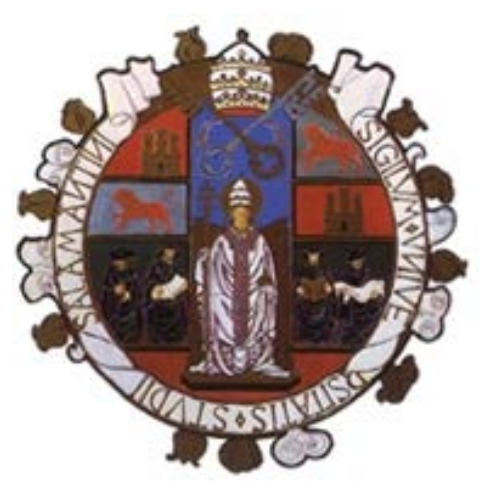

D. MIGUEL A. ARÉVALO GÓMEZ, Catedrático de Histología del Departamento de Histología y Anatomía Humana de la Universidad de Salamanca,

\section{INFORMA}

Que la Tesis titulada ALTERACIONES MORFO-FUNCIONALES DEL CORPUSCULO RENAL EN UN MODELO EXPERIMENTAL DE OBSTRUCCION URETERAL UNILATERAL, presentada por la Lda. Dña. Marta Ortiz Aranda para optar al grado de Doctor por la Universidad de Salamanca, ha sido realizada bajo mi dirección en el Departamento de Anatomía e Histología Humana de la Universidad de Salamanca y, considerándola concluida, autoriza su presentación a fin de que pueda ser defendida ante el tribunal correspondiente. Y para que así conste, firma la presente en Salamanca, a 25 de marzo de 2015.

Fdo.: Dr. Miguel A. Arévalo Gómez 


\section{AGRADECIMIENTOS.}

En primer lugar quiero dar las gracias a mi Director, el Prof. Dr. D.Miguel A. Arévalo Gómez ya que sin su apoyo esta tesis no hubiera sido posible. Quiero agradecerle no sólo el apoyo científico sino también el apoyo personal que me ha ofrecido durante estos años.

Al Prof. Dr. D. José Miguel López Novoa que me abrió desinteresadamente las puertas de su laboratorio y me asesoró en todas aquellas cuestiones fisiológicas en las que tuve dudas.

Quiero mostrar mi agradecimiento al Prof Dr. D. Eliseo Carrascal Marino, Catedrático de Histología, por su apoyo y por su amabilidad facilitándome la estancia en la Unidad de Histología.

Quiero dar las gracias también a los Profesores de la Unidad de Histología D. Francisco Collía Fernández, Dª Mํㅡㄹ Ángeles Pérez de la Cruz y D. Jose A. García Méndez por hacerme sentir como en casa en su departamento.

A la profesora Prof. Drª $\mathrm{D}^{\mathrm{a}}$ Purificación Galindo Villardón, por su ayuda en los análisis estadísticos pero también por su amabilidad, paciencia y su disponibilidad 24 horas.

A la Técnico de Laboratorio Angustias Pérez por su paciencia y su ayuda con la realización de diferentes técnicas inmunohistoquímicas de este trabajo.

A mis compañeros Rosa Sánchez, Javier Sánchez y Lorena Benito, porque la palabra compañero está muy devaluada pero ellos han demostrado siempre que lo son con su espíritu de equipo y su gran capacidad para hacerme sonreír.

A mis amigas de aquí y de allá, a mis cotorras, por estar siempre para lo que haga falta.

A mis padres por los esfuerzos que hicieron para que yo llegara aquí.

A mis niñas por aguantar mis neuras cuando estoy estresada.

A mi binomio, Fran, por tanto, por todo. 


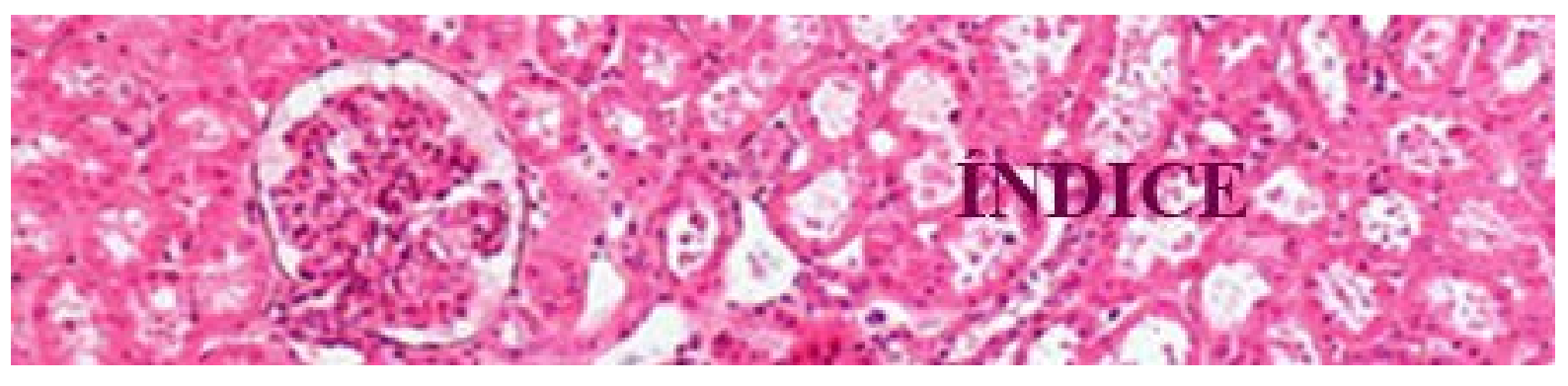




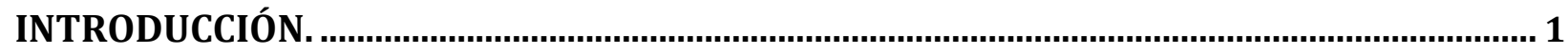

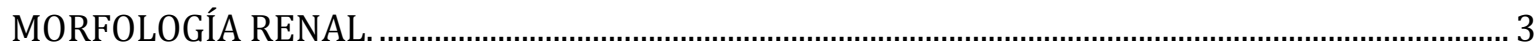

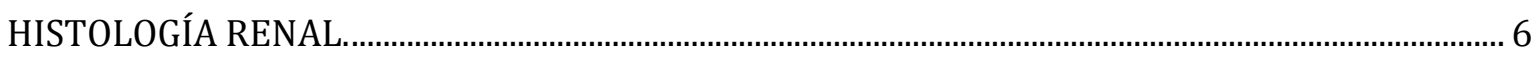

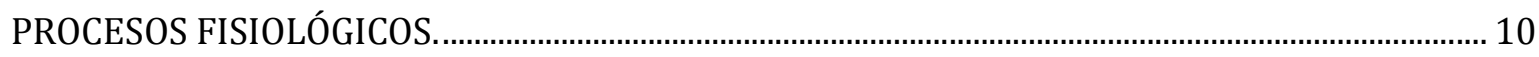

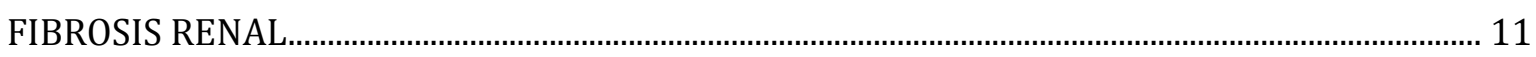

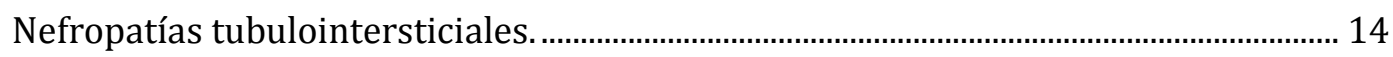

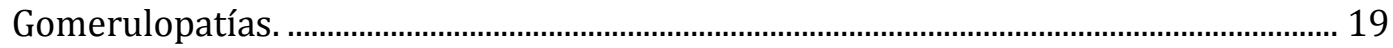

MECANISMOS DE SEÑALIZACIÓN EXTRACELULAR IMPLICADOS EN LA

PATOGÉNESIS RENAL ……………………………….................................................................. 21

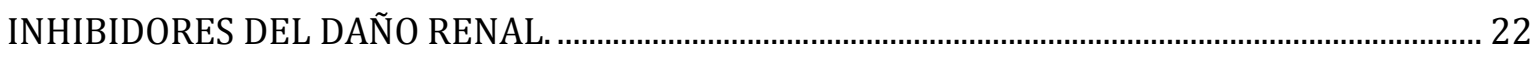

EL MODELO DE OBSTRUCCIÓN URETERAL UNILATERAL............................................................ 23

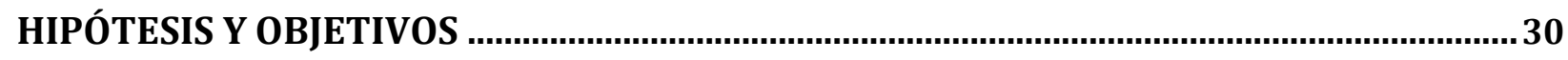

MATERIAL Y MÉTODOS.................................................................................................... 32

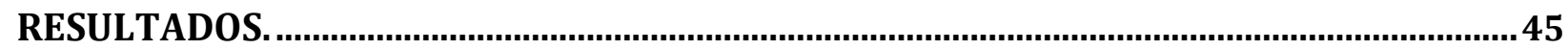

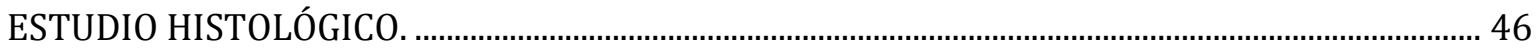

ESTUDIO MORFOMÉTRICO: TINCIÓN CON ROJO SIRIO................................................................... 51

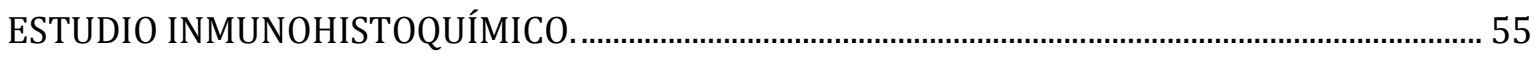

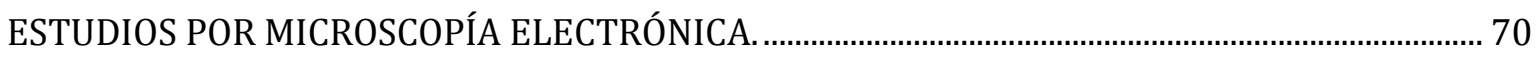

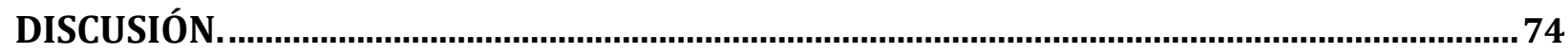

CONCLUSIONES.

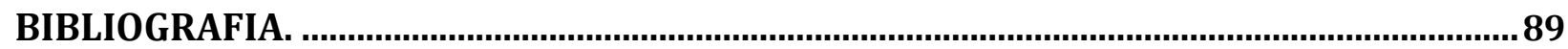




\section{ABREVIATURAS.}

\begin{tabular}{|c|c|}
\hline $\mathrm{ADH}$ & Hormona antidiurética \\
\hline Ag II & Angiotensina II \\
\hline ARNm & Ácido ribonucleico mensajero \\
\hline $\mathrm{BFG}$ & Barrera de filtración glomerular \\
\hline $\mathrm{bFGF}$ & Factor básico de Crecimiento de Fibroblastos \\
\hline $\mathrm{C}$ & Control \\
\hline CTGF & Factor de crecimiento del tejido conjuntivo \\
\hline ECA & Enzima convertidora de angiotensina \\
\hline EEM & Error estándar de la media \\
\hline EMT & Transdiferenciación epitelio-mesenquimal \\
\hline GAPs & proteínas activadoras de GTPasas \\
\hline GEFs & Factores intercambiadores de nucleótidos de guanina \\
\hline IL-1 & Interleucina 1 \\
\hline IRC & Inflamación renal crónica \\
\hline $\mathrm{L}$ & Ligados \\
\hline MBG & Membrana basal glomerular \\
\hline MEC & Matriz extracelular \\
\hline MMPs & Metaloproteinasas \\
\hline NL & No ligados \\
\hline OUU & Obstrucción ureteral unilateral \\
\hline PDGF & Factor de crecimiento derivado de plaquetas \\
\hline ROS & Especies reactivas al oxígeno \\
\hline Sham & Grupo con tratamiento simulado \\
\hline Smads & Mothers Against Decapentaplegic Homolog \\
\hline SPARC & Proteína secretada rica en Cys \\
\hline TNF- $\alpha$ & Factor de necrosis tumoral $\alpha$ \\
\hline $\mathrm{tPA}$ & Activador de plasminógeno \\
\hline TCP & Túbulo contorneado proximal \\
\hline TFG & Tasa de filtración glomerular \\
\hline TGF- $\beta$ & Factor de crecimiento transformante beta \\
\hline WT-1 & Tumor de Williams 1 \\
\hline$\alpha$-SMA & Alfa actina de músculo liso vascular \\
\hline
\end{tabular}




\section{ÍNDICE DE FIGURAS}

\section{FIGURAS}

PÁGINA

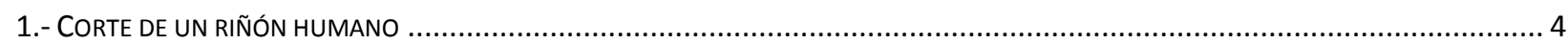

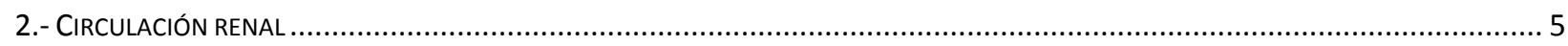

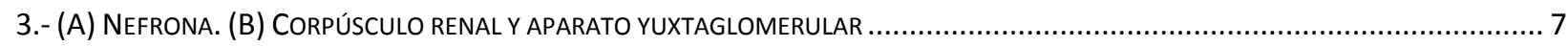

4.- Microfotografía tomadA CON TEM EN LA QUE SE MUESTRAN LOS PARÁMETROS EMPLEAdOS PARA LOS ANÁLISIS DE IMAGEN..... 52

5.- Micrografías REPRESENTATIVAS de MUESTRAS DE INTERSTICIO CORTICAL RENAL TEÑIDAS CON HEMATOXILINA-EOSINA................ 49

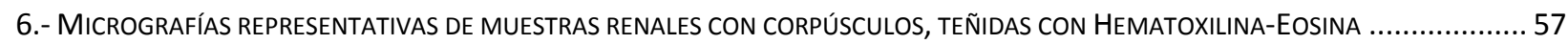

7.- Micrografías REPRESENTATIVAS DE MUESTRAS DE INTERSTICIO RENAL TEÑIDAS CON TRICRÓMICO dE MASSON..........................58

8.- Micrografías REPRESENTATIVAS de MUESTRAS DE CORPúSCULOS RENALES TEÑIDAS CON TRICRÓMICO DE MASSON .....................59

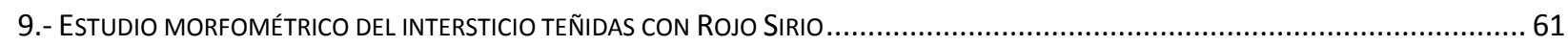

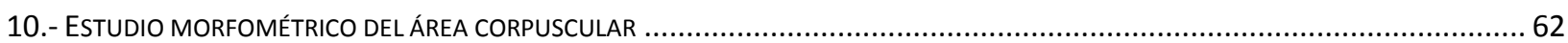

11.- GRÁFICA REPRESENTATIVA DEL ANÁLISIS DE IMAGEN QUE MUESTRA LA CUANTIFICACIÓN MESANGIAL ....................................63

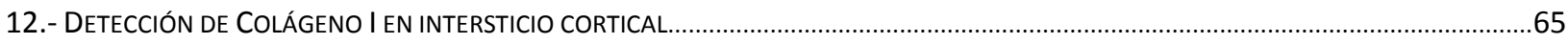

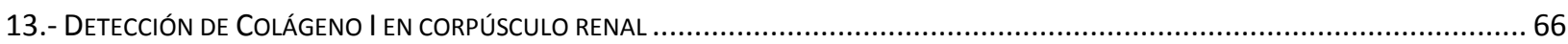

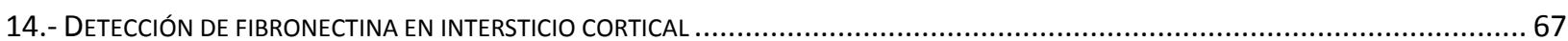

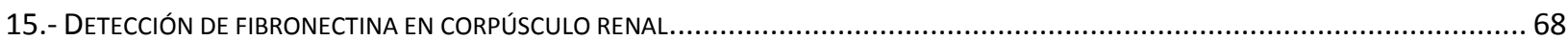

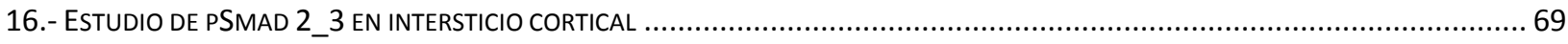

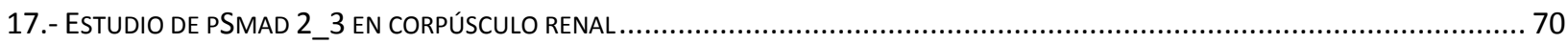

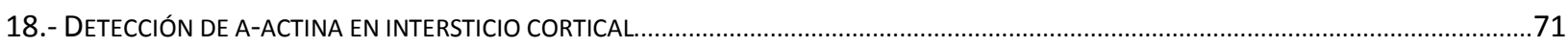

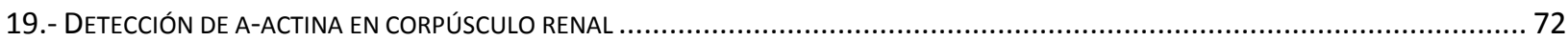

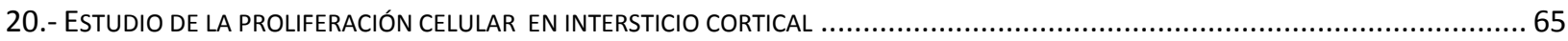

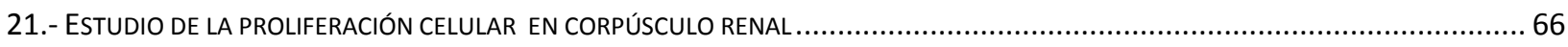

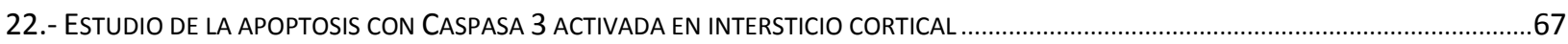

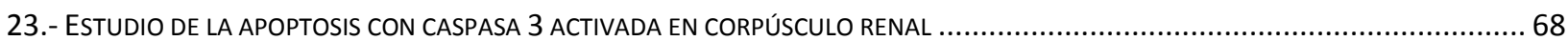

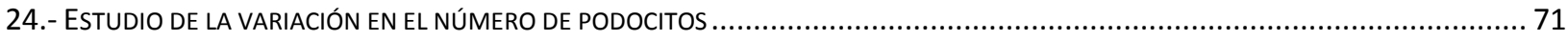

25.- MICROFOTOGRAFÍAS TOMADAS MEDIANTE MICROSCOPÍA ELECTRÓNICA DE TRANSMISIÓN EN CORPÚSCULO RENAL .......................81

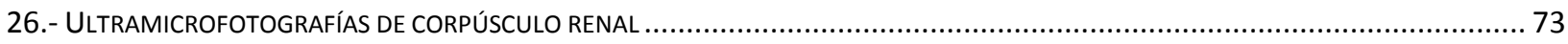

27.- (A) GRÁFICA dE LA CUANTIFICACIÓN DEL GROSOR DE LA MEMBRANA BASAL GLOMERULAR (B) GRÁFICA DE LA CUANTIFICACIÓN DEL GROSOR DE LA BASE DE LOS PEDICELOS 


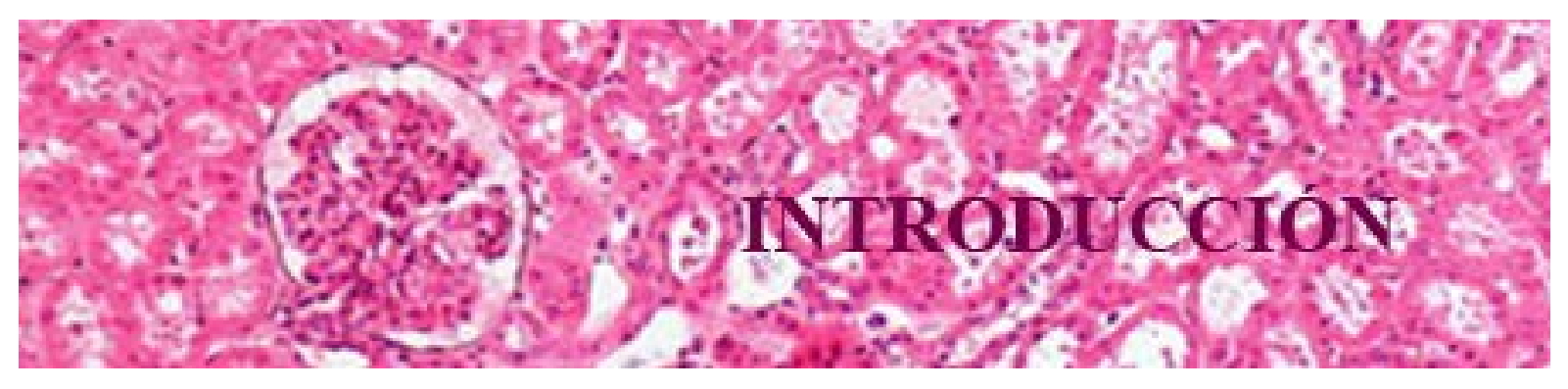


El riñón es una víscera esencial para el mantenimiento del equilibrio hidroelectrolítico de nuestro organismo que, además, se encarga de filtrar y excretar productos provenientes del catabolismo celular del organismo. Asimismo, el riñón es una glándula endocrina que segrega hormonas básicas para el control de la presión arterial y de otros parámetros biológicos (eritropoyetina, vitamina D activa, calicreínas, etc.). Por todo lo anterior, cualquier alteración morfo-funcional de los riñones supone un proceso grave que compromete seriamente la salud.

La progresión del daño renal a insuficiencia renal crónica (IRC) es el camino final común en el que convergen patologías renales de distintos orígenes (glomerulonefritis, diabetes, hipertensión) y que, una vez iniciada, no tiene mecanismos posibles de cura, si bien un adecuado tratamiento pueda hacer más lenta dicha progresión (1). El substrato morfológico que explica la progresión de la insuficiencia renal es una deposición progresiva de matriz extracelular tanto en el glomérulo (glomeruloesclerosis) como en el intersticio tubular (fibrosis tubulo-intersticial), por un mecanismo en parte común para las distintas patologías y en el que juega un papel clave la acción de mediadores autocrinos y paracrinos tales como la Angiotensina II (Ag II), y el factor de crecimiento transformante $ß$ (TGF-ß). La obstrucción de las vías urinarias produce en el riñón, una fibrosis tubulointersticial y una infiltración del intersticio por macrófagos $(2,3)$. Esta fibrosis se caracteriza por una acumulación de proteínas de la matriz extracelular, con depósitos de colágeno I, III y IV, y fibronectina. La expansión de la matriz extracelular provoca una atrofia tubular y una reducción de los capilares peritubulares. Los mecanismos celulares y moleculares responsables de la aparición de esta fibrosis no son completamente conocidos en la actualidad (4-11).

Hasta el momento, los estudios realizados en los procesos que suceden tras la obstrucción de las vías urinarias se han centrado en lo que sucede en el espacio tubulo-intersticial; sin embargo, muy poco o nada se ha descrito sobre las posibles alteraciones en corpúsculo renal, salvo algún dato proporcionado como en el trabajo sobre proliferación y apoptosis de Truong (12), por lo que el estudio de las mismos en el presente proyecto de tesis doctoral es un tema de interés biomédico y diagnóstico y de gran originalidad. 
El objetivo general de esta tesis es el estudio con microscopía óptica y ultraestructural de los procesos morfo-funcionales que puedan originarse en el corpúsculo renal tras un proceso de obstrucción ureteral unilateral experimental. 


\section{MORFOLOGÍA RENAL.}

\section{ANATOMÍA.}

Los riñones son dos órganos pertenecientes al sistema urinario que se encuentran situados retroperitonealmente dentro de la cavidad abdominal, a ambos lados de la columna vertebral. Tradicionalmente se describe su forma como de habichuela en la que su lado cóncavo se sitúa hacia la línea media. El centro de esta parte cóncava se denomina hilio y es el lugar de entrada y salida de la irrigación sanguínea, de los nervios y de los vasos linfáticos además de la parte inicial del sistema de transporte de orina, el uréter, lo que constituye la llamada pelvis renal.

Externamente el riñón está envuelto por tejido conjuntivo que constituye la cápsula renal, rodeada por tejido adiposo, la grasa perirrenal y una envoltura de tejido conjuntivo llamada fascia renal, que lo ancla a las estructuras adyacentes.

En un corte sagital pueden distinguirse dos zonas diferenciadas: una parte externa denominada corteza y una parte interna denominada medula (Figura 1). De la corteza surgen unas proyecciones que se introducen en la médula denominadas columnas de Bertini y en ella se encuentra el 75\% de las estructuras que constituyen las unidades morfo-funcionales de los riñones y que se denominan nefronas.

La médula renal está compuesta por entre 8 y 18 pirámides renales o pirámides de Malpighi ocupadas fundamentalmente por segmentos paralelos rectos de túbulos renales. La porción más distal de estos túbulos, denominados conductos colectores mayores, va a desembocar a los extremos de una papila perforándola y originando el área cribosa papilar (13-15). La papila de cada pirámide protruye en una estructura a modo de copa, denominada cáliz menor. Un conjunto de cálices menores se reúnen en un cáliz mayor y estos desembocan, a modo de embudo, en la pelvis renal, formando el inicio del uréter.

Cada pirámide medular y la región cortical que la cubre constituyen un lóbulo renal. De la base de las pirámides parten unas finas estriaciones o rayos medulares que ascienden 
perpendicularmente en la corteza renal. El resto de la corteza recibe el nombre de laberinto cortical. La porción de corteza centrada por un rayo medular y el parénquima situado a ambos lados del mismo constituye un lobulillo renal.

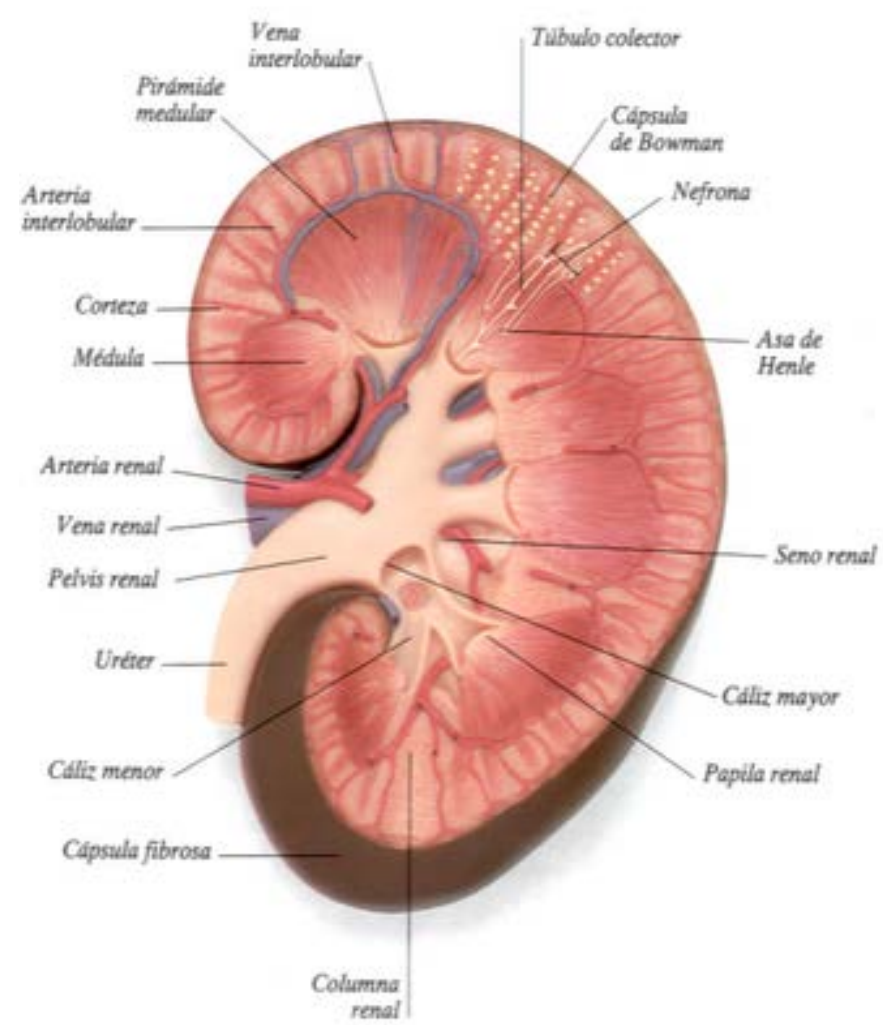

Figura 1: Corte de un riñón humano (Fisiología médica GPO: IV-3, Armenta Majarrez, M.F.) SUMINISTRO SANGUÍNEO, INERVACIÓN Y VASOS LINFÁTICOS RENALES.

Cada riñón recibe el flujo de sangre a través de la correspondiente arteria renal, que se origina en la aorta abdominal. La arteria renal, al entrar en el hilio del riñón, se va a dividir en dos grandes ramas, una anterior y otra posterior que, antes incluso de penetrar en el tejido renal, van a dividirse en varias arterias segmentarias. Una vez que estas se introducen en el parénquima renal originan las arterias interlobulares que discurren ascendiendo por las pirámides de Bertin hasta la base de cada pirámide medular ramificándose, a su vez, para formar las arterias arqueadas o arciformes, que van a lo largo del límite entre la médula y la corteza renal, y de las que surgen de forma radial, perpendiculaemente a la superficie renal, las llamadas las arterias interlobulillares. Las ramificaciones de estas arterias corticales originan las arteriolas aferentes que, penetrando en 
el corpúsculo renal, dan lugar a una serie de asas capilares denominadas glomérulo renal que drenan en las arteriolas eferentes. (16).

Tras abandonar el corpúsculo, las arteriolas eferentes se ramifican en una red de capilares peritubulares que se distribuyen por todas las porciones de los túbulos, a los que se adosan íntimamente. Esta disposición permite un proceso tan importante como es el paso a la sangre de sustancias reabsorbidas por las células tubulares Por otro lado, las arteriolas aferentes pertenecientes a glomérulos yuxtamedulares van a originar una serie de capilares que descienden siguiendo un largo trayecto descendente entre los componentes tubulares de la médula y que se denominan vasos rectos descendentes, los cuales se van a ramificar en forma de malla alargada alrededor de las asas de Henle y los tubulos colectores y originan, finalmente otros vasos rectos ascendentes que siguen un trayecto paralelo y opuesto a los descendentes. Esta disposición vascular va a facilitar el intercambio de líquidos e iones que se verifica en la médula renal.

El retorno venoso en el riñón sigue, en general, un trayecto opuesto a la circulación arterial hasta formar la vena renal que desembocará en la cava inferior (15) 


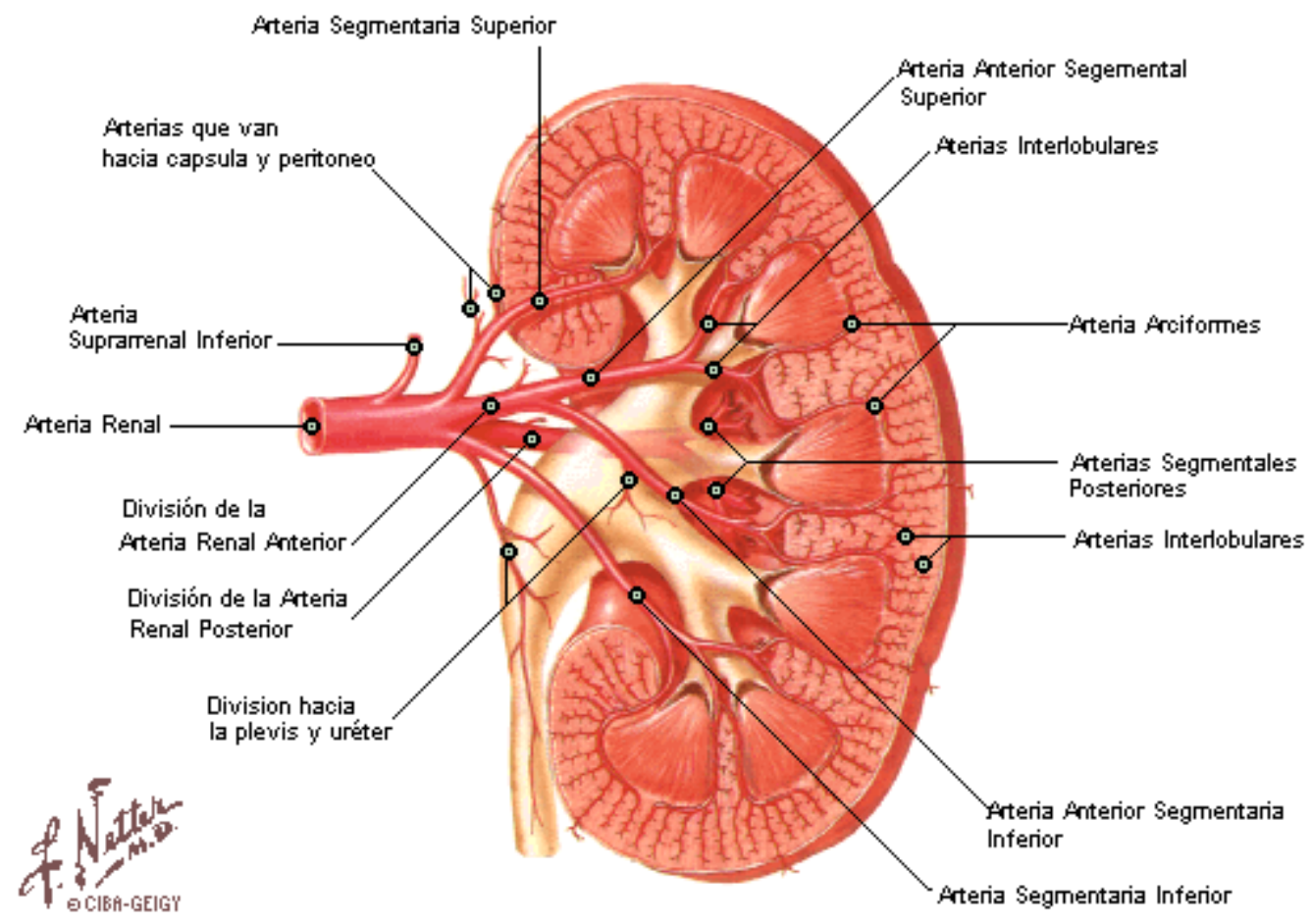

Figura 2: Circulación renal (www.fotosimagenes.com)

En cuanto a la inervación, el riñón presenta fibras nerviosas simpáticas que se originan principalmente en el plexo celíaco. El aumento de actividad simpática provoca la secreción de renina y favorece la reabsorción de sodio en el asa de Henle, el túbulo distal y el conducto colector. (17)

Los vasos linfáticos aparecen en el intersticio cortical paralelos al trayecto de los vasos sanguíneos y abandonan el riñón por el hilio. No existe circulación linfática en la médula renal y el drenaje de la parte externa de la corteza lo recibe una red de capilares linfáticos que discurren por la cápsula renal. $(15,18)$ 


\section{HISTOLOGÍA RENAL.}

La nefrona es la unidad morfo-funcional del riñón y es la encargada de formar la orina. Las nefronas son el equivalente a la porción secretora de las glándulas exocrinas, aunque también tienen una vertiente endocrina.

Cada nefrona está formada por dos componentes principales: el corpúsculo renal y el sistema tubular. El corpúsculo renal está constituido por una estructura esférica hueca de doble pared epitelial llamada cápsula de Bowman que en su interior alberga una red de asas capilares denominada glomérulo. El sistema tubular está formado por el túbulo proximal (con una porción contorneada y otra recta), el asa de Henle (con dos porciones, descendente y ascendente), el túbulo distal (con sus porciones recta y contorneada) y los túbulos colectores.

La morfología exacta de las nefronas variará según la posición relativa del corpúsculo dentro de la corteza y así hablaremos de superficiales, intermedias y yuxtamedulares, siendo el asa de Henle de éstas últimas la que más profundamente penetra en la médula mientras que en las superficiales no existe porción descendente estrecha del asa de Henle (15) 


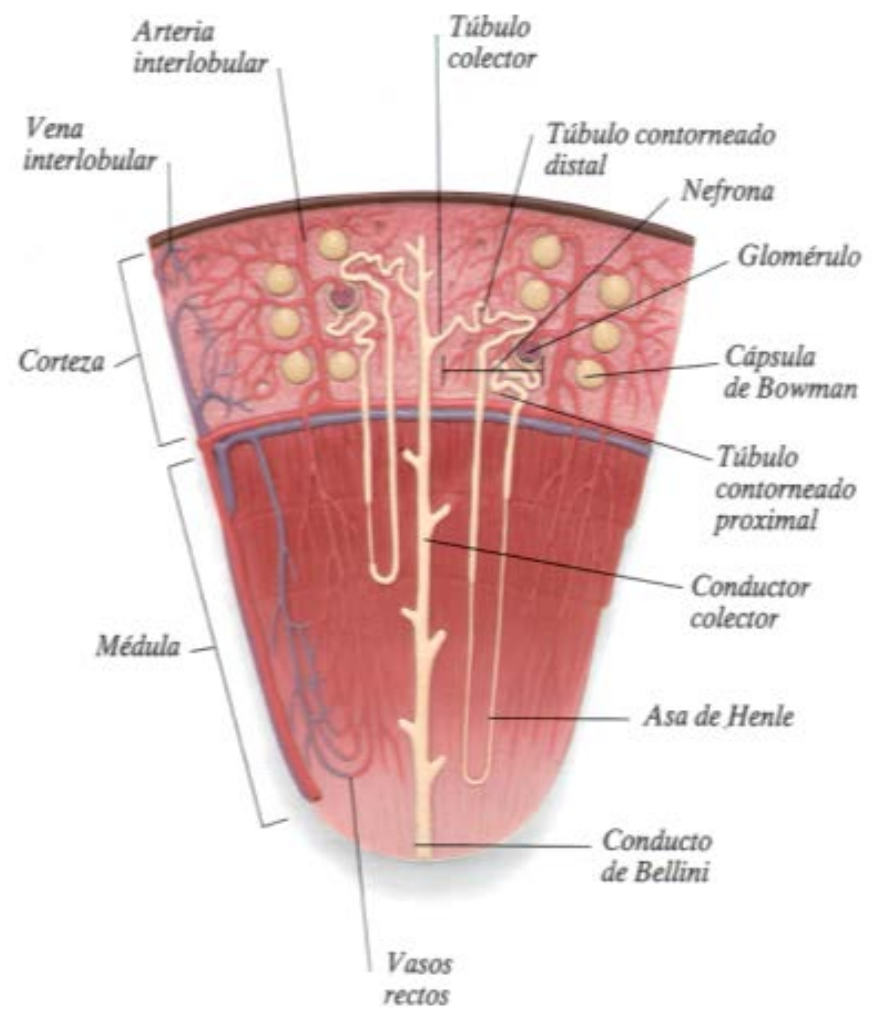

B

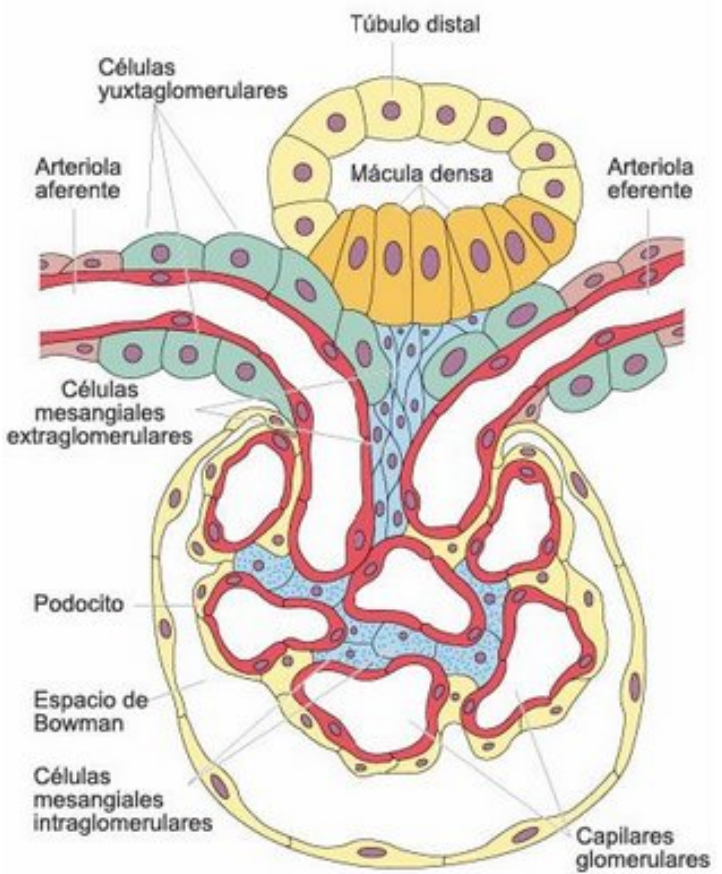

Figura 3: (A) Nefrona. (B) Corpúsculo renal y aparato yuxtaglomerular. (Fisiología médica GPO: IV-3, Armenta Majarrez, M.F.) 
El corpúsculo renal está formado por la cápsula de Bowman y el glomérulo, dentro de cuyas asas capilares se encuentra el mesangio, formado por células mesangiales rodeadas por una matriz extracelular segregada por dichas células y denominada matriz mesangial. La zona del corpúsculo por la que entran y salen los vasos sanguíneos, el polo vascular, se localiza en el lado opuesto al polo urinario, que conecta con el túbulo proximal.

El epitelio externo o parietal de la cápsula de Bowman es de tipo plano simple y se encuentra asentado sobre una membrana basal situada externamente. El espacio que queda entre las capas externa o parietal y la interna o visceral se denomina espacio urinario o de Bowman y se continúa con la luz del túbulo proximal. El epitelio visceral está en íntimo contacto con los capilares glomerulares y sus células se denominan podocitos y participarán activamente en la filtración glomerular.

Los podocitos son células estrelladas con un citoesqueleto prominente, retículo endoplásmico rugoso, aparato de Golgi bien desarrollados y lisosomas. Los podocitos emiten unas prolongaciones primarias de las que emergen otras finas secundarias terminando en unos ensanchamientos o pedicelos que se anclan en la membrana basal e interdigitan con los de las células adyacentes dejando entre ellos hendiduras de filtración, tabicadas por un fino diafragma de filtración. La correspondiente membrana basal de estas células se fusiona con la de las células endoteliales de los capilares glomerulares.

El endotelio de los capilares glomerulares está formado por una monocapa de células planas con un núcleo que protruye hacia la luz capilar y un fino citoplasma con fenestraciones, lo que le otorga un alto grado de permeabilidad.

La membrana basal del endotelio, fusionada con la de los podocitos forma una estructura trilaminar denominada membrana basal glomerular (MBG) que cubre totalmente las asas capilares glomerulares, excepto en la región axial, cuyo espacio intercapilar está ocupado por un tejido conjuntivo especial denominado mesangio. 
Las tres capas de la MBG se denominan: lámina clara interna, subendotelial, lámina densa, intermedia, y lámina clara externa, subepitelial.

Los componentes químicos fundamentales de esta membrana basal son:

- Colágenos de tipo IV y V

- Glicoproteínas: laminina, fibronectina y entactina.

- Proteoglicanos: del tipo heparán sulfato como el perlecano.

Estos componentes forman una red muy compleja que actúa, además de como elemento estructural y de unión para las células que la originan, como filtro ultraselectivo regulando el paso de macromoléculas desde la sangre al espacio urinario, en función de su tamaño, impidiendo el paso a partículas de gran tamaño, y carga eléctrica negativa, ya que los proteoglicanos, debido a que poseen idéntica carga, previenen de la pérdida de proteínas cuya carga también es fundamentalmente negativa.

La celularidad del mesangio está constituida en un $85-95 \%$ por células mesangiales embebidas en la matriz mesangial. El porcentaje celular restante lo constituirían células residentes con características de macrófagos (19). Las regiones mesangiales contiguas conectan el ovillo glomerular con el mesangio extraglomerular o células del lacis que tienen una forma irregular, con numerosas prolongaciones dirigidas hacia la membrana basal glomerular (MBG) y son las principales productoras de matriz mesangial. Los constituyentes de la matriz mesangial son los colágenos tipos IV y V, las glicoproteínas laminina y fibronectina y los proteoglicanos.

Las células mesangiales contienen $\alpha$-actina y miosina, lo que les otorga propiedades contráctiles (20), además de poseer receptores para Angiotensina II, por lo que son capaces de regular la filtración glomerular y el flujo sanguíneo Pero, además, las células mesangiales tienen otras funciones muy importantes ya que tienen capacidad fagocítica y pinocitótica y son capaces de interactuar con células inflamatorias. 
El colágeno que aparece, tanto en la MBG como en el mesangio, es fundamentalmente del tipo IV que es exclusivo de estas zonas, aunque también se encuentran otros tipos como el V y VI. Los monómeros de triple hélice de colágeno IV forman una red flexible de tipo laminar y multicapa. Es un colágeno que no se polimeriza en fibrillas, sino que forma un fieltro de moléculas orientadas al azar, asociadas a proteoglicanos y glicoproteínas estructurales. En algunas condiciones de cultivo, y en situaciones patológicas, las células mesangiales también sintetizan cantidades relativamente grandes de colágenos intersticiales (tipos I y III)

La fibronectina es una glicoproteína dimérica en la que cada subunidad tiene 5-6 dominios, cada uno especializado en la unión a una molécula determinada o a receptores celulares específicos (21). Constituyen un componente fundamental del mesangio y del intersticio tubular del riñón y parecen tener un papel básico en la formación de cicatrices y en la reparación tisular. En las zonas fibróticas se detecta un cúmulo de isoformas de fibronectina, que parecen actuar como moduladoras de la respuesta inmune, atrayendo monocitos y linfocitos al riñón dañado.

La laminina forma un gran complejo flexible constituido por tres largas cadenas dispuestas en forma de cruz y presenta varios dominios funcionales de unión al colágeno tipo IV, heparán sulfato, entactina y dos más para los receptores de la laminina situados en la superficie celular (21, 22). Abunda en las membranas basales y es indispensable para el anclaje de las células a la membrana basal (como ocurre en el caso de los podocitos).

La entactina, que se une a la laminina en el cruce de sus cadenas, está constituida por una cadena única con tres dominios. Uno de ellos se asocia al perlecano y al colágeno IV, actuando como puente adicional entre la matriz y la red de laminina (23). La vitronectina se encuentra en el plasma y en la matriz y parece jugar un papel en el anclaje de las células a la matriz (24)

Los proteoglicanos están formados por una proteína central unida a una o varias cadenas de glicosaminoglicanos, lo que les da una carga negativa que les permite unirse a otros componentes de la matriz y a las membranas celulares. Se encuentran en la superficie celular, membrana basal y 
matriz extracelular. El heparán sulfato perlecano forma parte de la membrana basal y su unión con la entactina, laminina, colágeno IV y fibronectina le anclan a la matriz, reforzando la estructura de la membrana basal. En la matriz mesangial podemos encontrar principalmente proteoglicanos tipo heparan sulfato (perlecano) y condroitin/dermatan sulfatos (versican, decorina y biglicanos).

\section{PROCESOS FISIOLÓGICOS GLOMERULARES BÁSICOS.}

Los riñones son los órganos encargados de regular el volumen y la composición de los líquidos corporales, controlando de esa manera el equilibrio electroquímico. Además, a través de la orina también se eliminan productos metabólicos de desecho (incluyendo hormonas inactivadas) y productos exógenos junto con sus metabolitos.

El líquido que filtra a través del glomérulo hacia la cápsula de Bowman recibe el nombre de ultrafiltrado glomerular. Este proceso se realiza a través de la membrana glomerular, cuya estructura ya se ha detallado anteriormente.

El ultrafiltrado atraviesa tres capas distintas antes de entrar en el espacio urinario entre la cápsula de Bowman: el endotelio fenestrado, la MBG y el diafragma de la hendidura epitelial que queda entre los pedicelos de los podocitos. Pero la permeabilidad de cada una de ellas es varios cientos de veces superior a la de las membranas capilares habituales, lo que determina la gran cantidad de filtrado glomerular que se forma con el tiempo. A pesar de su gran permeabilidad, la MBG tiene una gran selectividad en función de parámetros como el tamaño molecular o la carga electrostática de las moléculas que intenten atravesarla. (32) Para un peso molecular (Pm) de 5200 Da (caso de la Inulina) la permeabilidad es del $100 \%$, prácticamente como el agua, sin embargo, de una proteína de Pm 69000 Da sólo se filtra el 0.5 \%. El peso molecular de la proteína plasmática más pequeña, la albúmina, es de 69000 Da, luego la membrana glomerular es prácticamente impermeable a todas las proteínas plasmáticas pero muy permeable a gran cantidad de las sustancias disueltas en el plasma normal. 
Otra de las razones básicas para la alta selectividad de la MBG es la carga eléctrica de determinadas moléculas de la misma. Los poros de la membrana son lo bastante grandes como para permitir el paso de moléculas con diámetros de hasta $8 \mathrm{~nm}$ o con peso molecular igual o menor a 69000D. El diámetro molecular de la albúmina es $6 \mathrm{~nm}$, algo menor que el tamaño de los poros, sin embargo, la albúmina no atraviesa, en condiciones normales, la MBG debido a su carga eléctrica, ya que la MBG posee una red de proteoglicanos cargados negativamente y las proteínas, cuya carga fundamental es negativa, se van a ver rechazadas por repulsión electrostática.

Otro factor que influye es la presión de perfusión, sobre todo cuando la molécula estuviera en el límite de paso, después de tener en cuenta los factores selectivos anteriormente expuestos, (32).

\section{FIBROSIS RENAL.}

En condiciones normales los mecanismos de reparación tisular responden a una lesión con un aumento en la producción de componentes de la matriz produciéndose un equilibrio entre la síntesis de macromoléculas de matriz y su degradación. Ante una lesión, los fibroblastos responden migrando hacia la zona dañada y allí proliferan, produciendo gran cantidad de colágeno, el cual contribuye al aislamiento y reparación de los tejidos dañados. Pero, si este proceso se mantiene por persistir las causas de la lesión, el exceso de deposición de matriz provoca un estado de fibrosis que conduce a la destrucción y la pérdida de la función tisular. (25).

Las principales células productoras de matriz extracelular son los fibroblastos en el intersticio y las células mesangiales en el corpúsculo. En menor proporción, las células del epitelio tubular, los podocitos y las células endoteliales de los capilares contribuyen mediante la síntesis de sus propias membranas basales.

Los fibroblastos también contribuyen a la progresión de la fibrosis al ser origen de los miofibroblastos, principales productores de matriz en nefropatías tubulointersticiales. 
Las células mesangiales son las principales productoras de matriz mesangial glomerular. En condiciones normales, la producción de matriz mesangial se autorregula a través del contacto célula-célula, pero en condiciones patológicas las células mesangiales incrementan la producción de las macromoléculas de la matriz y de colágenos I y III, además de sintetizar nuevas proteínas de matriz como tenascina y la isoforma de fibronectina EDA (20) El acúmulo de matriz mesangial conducirá a la aparición de glomeruloesclerosis y la pérdida de la función glomerular.

Las células tubulares epiteliales y de los vasos forman finas capas de matriz que se conectan a través de la fibronectina y la laminina, con las membranas de las células intersticiales y con las estructuras fibrilares de la matriz intersticial (26). La mayoría de los modelos de enfermedad estudiados presentan un aumento de la citoquina profibrótica TGF- $\beta 1$ (27) y la expresión de los receptores de TGF- $\beta$ está a menudo sobre regulada en el epitelio tubular (28) lo que indica que este tipo celular es probablemente una diana natural in vivo de la citoquina profibrótica. El TGF- $\beta 1$ induce el incremento de los colágenos I y III y la síntesis de nuevas proteínas de matriz. Las células tubulares activadas liberan estímulos quimiotácticos y pueden diferenciarse en miofibroblastos (29).

En condiciones normales, las células residentes son las responsables de regular la degradación de su propia matriz secretando diversos tipos de proteinasas con actividad específica (30, 31): metaloproteinasas (MMPs) y la familia del activador de plasminógeno/plasmina.

En condiciones patológicas el recambio de las moléculas de la matriz se encuentra alterado por la presencia de determinados factores de crecimiento y citoquinas, que inducen la síntesis de componentes de matriz e inhiben los mecanismos que controlan su degradación. El incremento en el contenido de colágeno que se detecta en el modelo de obstrucción ureteral unilateral (OUU), se ha relacionado con una importante disminución de la actividad de las MMPs con la consecuente disminución de su degradación. 
El aumento patológico de matriz extracelular en el riñón conlleva la aparición de glomeruloesclerosis, fibrosis túbulo-intersticial, atrofia y dilatación tubulares, al igual que rarefacción de los capilares glomerulares e intersticiales $(1,33,34)$.

La patogénesis de la enfermedad renal crónica se caracterizará por la acumulación de matriz extracelular en el glomérulo y en el intersticio tubular con pérdida progresiva de la función renal, que desembocará en una fibrosis generalizada (35) y, progresivamente, conducirá al fallo orgánico (36).

La respuesta inflamatoria inicial conduce a un aumento en el número de miofibroblastos que se diferencian a partir de otros tipos celulares, mayoritariamente los fibroblastos intersticiales y las células mesangiales (36). También se producen miofibroblastos mediante la transdiferenciación epitelio-mesenquimal (EMT) desde las células epiteliales tubulares. (3, 36-39) aunque la importancia de este fenómeno ha sido cuestionada últimamente (40), como veremos más adelante.

En la diferenciación de miofibroblasos intervienen diversos factores, pero el factor de crecimiento transformante 1 (TGF- $\beta 1$ ) ocupa la posición principal $(36,39)$ Las citoquinas segregadas por células tubulares o la infiltración de leucocitos puede activar el proceso (41). También actúan como mediadores celulares las GTPasas RAS(42)

Este aumento conduce al incremento de los niveles de proteínas de matriz como son la laminina, fibronectina y el colágeno $(36,43)$, especialmente de los tipos I y III $(29,39,44)$. También se producirá un aumento de las especies reactivas del oxígeno (ROS). Las ROS son compuestos que se derivan de la molécula de oxígeno por reducción química parcial y juegan un rol fisiológicamente importante y, al mismo tiempo, pueden ejercer efectos tóxicos. Todas las ROS son producidas como consecuencia del metabolismo y son esenciales para la producción de energía, la síntesis de compuestos biológicamente esenciales y la fagocitosis, un proceso crítico para el sistema inmunológico. También juegan un papel crucial en la transducción de señales necesarias para la 
comunicación y función de las células. El aumento de las ROS activa vías relacionadas con apoptosis celular, principal forma de muerte celular en la OUU, e inflamación e induce la síntesis de más moléculas profibróticas (43). Estudios recientes también describen la necroptosis como una forma de muerte celular activada por vías específicas intracelulares por lo cual tanto los procesos de apoptosis como los de necroptosis tendrían una gran importancia por la posibilidad de orientar terapéuticamente tanto los inductores extracelulares y los mediatos intracelulares del proceso (45).

En este aumento de matriz celular existe un punto de no retorno en el que la reparación ya no es posible y el órgano se dirige hacia el colapso.

En la fibrosis túbulo-intersticial, se considera que los fibroblastos y los miofibroblastos intersticiales son los responsables de la síntesis y acumulación de matriz extracelular (MEC) en el espacio extracelular (46-48). El intersticio normal contiene fibroblastos y células dendríticas, sin embargo, el estrés mecánico, las citoquinas y otros factores inducen en los fibroblastos la adquisición del fenotipo de miofibroblastos. Aunque no está admitido unánimemente, los Miofibroblastos también pueden derivar de células células endoteliales y quizá epiteliales, de la EMT $(38,49-52)$

La glomeruloesclerosis es causada por una síntesis anómala de MEC en el corpúsculo renal, principalmente en la matriz mesangial, provocando un estrechamiento de los capilares glomerulares (53), la ultrafiltración excesiva de proteínas y la disminución de la tasa de filtración glomerular (TFG) (54)

La patogénesis de la enfermedad renal crónica se caracterizará, por tanto, por la pérdida progresiva de la función renal y la acumulación de matriz extracelular en el glomérulo y en el intersticio tubular, lo que originará una fibrosis generalizada (35).

\section{NEFROPATÍAS TUBULOINTERSTICIALES.}

Se caracterizan por la presencia de fibrosis intersticial, atrofia tubular e infiltración celular (55). En estadios iniciales, la pérdida de la filtración glomerular ocurre lentamente y el efecto más 
destacado es la alteración de la función tubular (55). En contraste con la enfermedad glomerular, la hipertensión se desarrolla tardíamente y ocurre tras un descenso significativo de la TFG (56).

Las lesiones tubulointersticiales afectan tanto a la corteza como a la médula, ya que si bien las lesiones primarias ocurren en túbulo e intersticio, muchas de las enfermedades desarrollan anomalías estructurales y funcionales en el glomérulo.

Las células epiteliales tubulares son un componente integrante de la patogénesis de estas enfermedades por su participación en los cambios progresivos intersticiales (57).

En resumen, se caracterizan por el aumento del volumen intersticial debido, fundamentalmente, a la fibrosis y a los distintos grados de infiltración de células inflamatorias crónicas (58). Es una reacción inflamatoria que se perpetúa o que escapa a los mecanismos de control en la defensa normal frente al daño (59). El proceso sigue cuatro fases:

\section{Fase de daño y activación celular.}

El daño inicial en las células tubulares epiteliales puede ser directo, como ocurre en caso de obstrucción de vías urinarias o en condiciones nefrotóxicas, o indirecto, debido a isquemias secundarias, enfermedades vasculares, daño glomerular o incremento en la carga de reabsorción tubular (60).

Tanto el desencadenante haya sido por unas u otras de las causas mencionadas, el proceso fibrótico se inicia en el epitelio tubular que secreta quimiocinas, las cuales atraen a más células mononucleares, y factores de crecimiento (entre ellos el TFG- $\beta$ ) que a su vez estimulan a los fibroblastos intersticiales. El factor inicial desencadenante también puede inducir en las células tubulares la producción de diversas moléculas inflamatorias o profibróticas, y la síntesis de proteínas de matriz, tanto en la membrana basal como en el intersticio (60). En fases posteriores los cambios celulares del epitelio tubular contribuyen al daño crónico de la función renal. Las células tubulares responden al estímulo inicial proliferando o hipertrofiándose, pero, a medida que progresa la enfermedad, pueden entrar en apoptosis o sufrir la llamada transición epitelio- 
mesénquima (EMT) en la que se transforman en miofibroblastos, si bien algunos autores discuten este último concepto $(40,61-63)$.

Respecto a las células infiltradas, pueden proceder de la proliferación in situ de los macrófagos intersticiales residentes (64) pero la mayoría son células que han migrado desde la sangre al intersticio a través del endotelio capilar. Se cree que el estímulo para este flujo se encuentra en las moléculas quimioatrayentes que son secretadas a través de la membrana basolateral de los túbulos o que pasan a través de las células tubulares desde la luz al intersticio directamente. Con esto la respuesta inflamatoria se ve incrementada, al producirse más moléculas proinflamatorias que pueden amplificar el daño tubular y reclutar más células inflamatorias o estimular la proliferación de fibroblastos, la migración o la síntesis de colágeno (65).

La mayor parte del infiltrado intersticial está constituida por linfocitos $\mathrm{T}$ y, en menor medida, por las células agresoras naturales. La acumulación intersticial de monocitos produce una gran cantidad de citoquinas quimioatrayentes, que a su vez colaboran con la amplificación de la respuesta inflamatoria (66). En el parénquima renal también se reclutan mastocitos y macrófagos que participan en el daño proteolítico y contribuyen al proceso fibrogénico como fuente de moléculas profibróticas (59).

Las células infiltradas y el tejido fibroso ocupan de forma gradual el espacio intersticial dando lugar a una fibrogénesis irreversible al reemplazar por nueva matriz el espacio dejado por la atrofia tubular y el daño parenquimatoso (67).

Los fibroblastos intersticiales se activan en respuesta al daño estimulados por diversas moléculas que proceden de células tubulares estimuladas, leucocitos o de los propios fibroblastos y proliferan y sintetizan matriz extracelular (60). La matriz extracelular puede ejercer un control sobre los fibroblastos mediante un sistema bidireccional de integrinas (58). Una de las citoquinas clave involucrada en la estimulación de los fibroblastos es TGF- $\beta$ (68). 
La mayoría de las formas de enfermedad renal progresiva presentan un aumento del número de miofibroblastos intersticiales que se relaciona con el grado de fibrosis intersticial (69) siendo los miofibroblastos los mayores responsables del exceso de producción de matriz extracelular en las nefropatías fibróticas.

En el riñón alterado, los miofibroblastos se agregan alrededor de los túbulos dañados y de las arteriolas. La oclusión microvascular, debida a la fibrosis, y la constricción de los vasos, por la acción de los miofibroblastos y los agentes vasoactivos, provocan isquemia tisular, alteraciones en la hemodinámica glomerular y aumento en la producción de Ag II, lo que amplifica la fibrogénesis (70) y perpetúa el daño (71).

En estas fases iniciales el grado de muerte celular excede al de proliferación celular rompiéndose el equilibrio que mantiene estable el número celular.

\section{Fase de señalización fibrogénica.}

Debido a los acontecimientos celulares inducidos por el daño inicial, se sintetizan una serie de moléculas que se unen a sus receptores correspondientes en las células tubulointersticiales, y producen la acumulación de matriz en la membrana basal y en el espacio intersticial.

El TGF- $\beta$ juega un papel primordial en el desarrollo de la fibrosis y, si bien no se conoce como ocurre exactamente la activación de TGF- $\beta$ renal, in vitro se ha comprobado que es inducida por plasmina, furina, glicosidasa, transglutaminasa, MMP-9, pH ácido y trombospondina (72).

La activación de TGF- $\beta$ y su unión a receptores específicos de membrana celular desata una cascada de acontecimientos que promueven la fibrosis. TGF- $\beta$ contribuye directamente a la acumulación de matriz extracelular estimulando la transcripción de genes que expresan componentes de la matriz como colágenos tipo I, III y IV, fibronectina y laminina. Simultáneamente promueve la acumulación de matriz al aumentar la producción de inhibidores de proteasas y disminuir la actividad de las mismas (27). Así mismo, el TGF- $\beta$ también estimula la migración y 
proliferación de fibroblastos y su proliferación a miofibroblastos, la quimiotaxis de monocitos y macrófagos y los procesos de EMT $(73,74)$.

Casi todos los modelos de fibrosis renal, humanos o experimentales, tienen como denominador común la sobreexpresión de TGF- $\beta$ (68). El factor de crecimiento del tejido conjuntivo (CTGF) es un importante mediador de la actividad del TGF- $\beta$ y se detecta una concentración alta del mismo en casos de daño crónico en riñones humanos (75) y en ratones con neuropatía diabética (72). La angiotensina II estimula la producción de TGF- $\beta$ por células mesangiales (76), células tubulares renales y fibroblastos (72), habiendo quedado demostrado que la inducción de TGF- $\beta$ mediada por Ag II juega un papel fundamental en la progresión de la enfermedad (72). Experimentalmente se ha confirmado el papel de la Ag II en la fibrogénesis ya que utilizando modelos de ratones genéticamente deficientes en angiotensinógeno se ha constatado una menor fibrosis renal inducida por OUU (77) o por infusión de anticuerpos antimembrana basal (78).

Un papel importante juega igualmente la endotelina-1, ya que aumenta la expresión de TGF$\beta$, promoviendo la fibrosis por estimulación directa de síntesis de matriz extracelular y por su capacidad de disminuir la actividad colagenasa (72).

El factor de crecimiento derivado de plaquetas (PDGF) está implicado en la fibrogénesis intersticial renal debido a su capacidad para transformar fibroblastos en miofibroblastos (72).

Otras citoquinas que parecen promover la fibrosis son la interleucina 1 (IL-1)(31) y el factor de necrosis tumoral alfa (TNF- $\alpha$ )(31) o el factor de crecimiento de fibroblastos básico (bFGF) (79). Al mismo tiempo que libera citoquinas y factores de crecimiento el riñón libera factores antifibrogénicos que contrarresten los efectos como el interferón gamma (80). 


\section{Fase fibrogénica.}

Como ya hemos mencionado, el acúmulo de matriz extracelular es consecuencia de una alteración en el balance entre la síntesis de componentes de la matriz y de la disminución de su degradación.

La cicatriz intersticial está constituida por proteínas y glicoproteínas normales de la matriz intersticial (colágenos I, III, V, VII, XV, fibronectina), componentes que en circunstancias no patológicas están limitados a las membranas basales tubulares (colágeno IV y laminina) y proteínas sintetizadas de novo como tenascina, algunas isoformas de fibronectina y ciertas cadenas de laminina (72). La primera en aparecer tras el daño es la fibronectina, que es producida por fibroblastos y miofibroblastos, células mesangiales, macrófagos y células epiteliales tubulares (22) y gracias a sus propiedades quimiotácticas y adhesivas interviene en el reclutamiento de los fibroblastos y la deposición de otras proteínas extracelulares (81).

Otros componentes que se ven aumentados en el intersticio fibrótico son el ácido hialurónico (82), las glicoproteíanas trombospondinas, y SPARC (proteína secretada ácida rica en cisteína) (83), que actúan como inhibidoras de la adhesión celular y la proliferación y estimulan la expresión de TFG- $\beta$ (84) y los proteoglicanos extracelulares, que constituyen un reservorio de factores de crecimiento como bFGF (Factor básico de Crecimiento de Fibroblastos) y TFG- $\beta$, a los que secuestran de manera inactiva pero de donde pueden ser movilizados.

Hay que tener en cuenta que en estadios iniciales la cicatriz intersticial constituye una estructura muy inestable y susceptible de ser degradada, pero con el transcurso del tiempo, los puentes de unión que se establecen le aportan estabilidad y resistencia a la actividad de las proteasas.

Las regiones perivasculares y periglomerulares de la corteza están implicadas en los procesos tempranos de la enfermedad y, a medida que esta progresa también lo hace el grosor de su membrana basal (60). En fases tardías además se observa una atrofia progresiva de los túbulos 
dañados y una contracción de los miofibroblastos, que parecen contribuir en gran medida al aumento descontrolado de tejido fibroso (67).

Al mismo tiempo que en el proceso fibrótico se acelera la síntesis de componentes de matriz, se inactiva las proteasas encargadas de su degradación, siendo las más importantes las MMPs, que además de degradar estimulan la activación y la proliferación, de la cascada dependiente de plasmina, etc.

\section{Fase destructiva.}

La acumulación y la expansión de los componentes de la matriz en el espacio intersticial tiene un efecto destructivo sobre el parénquima renal y, por tanto, sobre su función. Los túbulos renales ( $80 \%$ del volumen renal) se ven atrofiados como consecuencia de la fibrogénesis que ellos mismos han contribuido a iniciar.

La apoptosis va asociada a la fibrosis y es muy probable que la isquemia tubular favorezca la muerte celular por apoptosis y/o necrosis ya que la matriz intersticial fibrótica además de aislar a los túbulos de su aporte de oxígeno obstruye los capilares peritubulares postglomerulares. La pérdida de los túbulos y la disminución del área de superficie de los capilares peritubulares son una característica histopatológica de la enfermedad renal progresiva asociada a la pérdida de la función renal.

\section{GLOMERULOPATÍAS.}

Pueden ser de tipo inflamatorio-inmune (glomerulonefritis) o de tipo metabólico-mecánico.

La glomerulonefritis puede ser mesangioproliferativa, que se caracteriza por una proliferación de las células glomerulares en mesangio o proliferativa intracapilar, si el proceso ocurre en el endotelio. Algunas glomerulopatías inducen la proliferación de las células parietales y viscerales de la cápsula de Bowman, originando las llamadas semilunas del espacio de Bowman. 
La patogenia de la mayoría de las glomerulonefritis se basa en cuatro mecanismos inmunitarios básicos: presencia de inmunocomplejos circulantes, inmunocomplejos formados in situ, activación de la vía alternativa del complemento y procesos mediados por células.

Las de tipo metabólico-mecánico tienen su origen en cualquier proceso capaz de alterar patológicamente las estructuras de la barrera de filtración.

Numerosas glomerulopatías presentan como característica alteraciones estructurales del glomérulo que son el resultado de un exceso de deposición de matriz extracelular en el mismo. Este proceso recibe el nombre de glomeruloesclerosis y origina cambios funcionales que se hacen patentes con la reducción progresiva de la TFG, el desarrollo de proteinuria de origen glomerular y el establecimiento de una hipertensión dependiente del aumento de volumen extracelular (56).

Hay una amplia variedad de glomerulopatías primarias que tiene en común presentar en sus estados finales un incremento en la proliferación mesangial y la presencia de glomeruloesclerosis.

Se ha analizado la composición de la matriz extracelular en el glomérulo esclerosado mediante inmunohistoquímica, mostrando un cambio en la distribución y composición de la matriz glomerular en la progresión de la enfermedad (85). En estadios iniciales no se detectan colágenos I y III pero en fases más avanzadas, el mesangio presenta una marcada tinción de colágenos IV y VI, laminina y fibronectina, ampliándose el área ocupada por fibronectina a las paredes de los capilares glomerulares y a medida que la glomeruloesclerosis progresa disminuye la intensidad de todos ellos y se observa la expresión focal de colágenos I y III en los glomérulos esclerosados y hialinos y en zonas adyacentes. La intensidad de tinción es mayor en casos de cápsulas de Bowman gravemente dañadas.

Con el avance de la enfermedad también se detecta muerte celular en el glomérulo y el espacio que estaba ocupado por las células del parénquima renal va siendo sustituido por la matriz (86). Este acúmulo excesivo de matriz extracelular que se produce durante la progresión del daño 
glomerular implica la disminución del diámetro de los capilares glomerulares y la TFG, y finalmente dará lugar a la aparición de la IRC (87).

Los mecanismos implicados en el daño son diversos. Uno de ellos es el daño hemodinámico, que origina alteraciones en las células mesangiales por aumento de la filtración, la hipertensión y la distensión glomerular (88).

Las células mesangiales juegan un papel fundamental en la proliferación y exceso de producción de matriz extracelular (89). Son diversos los mecanismos que inician el daño que estimula a las células mesangiales. Entre éstos se incluyen inmunocomplejos, proteínas del complemento, fuerzas de distensión, factores de crecimiento y citoquinas que, produciendo la liberación de factores quimiotácticos inician el daño (90). La angiotensina II es una de las principales moléculas implicadas en la activación de las células residentes renales en condiciones patológicas (91).

Otras moléculas patogénicas relacionadas con el desarrollo de la glomeruloesclerosis son: endotelina (92), las especies reactivas de oxígeno ROS (93) y TGF-ß1 (94).

El reclutamiento de las células inflamatorias amplifica la respuesta profibrótica de proliferación de las células mesangiales (95), la adquisición de la proteína contráctil $\alpha$-SMA (96), la producción de componentes de matriz (89), y una mayor producción de citoquinas y factores de crecimiento (97).

\section{MECANISMOS DE SEÑALIZACION EXTRACELULAR IMPLICADOS EN LA PATOGÉNESIS RENAL.}

Existen diversos mecanismos intracelulares que sirven de señal para algunas moléculas que juegan roles conocidos en la enfermedad renal. Algunas de ellas han sido objeto de múltiples estudios.

La Angiotensina II, a través de la unión a los receptores $\mathrm{AT}_{1}$, induce contracción celular, hipertrofia, proliferación, migración, producción de componentes de la matriz extracelular, 
respuesta inflamatoria y apoptosis, mientras que la interacción con los receptores $\mathrm{AT}_{2}$ promueve apoptosis e inhibe la proliferación y la hipertensión (4).

Múltiples estudios han puesto en evidencia la alteración de la vía de señalización del TGF- $\beta$ (98) . La señalización comienza cuando el ligando activo se une y estimula a dos clases de receptores transmembrana específicos con actividad intrínseca kinasa de serina/treonina, denominados receptores tipo I y tipo II (6). Ambos receptores son necesarios para la transducción de la señal. Algunas proteínas de superficie como betaglicano y endoglina, actúan como coreceptores.

Las Smads (Mothers Against Decapentaplegic Homolog) son proteínas citoplasmáticas que actúan como efectores intracelulares de los receptores kinada de serina/treonina de la superfamilia TGF- $\beta$.

Un receptor transmembrana de la familia TGF- $\beta$ es la endoglica, glicoproteína homodimérica que desempeña un papel esencial en la morfogénesis vascular. La mayoría de las funciones conocidas de la Endoglina están relacionadas con su capacidad para modular las respuestas celulares dependientes de TGF- $\beta 1$.

Aunque la endoglina forma parte del complejo receptor de TGF- $\beta$, puede encontrarse de forma independiente en la superficie celular. De hecho sólo un pequeño porcentaje de endoglina expresada en la superficie celular se une a TGF- $\beta$ (99). Por otro lado la sobreexpresión de endoglina disminuye la expresión de moléculas de matriz extracelular, lo cual afecta a la morfología y a la adhesión celular en ausencia de TGF- $\beta$ (8) lo que sugiere que puede realizar una función independiente a la relacionada con la señalización a través de TGF- $\beta$.

Por último mencionar a las GTPasas Ras, proteínas monoméricas que sirven como interruptores moleculares para una gran variedad de rutas de transmisión de señales celulares. Para que Ras sea efectivo en respuesta a las señales extracelulares requiere una interacción directa 
con proteínas reguladoras de su actividad, que incluyen las proteínas activadoras de GTPasas (GAPs) y los factores intercambiadores de nucleótidos de guanina (GEFs).

Ras puede constituir un punto de convergencia en la transducción de señales extracelulares, inducidas por el daño renal, desde los receptores hasta el núcleo celular y en cultivos de fibroblastos tiene un papel fundamental en el control de la proliferación celular (100) si bien no se ha comprobado in vivo, por lo que tendría un papel fundamental en la regulación de los procesos característicos de la progresión de la enfermedad renal.

\section{INHIBIDORES DEL DAÑO RENAL.}

Numerosas investigaciones que emplean la inhibición farmacológica de mediadores tempranos de fibrosis, como macrófagos, fibronectina y el fenotipo del miofibroblasto, han demostrado que atenúan la fibrosis intersticial en diferentes modelos de enfermedades renales (101). 


\section{EL MODELO DE OBSTRUCCIÓN URETERAL UNILATERAL.}

\section{Importancia del modelo.}

La obstrucción ureteral unilateral (OUU) es un modelo experimental ampliamente utilizado en la investigación de los mecanismos implicados en la patología fibrótica túbulo-intersticial en el riñón obstruido $(102,103)$. La OUU como modelo experimental de daño renal fue desarrollada por el Dr. Saulo Klahr en 1998 (104). Se trata de una maniobra que causa de forma aguda la obstrucción completa del uréter y, aunque esta circunstancia patológica apenas ocurre en humanos, la obstrucción ureteral presenta la ventaja de que la fibrosis evoluciona de manera altamente reproducible, reflejando de forma acelerada la secuencia de acontecimientos patogénicos de la nefropatía obstructiva. Numerosos experimentos han corroborado la utilidad del modelo de OUU en la identificación de moléculas y procesos fundamentales involucrados en la patogénesis de la fibrosis renal, así como en la evaluación de aproximaciones terapéuticas potenciales que contribuyen a la mejora de la enfermedad renal. $(46,49,103,105,106)$

La nefropatía obstructiva causada por obstrucción del tracto urinario es una patología renal que induce daño tubulointersticial. Se denomina también uropatía obstructiva o hidronefrosis y se manifiesta clínicamente como una disminución repentina o gradual e insidiosa de la función renal, debido a anomalías anatómicas o funcionales de la uretra, vejiga, uréteres o pelvis renal (104). Estos defectos pueden ser congénitos o adquiridos, y también pueden aparecer en el curso de enfermedades extrínsecas al tracto urinario (104). La nefropatía obstructiva congénita constituye la principal causa de insuficiencia renal en niños y representa el 16,1\% de los trasplantes pediátricos en Norte América realizados en 2001 (107). Esta cifra resulta especialmente elevada si se compara con el $0,3 \%$ de pacientes afectados por nefropatía obstructiva con insuficiencia renal en la población total estadounidense (107). Aunque la incidencia de la nefropatía obstructiva disminuye después de la infancia, se detecta un incremento a la edad de 60-65 años, particularmente en hombres, por estar asociada con enfermedades prostáticas (hiperplasia, cáncer) (104). 
Sin embargo, el análisis de la respuesta del tracto urinario a la obstrucción no es la única ventaja de este modelo. La OUU provoca daño renal subagudo caracterizado por daño celular tubular, inflamación y fibrosis intersticial; alteraciones que son clave en el daño renal de cualquier etiología, lo que acredita a la OUU como un buen modelo para el estudio, tanto del daño renal agudo, como de los acontecimientos que tienen lugar hasta el desarrollo de la enfermedad renal crónica. (106)

\section{Patogénesis del riñón obstruido.}

Las alteraciones tubulointersticiales constituyen la característica patológica fundamental del riñón obstruido, apareciendo infiltrado inflamatorio, aumento de células intersticiales, EMT, atrofia tubular, acumulación de miofibroblastos e incremento de matriz intersticial.

En las primeras horas que siguen a la OUU completa, ocurren una serie de cambios en el flujo sanguíneo renal y en la presión glomerular como resultado del estrés mecánico que provoca la ligadura. En la primera fase (0-90 min.) se produce un incremento del flujo sanguíneo renal y de la presión glomerular, como consecuencia de una vasodilatación de las arteriolas aferentes. Durante la segunda fase (90 min-5 h.) el flujo sanguíneo renal disminuye y la presión glomerular se incremente debido a una vasoconstricción de las arteriolas eferentes. En la tercera fase (5-18 h.) ocurre una disminución de ambos parámetros como respuesta a una vasoconstricción de las arteriolas aferentes.(108)

Estos cambios hemodinámicos que siguen a la obstrucción ureteral son el resultado de la intervención de distintos mediadores. El incremento en el flujo sanguíneo renal y en la presión glomerular que se detecta inmediatamente después de la obstrucción, parece estar regulado por la acción de prostaglandinas vasodilatadoras (104). Durante la vasodilatación que ocurre en la fase temprana de la OUU se producen localmente en el riñón moléculas vasoconstrictoras como angiotensina II (109), tromboxano $A_{2}$ (104) y endotelina-1 (110), que contribuyen a la disminución 
del flujo sanguíneo renal y a la consiguiente vasoconstricción renal sostenida que ocurre después de la OUU aguda.(19)

La dilatación tubular y la presencia de células infiltradas que acompañan al incremento de presión intrapélvica, son manifestaciones tempranas de los cambios que la ligadura induce sobre la estructura renal. En riñones sanos, los escasos macrófagos residentes en la corteza renal se encuentran principalmente en el glomérulo, y la médula carece de leucocitos (19). En respuesta al trastorno mecánico producido por la obstrucción ureteral, el epitelio tubular puede sintetizar moléculas quimiotácticas, que favorecen la infiltración de macrófagos en el intersticio tubular (2). Cuatro horas después de la ligadura, se detecta en el espacio tubulointersticial un infiltrado celular constituido principalmente por macrófagos y en segundo lugar por linfocitos T citotóxicos, sin que se aprecie un número significativo de linfocitos T cooperadores en el parénquima renal (111). Los leucocitos infiltrantes son los responsables, al menos en parte, de la disminución del flujo sanguíneo renal y la TFG (104), y de la síntesis del potente factor profibrogénico TGF- $\beta 1$ después de la obstrucción (2). Por tanto, los linfocitos T y los macrófagos pueden contribuir a la progresión de la lesión mediando el daño tubular con la consiguiente atrofia, y promoviendo la fibrosis intersticial.

El incremento de las moléculas de adhesión por los leucocitos y las células del parénquima renal en el riñón obstruido, parece jugar un papel importante en la infiltración de células inflamatorias en el intersticio tubular y en la interacción de estas células activadas con las células del parénquima renal. En comparación con los riñones normales y contralaterales, la ligadura induce un marcado aumento en los niveles de ARNm de las moléculas de adhesión ICAM-1 y VCAM1 que se mantiene en la obstrucción crónica (112). Estos resultados sugieren que el incremento de ICAM-1 y VCAM-1 inducido por la ligadura, puede contribuir a la infiltración de células inflamatorias en el compartimento tubulointersticial durante la hidronefrosis crónica. El incremento de la expresión tubular de ICAM-1 coincide en este modelo con el incremento en la 
proliferación y la apoptosis tubular, por lo tanto, ICAM-1 puede estar involucrada en los efectos perjudiciales que las células inflamatorias activadas ejercen sobre el epitelio de los túbulos renales.

El incremento gradual inducido por la ligadura en la expresión tubular de la quimiocina MCP-1 a las 12, 48 y 96 horas, parece que puede contribuir de manera importante a la infiltración inflamatoria y al desarrollo de la patología fibrótica intersticial, al coincidir con un incremento significativo del número de macrófagos intersticiales y de la expresión peritubular de TGF- $\beta 1$ (113).

La liberación de diversas sustancias vasoactivas por las células infiltradas del riñón hidronefrótico, como IL-1, leuconeutrieno $\mathrm{D}_{4}$ y tromboxano $\mathrm{A}_{2}$, parece tener un papel modulador significativo en las alteraciones del transporte tubular y la hemodinámica glomerular observadas en la evolución temprana de la obstrucción (114).

La disponibilidad de animales con modificaciones genéticas que eliminan la expresión de genes responsables de la migración celular, como selectinas, receptor CD44 (presente en macrófagos y linfocitos) o su principal ligando, la molécula de adhesión osteopontina, permite conocer la importancia de estas moléculas en el modelo OUU. Ratones con déficit (knockout) de osteopontina o CD44 presentan una disminución en la infiltración celular y en la fibrosis tubulointersticial inducidas por la obstrucción cuando se comparan con los animales silvestres $(115,116)$. Experimentos de ligadura de uréter realizados en ratones knockout para las moléculas de adhesión selectinas -E, -P y -L, demuestran una menor infiltración de macrófagos y menor grado de células tubulares apoptóticas, que corresponde con una reducción de la atrofia tubular y la fibrosis intersticial (117).

Los cambios que origina la fibrosis tubulointersticial se manifiestan de forma temprana en el riñón obstruido. A los 3 días de la obstrucción se detecta un aumento en el volumen relativo del intersticio cortical, acompañado por un incremento de la deposición de colágenos I, III y IV, este último también sobreexpresado en la membrana basal tubular (118). El mantenimiento de la 
ligadura desarrolla una red fibrótica, que se establece en la primera semana después de la obstrucción ocupando el espacio intersticial aumentado (104). La acumulación de los componentes de matriz extracelular como colágenos, fibronectina y proteoglicanos heparán sulfato, así como fibroblastos, contribuye a la formación de la red fibrótica (119). Si la obstrucción persiste, la deposición progresiva de elementos de la matriz origina cicatrices fibróticas en el parénquima renal.

Las células tubulares y el incremento de la proliferación y activación miofibroblástica, estimulada en parte por las citoquinas liberadas por macrófagos y linfocitos T (111), contribuyen a la deposición de las moléculas de matriz extracelular (104).

Un aspecto fundamental de la patogénesis de la obstrucción ureteral crónica son los complejos cambios que ocurren en el fenotipo de las células renales y la pérdida de la masa tisular, que refleja el desequilibrio existente entre proliferación y muerte celular en el riñón obstruido. Una semana después de la ligadura se detecta la pérdida de masa renal característica de la obstrucción ureteral, que se acelera entre la segunda y la cuarta semana (61). Esta pérdida de tejido coincide con una marcada disminución en el peso seco del riñón y en el área tubular, al mismo tiempo que se detecta el mayor incremento de muerte celular en los túbulos renales. Estos hechos sugieren que la apoptosis tubular puede estar relacionada con la atrofia tubular y la pérdida de tejido renal característica de la obstrucción ureteral (12).

Las células intersticiales muestran un incremento continuo en la frecuencia de apoptosis y proliferación desde el primer día de la ligadura, por lo que ambos fenómenos parecen desempeñar un papel importante en el incremento paralelo del daño intersticial observado en este modelo (12). Estudios in vitro confirman que los fibroblastos en cultivo procedentes del intersticio cortical de riñones con obstrucción ureteral muestran una mayor tasa de proliferación que los fibroblastos procedentes de riñones normales y contralaterales (120). No se han observado cambios significativos en apoptosis y proliferación de las células glomerulares en riñones obstruidos (12). 
El empleo de ratones con modificaciones genéricas que eliminan total o parcialmente la función de genes que controlan la apoptosis y la proliferación celular, ha permitido profundizar en el significado de estos procesos en la patogénesis de la OUU. La ligadura en ratones knockout para reguladores negativos de la proliferación celular, como los inhibidores de kinasas de ciclinas (CKIs de cyclin kinase inhibitors) p27 ${ }^{\mathrm{KIP} 1}$ y p21 WAF/CIF, muestra un nivel de proliferación tubular mayor en ratones knockout para p27KIP1 que los silvestres (121), mientras que las modificaciones en los animales knockout de p21 WAF/CIF la única modificación que se detecta es una proliferación miofibroblástica mayor que en los silvestres (122). Sin embargo, estas modificaciones genéticas no producen ningún cambio detectable sobre la fibrosis tubulointersticial inducida por la obstrucción, quizá porque la falta de la expresión de estos genes puede compensarse con la de otros, por ser redundantes $(121,122)$. El papel en la apoptosis y la fibrosis tubulointesticial del factor de transcripción pro-apoptótico p53 inducido por la ligadura (123) se ha estudiado en modelos de ratones deficientes. Ratones knockout para p53 (homo y heterocigotos) presentan entre un 50 y un 70\% menos de apoptosis intersticial y tubular en el día 15 de la ligadura, acompañado por una menor atrofia tubular y una reducción del volumen intersticial (124).

En la nefropatía obstructiva inducida por OUU existe un número elevado de células tubulares que se encuentran en un estado de transición entre epitelio y mesénquima (EMT). Marcando genéticamente las células del túbulo proximal, Iwano y cols. han demostrado que los fibroblastos intersticiales pueden derivar del epitelio tubular tras el daño obstructivo (62). Estas células adquieren características de mesénquima al expresar $\alpha$-SMA y vimentina, además conservan la expresión de marcadores tubulares como la lectina, a la vez que dejan de expresar cadherina E, y producen componentes de la matriz extracelular como fibronectina y colágeno de tipo I $(28,62,125)$. La inducción de $\alpha$-SMA muestra un patrón bifásico en el riñón obstruido, apareciendo el primer pico de inducción temprana en el periodo comprendido entre el día 1 y 3, y el segundo pico a los 7 días de obstrucción (52). Los resultados obtenidos en el grupo de Liu sugieren que la activación de los miofibroblastos en la nefropatía obstructiva es un proceso 
dinámico, en el que en un estadio temprano (3 días) los miofibroblastos proceden principalmente de la activación local de los fibroblastos residentes, mientras que en una fase tardía (7 días) derivan predominantemente del epitelio tubular vía EMT $(52,126)$.

Estudios recientes in vivo en procesos de OUU han demostrado que la EMT juega un papel menos importante del que se creía hasta hace poco en la aparición de los miofibroblastos. Los últimos estudios sugieren que, del total de miofibroblastos, un 50\% provienen de la proliferación de fibroblastos residentes activados, un 35\% de la diferenciación de células provenientes de la médula espinal, un 10\% de la transición endotelial-mesenquimal y sólo un 5\% de EMT. (40)

Se ha demostrado que ratones que carecen de tPA (activador de plasminógeno) están protegidos del desarrollo de fibrosis túbulo-intersticial en la patología obstructiva $(108,127)$. Estos estudios revelan que la carencia de tPA bloquea selectivamente la EMT tubular, pero no afecta a la activación de los miofibroblastos a partir de los fibroblastos intersticiales. La explicación se encuentra en que la falta de tPA reduce la inducción de la MMP-9 en los riñones obstruidos de los ratones tPA-/-, lo cual conduce a una preservación de la estructura de la membrana basal tubular. En ausencia de EMT, la progresión de la acumulación de miofibroblastos no sólo está disminuida, sino que además, revierte (127). Estos resultados confirman que la EMT desempeña un papel fundamental en la patogénesis de la fibrosis intersticial renal.

Entre la gran cantidad de citoquinas, componentes vasoactivos, quimiocinas y factores de crecimiento que están sobreexpresados en la uropatía obstructiva, la Ag II puede considerarse como uno de los elementos claves en el inicio y la progresión del daño renal (128). Las células del parénquima renal sintetizan rápidamente Ag II por activación del sistema intrarenal reninaangiotensina tras la ligadura. AgII, además de sus efectos hemodinámicos directos, ejerce su acción indirecta profibrótica a través de NF- $\kappa B$, TNF- $\alpha$ y TGF- $\beta 1$ (128). El papel de AgII como factor profibrótico se ha demostrado bloqueando el sistema renina-angiotensina por inhibición de la ECA, 
una maniobra que reduce significativamente la fibrosis renal inducida por la obstrucción ureteral $(118,129,130)$.

La Ag II actúa como un potente promotor que potencia la capacidad del TGF- $\beta 1$ para inducir la EMT en las células del epitelio tubular durante la nefropatía obstructiva (126). El empleo de animales modificados genéticamente confirma la contribución fundamental de la AgII al desarrollo de la fibrosis en el modelo de nefropatía obstructiva $(131,132)$.

TGF- $\beta 1$ se considera el principal factor estimulante de la fibrogénesis en el modelo de nefropatía obstructiva inducida por ligadura (104). La OUU induce un aumento de expresión de TGF- $\beta 1$ en las células tubulares (133) y en el tejido fibrótico, producido principalmente por las células peritubulares del intersticio renal (113). Este incremento se ha relacionado directamente con la síntesis de componentes de matriz extracelular, puesto que correlaciona con la infiltración macrofágica y el incremento de la expresión intersticial de fibronectina y colágenos I, III y IV (113). TGF- $\beta 1$ también promueve la fibrosis inhibiendo la degradación de la matriz extracelular al incrementar la expresión de los TIMPs y disminuir la actividad de las MMPs (104). Esta citosina actúa además como factor quimiotáctico para fibroblastos y células inflamatorias, induce la síntesis de receptores para proteínas de matriz, estimula la proliferación de fibroblastos y la trasdiferenciación de las células tubulares $(104,126)$, actividades que aceleran el proceso fibrótico.

\section{Adaptaciones estructurales y manifestaciones funcionales.}

La OUU induce en el riñón contralateral una hipertrofia compensadora como adaptación estructural en respuesta al daño, como demuestra el incremento del volumen glomerular (134, 135) y un aumento de la TFG del mismo, así como de su función tubular como compensación de la pérdida de la función renal en el riñón obstruido. Esta adaptación se establece mediante un mecanismo no bien definido, pero que probablemente es similar al modelo de nefrectomía. Así mismo, tiene lugar un aumento de la filtración glomerular y de la función tubular en el riñón contralateral que compensa la pérdida de la función renal del riñón obstruido. Por esta razón, la 
excreción absoluta de agua y sodio en la OUU no se modifica y, por tanto, no hay cambios en la presión arterial. Este modelo cursa sin proteinuria, circunstancia que puede estar relacionada con la ausencia de un daño glomerular manifiesto.

Así mismo, muchos datos indican que los daños sufridos después de la OUU contribuyen a la progresión de la inflamación renal crónica (IRC) $(103,136)$. 


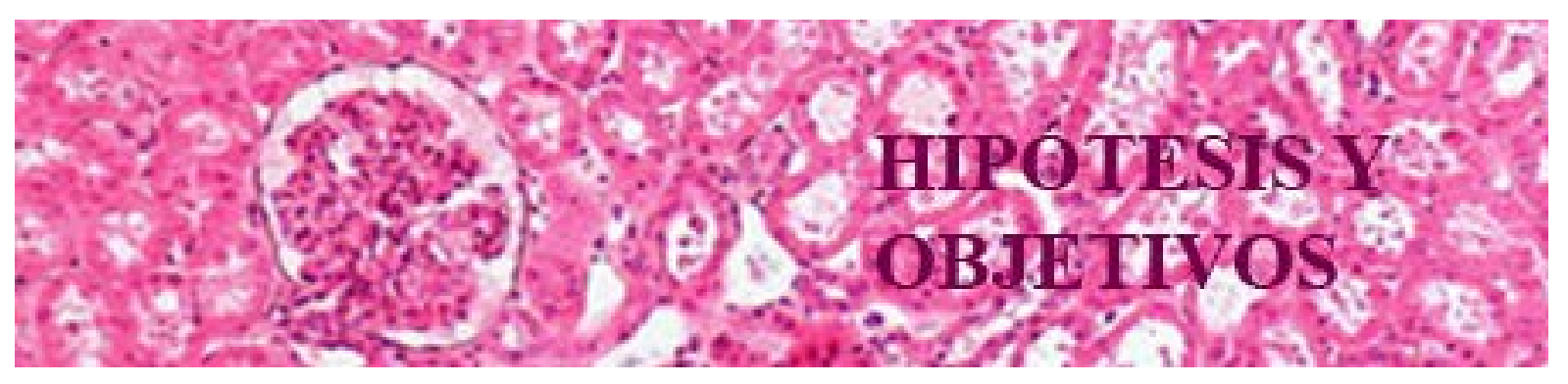


La obstrucción ureteral unilateral (OUU) en el ratón provoca un daño renal con repercusiones tanto estructurales como funcionales. Estas alteraciones son similares a los acontecimientos patogénicos que ocurren en la nefropatía obstructiva en el humano. Se trata de un modelo experimental utilizado en multitud de estudios de investigación renales, sin embargo, prácticamente la totalidad de los mismos se han centrado en los fenómenos tubulointersticiales que acaecen, no habiendo hasta ahora trabajos que traten en profundidad sobre las posibles modificaciones que pueden suceder en los corpúsculos renales tras la OUU.

Nuestra hipótesis de trabajo es que la OUU produciría también modificaciones histológicas en los corpúsculos renales cuya implicación está por demostrar. Para comprobar esta hipótesis hemos diseñado un estudio que nos permita su evaluación mediante diversas técnicas.

El objetivo de esta tesis es el estudio de los procesos morfológicos que puedan acontecer en el corpúsculo renal tras la realización experimental de una obstrucción ureteral unilateral.

Para ello se realizó lo siguiente:

1.- Estudio con técnicas de microscopía óptica convencional de las alteraciones que puedan originarse en el corpúsculo renal tras un proceso de obstrucción ureteral unilateral experimental.

2.- Estudio inmunohistoquímico de los procesos descritos en el punto anterior.

3.- Estudio ultraestructural con técnicas de microscopía electrónica. 


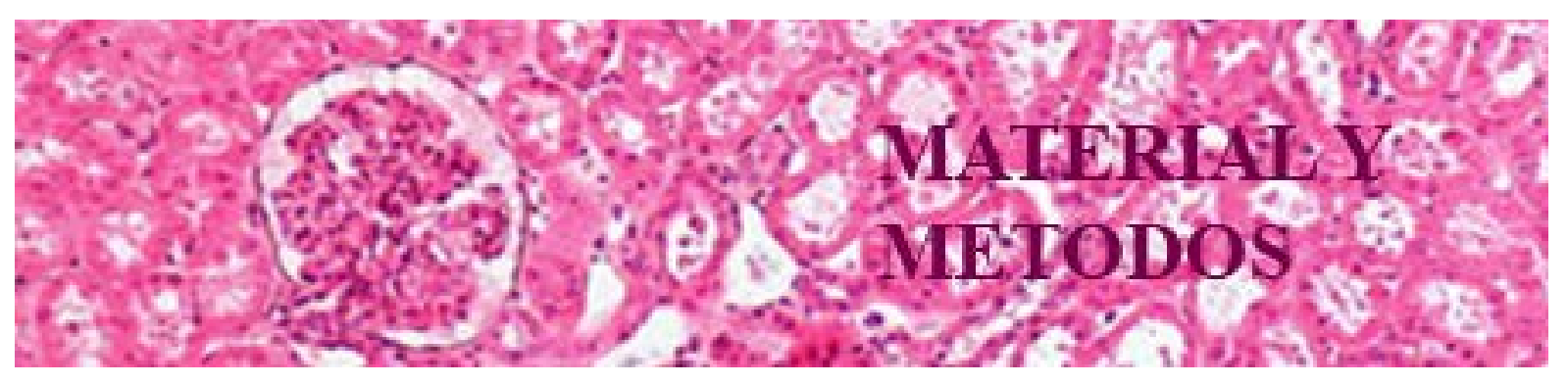




\section{ANIMALES DE EXPERIMENTACIÓN.}

Este trabajo ha sido realizado con ratones de la cepa C57BL/6 (B6) procedentes del Servicio de Experimentación Animal de la Universidad de Salamanca. Al inicio del estudio los animales tenían una edad de dos meses y un peso en torno a los 25 gramos, aproximadamente.

\section{Dieta.}

Los animales se alimentaron a base de una dieta estandarizada (Panlab), cuyo análisis es el siguiente:

- Proteína bruta $15.60 \%$

- Materias grasas brutas $2.80 \%$

- Celulosa bruta $4.80 \%$

- Cenizas brutas $4.60 \%$

Los ingredientes de esta dieta incluyen granos de cereales, semillas oleaginosas, productos de panadería y de fabricación de pastas alimenticias, productos de pescado y minerales. Además se añadieron como aditivos cobre (sulfato cúprico pentahidratado) y las vitaminas A, D3 y E (tocoferol).

\section{Condiciones ambientales.}

Durante el periodo experimental, los animales se mantuvieron en jaulas de $30 \mathrm{~cm}$. En cada jaula se colocaron como máximo cuatro animales, donde tenían libre acceso a comida y agua.

Las condiciones ambientales permanecieron constantes: la temperatura fue de unos $20^{\circ} \mathrm{C}$, la humedad del $60 \%$ aproximadamente, y el tiempo diario de luz (fotoperiodo) de 12 horas.

\section{Normativa.}

El material y los métodos experimentales empleados con los animales de laboratorio se aplicaron de acuerdo a las siguientes disposiciones legales: 
- Directiva del Consejo de Europa 86/609/CEE del 24 de Noviembre de 1986 relativa a la protección de los animales utilizados para experimentación y otros fines científicos.

- Real Decreto 1201/2005, de 10 de octubre, sobre protección de los animales utilizados para experimentación y otros fines científicos. BOE núm. 252. 21 octubre 2005.

- Real Decreto 178/2004, de 30 de enero, por el que se aprueba el Reglamento general para el desarrollo y ejecución de la Ley 9/2003, de 25 de abril, por la que se establece el régimen jurídico de la utilización confinada, liberación voluntaria y comercialización de organismos modificados genéticamente (BOE 27; 31-01-2004).

- Decisión del Consejo de 23 de marzo de 1998 relativa a la celebración por la Comunidad del Convenio Europeo sobre la protección de los animales vertebrados utilizados para experimentación y otros fines científicos (DOCE L 222; 24-08-1999).

\section{GRUPOS EXPERIMENTALES.}

En el diseño del estudio se plantearon estos cuatro grupos experimentales:

1. Riñón izquierdo de ratones sometidos a obstrucción ureteral unilateral (OUU) por ligadura del uréter izquierdo, mantenida durante 15 días.

2. Riñón derecho, no obstruido, del mismo animal anterior.

3. Riñones de ratones normales sin ligadura utilizados como control.

4. Riñones de ratones normales sometidos a anestesia e incisión de la cavidad abdominal pero sin practicarles ligadura. Se denominan Sham,

Se efectuaron dos bloques de los citados 4 grupos, uno fue destinado a los estudios de microscopía óptica y otro para los de microscopía electrónica 


\section{PROCEDIMIENTO EXPERIMENTAL DE LA OBSTRUCCIÓN URETERAL UNILATERAL.}

\section{Anestesia.}

Los animales se anestesiaron con una solución inhalatoria de Forane ${ }^{\circledR}$ (isoflurano).

\section{Procedimiento quirúrgico.}

Se fijó el animal a una tabla-quirófano y se rasuró el campo operatorio en la zona abdominal. En este punto se practicó un pequeño corte en la porción abdominal, suficiente como para poder localizar el uréter izquierdo. Una vez localizado y limpiado de adherencias, se ligó con una sutura no absorbible (4-0) en dos puntos, con el fin de que resultara prácticamente imposible la ineficacia de la ligadura. A continuación, se cerró el abdomen por planos. Todo este proceso se realizó en condiciones asépticas y se mantuvo junto al animal una lámpara térmica, con objeto de mantener la temperatura corporal.

\section{RECOGIDA DE MUESTRAS.}

Transcurridos los 15 días tras la operación quirúrgica, los animales se anestesiaron de nuevo con pentobarbital y se procedió a la recogida de piezas.

Los animales destinados para ser estudiados con técnicas de microscopía óptica se sometieron a apertura de la parrilla costal y se perfundieron mediante punción directa en el ventrículo izquierdo del corazón, inyectando $50 \mathrm{ml}$ de ClNa al 0,9\% a una velocidad y presión de perfusión constante, para el lavado sanguíneo total. Inmediatamente al inicio de la perfusión, se efectuó un corte de los vasos hepáticos para el drenaje sanguíneo. A continuación, se perfundió con $50 \mathrm{ml}$ de formol tamponado al 10\%. Una vez finalizada la perfusión se extrajeron los riñones, se decapsularon y se cortaron sagitalmente para sumergirlos, posteriormente, en formol tamponado al $10 \%$.

Para los estudios con microscopía electrónica se siguió el mismo procedimiento, pero, tras el lavado con $\mathrm{ClNa}$, los animales se perfundieron con glutaraldehido 2,5\%. 


\section{ESTUDIOS HISTOLÓGICOS.}

\section{Procesado de muestras para Microscopía óptica.}

Los riñones se mantuvieron en el fijador durante 24 horas como máximo. Tras ese periodo, se lavaron con agua corriente y se sumergieron en alcohol al 70\% durante toda la noche. Posteriormente, se procesaron como sigue:

Se sometió a los tejidos a una deshidratación, requisito necesario para su inclusión posterior en parafina:

- Etanol al 80\% durante 1 hora.

- Etanol al 90\% durante 1 hora.

- Etanol al $100 \%$ dos pases de hora.

- Etanol de 100o - tolueno en proporción 1:1 durante 1 hora.

- Tolueno puro durante 2-3 horas.

Después de la deshidratación, los tejidos se sumergieron en parafina líquida y mantenidos en estufa a $60^{\circ} \mathrm{C}$ durante 24 horas.

Al día siguiente, los tejidos se introdujeron en moldes metálicos específicos para la formación de bloques y se les añadió parafina limpia. Una vez enfriados durante 2-3 horas a 4ํㅡ los bloques formados y numerados convenientemente, se desmontaron de los moldes metálicos y mantenidos a dicha temperatura hasta su corte.

Los bloques se cortaron con un microtomo Microm HM 310. De esta manera, se efectuaron secciones de $3 \mu \mathrm{m}$ de grosor para las tinciones con hematoxilina y eosina, tricrómico de Masson y los estudios inmunohistoquímicos. Para la técnica de rojo sirio las secciones fueron de $5 \mu \mathrm{m}$. Los cortes se recogieron en portaobjetos de vidrio. En el caso de las muestras destinadas a inmunohistoquímicas los portaobjetos utilizados estaban silanizados previamente para incrementar la adherencia de los tejidos. 


\section{Técnicas de tinción:}

\section{Tinción con hematoxilina-eosina.}

Los cortes se desparafinaron e hidrataron de la forma que sigue:

- Xilol 3 pases de 5 minutos cada uno

- Etanol/Xilol 1:1 durante 5 min

- Etanol $100 \%$ durante 5 días.

- Etanol 90\% durante 5 min.

- Etanol 80\% durante 5 min.

- Etanol 70\% durante 5 min.

- Lavado en agua corriente durante $10 \mathrm{~min}$.

A continuación, los portas se cubrieron con hematoxilina de Carazzi durante 5 minutos y lavados con agua en varios cambios. Posteriormente se cubrieron con eosina durante 8 minutos y se deshidrataron con soluciones crecientes de alcoholes según se expone a continuación:

- Alcohol 70\% durante 5 min.

- Alcohol 80\% durante 5 min.

- Alcohol 90\% durante 5 min.

- Alcohol $1000 \%$ durante 5 min.

- Xilol 3 pases de 5 min.

Posteriormente los portas se montaron con DPX y cubreobjetos.

\section{Tricrómico de Masson.}

Con el fin de ver el posible aumento de tejido conectivo en las muestras, se realizó la técnica de tinción de Tricrómico de Masson, cuyo procedimiento técnico fue el siguiente: 
Los cortes se desparafinaron e hidrataron de la forma anteriormente descrita. Se mantuvieron durante una noche en líquido de Bouin $(750 \mathrm{ml}$ de solución acuosa saturada de ácido pícrico (al 1-2\% en agua destilada), $250 \mathrm{ml}$ de formalina concentrada (40\% de formaldehído con un 60\% de metanol) y $50 \mathrm{ml}$ de ácido acético glacial, $\mathrm{pH} 2.2$ ).

A continuación, se lavaron los cortes con agua destilada hasta el aclaramiento total del color amarillo proporcionado por el ácido pícrico. Seguidamente, las muestras se tiñeron con hematoxilina férrica de Weigert $(0.5 \mathrm{~g}$ de hematoxilina cristalizada, $0.75 \mathrm{~g}$ de cloruro férrico, $1 \mathrm{ml}$ de ácido acético glacial en $100 \mathrm{ml}$ de agua) durante 10 minutos.

De nuevo se lavaron las preparaciones con agua destilada y se tiñeron con la solución escarlata de Biebrich-fucsina ácida (90 ml de Escarlata de Biebrich (C.I. 26905) al $1 \%$ en agua destilada, $10 \mathrm{ml}$ de fucsina ácida en solución acuosa al 1\%, $1 \mathrm{ml}$ de ácido acético glacial) durante 25 minutos.

Luego se lavaron con agua destilada y, durante 10 minutos, se tiñeron con una solución acuosa de ácido fosfotúngstico al $5 \%$.

A continuación, se tiñó con solución de verde luz (light green) al 2\% (99 ml de agua destilada, 2 g de verde luz SF amarillento (C.I. 42095) y $1 \mathrm{ml}$ de ácido acético glacial).

Los cortes así teñidos se lavaron y se diferenciaron con ácido acético al $1 \%$ durante 3-5 minutos. Después de la deshidratación, se montaron las preparaciones y se almacenaron hasta su observación.

\section{Tinción con rojo sirio.}

Dado que el tricrómico de Masson es una técnica en la que es difícil igualar de manera constante las características tintoriales entre preparaciones efectuadas en diferentes momentos, para la cuantificación de la fibrosis renal mediante análisis de imagen, las preparaciones se tiñeron con rojo sirio (137), cromógeno que tiñe selectivamente las fibras de colágeno. 
Se eligió esta técnica para el análisis cuantitativo de la fibrosis porque presenta las siguientes ventajas:

- El rojo sirio es un cromógeno que tiñe las fibras de colágeno, componente fundamental del tejido conectivo.

- Se facilita el aislamiento del glomérulo, ya que rodeando a la cápsula de Bowman existe una pequeña cantidad de fibra que se tiñe con rojo sirio, de tal manera que el corpúsculo renal queda, en la mayoría de los casos, bien delimitado.

- Los núcleos no se contrastan, con lo que se evitan interferencias en la cuantificación.

- Es una técnica fácilmente reproducible, lo que permite obtener preparaciones uniformes y por tanto comparables.

Para preparar la solución de rojo sirio se mezclaron $10 \mathrm{ml}$ de rojo sirio (F3BA C.I. 35780) con $90 \mathrm{ml}$ de una solución saturada de ácido pícrico (para garantizar la saturación es conveniente que queden restos de ácido pícrico sin disolver) y se dejó reposar durante 48 horas. Una vez efectuada la solución, ésta se mantiene estable durante largo tiempo pudiendo ser usada en posteriores estudios.

El procedimiento técnico fue el siguiente:

Los cortes se desparafinaron e hidrataron según el protocolo citado anteriormente.

Posteriormente se tiñeron con la solución de rojo sirio durante 30 minutos a temperatura ambiente, tras los cuales, los portas, se aclararon y protegieron los cortes con medio de montaje y cubreobjetos. Es necesario esperar unas 24 horas antes de manipular la preparación.

Para la cuantificación del rojo sirio en las preparaciones se utilizó un sistema de análisis de imagen por ordenador que consta de los siguientes elementos:

- Dispositivo de captación de imágenes: videocámara de alta resolución Sony CCD-IRIS blanco y negro de alta. 
- Microscopio óptico modelo Nikon eclipse 50i. y objetivo de 20X plano apocromático

- Filtro óptico verde modelo IF 550 para aumentar el contraste

- Ordenador personal para transformar, manipular y almacenar la imagen (CPU 486 DX$100 \mathrm{MHz})$.

- Dispositivo de presentación de la imagen (monitor de alta resolución Sony).

Sobre los portaobjetos, codificados y teñidos con rojo sirio, se capturaron, y digitalizaron imágenes con el programa FIBROSIS HR ${ }^{\circledR} 5.1$ (ImageSP, Barcelona). Se procesaron un total de 25 corpúsculos y 10 campos intersticiales por cada portaobjetos, que fueron cuantificadas posteriormente con el mismo programa. (138)

El rojo sirio tiñe casi exclusivamente las fibras colágenas, componente fundamental de la matriz extracelular y el programa, tras restar el color del fondo, transforma automáticamente las imágenes en 256 tonos de grises, seleccionando los que corresponden a tinción con rojo sirio y cuantifica estos elementos de las imágenes. En el caso de las imágenes glomerulares, es necesario aislar el área corpuscular, indicando en el monitor donde está localizado el glomérulo. Después el programa discrimina el área del corpúsculo renal, ya que la cápsula de Bowman está normalmente rodeada por una pequeña cantidad de tejido conjuntivo marcada por el colorante.

Los valores que se obtienen de cada imagen glomerular son los siguientes:

- Área intersticial ocupada por rojo sirio en $\mu \mathrm{m} 2$.

- Área corpuscular total en $\mu \mathrm{m} 2$.

- Área mesangial en $\mu \mathrm{m} 2$.

Los valores obtenidos en el análisis morfométrico se exportaron a un programa cálculo informático (Microsoft Excel para Windows®). 


\section{Inmunohistoquímica.}

Las técnicas descritas anteriormente ofrecen mucha información sobre las muestras pero no permiten discriminar selectivamente moléculas determinadas e implicadas en los posibles mecanismos de daño renal que no son detectables mediante las mismas. Es por ello por lo que hemos efectuado un estudio inmunohistoquímico analizando la expresión de Colágeno I, Fibronectina, pSmad2-3, $\alpha$-Actina, Ki67 (clon Mib-1), Caspasa 3 activada y WT-1.

El procedimiento técnico fue el siguiente:

Se utilizaron cortes de $3 \mu \mathrm{m}$ de todos los grupos y para cada una de los anticuerpos utilizados en el estudio, que se desparafinaron y se hidrataron de la misma forma que para las técnicas de tinción anteriores.

A continuación, se realizó el desenmascaramiento antigénico mediante la incubación de las secciones con una solución de citrato (BioGenex, CA) en microondas durante tres minutos.

Para inhibir la peroxidasa endógena se utilizó agua oxigenada al 3\% durante 10 minutos y, nuevamente, se realizó un lavado de 5 minutos con PBS. A continuación, se incubaron los cortes durante una hora con suero bloqueante, con el fin de que no tuviera lugar un marcaje inespecífico.

Los pasos posteriores se realizaron de forma automatizada mediante el sistema Bondmax® (Leica Biosystems, Melbourne, Australia). Previamente se habían efectuado comparaciones entre el método manual y el automático mostrando ambos similares resultados en los patrones de tinción, pero con una mayor reproductibilidad e intensidad de tinción con el método automático por lo que este fue el de elección para realizar la técnica de inmunohistoquímica.

El sistema retiró el exceso de líquido que pudiera quedar en las preparaciones y las mismas se incubaron durante una hora con el anticuerpo primario correspondiente en cada caso.

Los anticuerpos primarios utilizados fueron los siguientes: 
- Anti Colágeno I policlonal de conejo: (Chemicon International, Temecula, CA, USA) a una dilución de 1:100.

- Anti $\alpha$-Actina de músculo liso monoclonal de ratón: Dako Diagnostics, Copenhagen, Denmark dilución 1:50.

- Ki67 (clon Mib1) monoclonal de conejo: Master Diagnostica, Granada, Spain a una dilución 1:100.

- Anti Fibronectina policlonal de conejo: Sigma-Aldrich, St Louis, MO, USA a una dilución $1: 100$.

- Anti Caspasa 3, policlonal de conejo: Cell Signaling Technology, MA, USA a una dilución $1: 50$.

- Anti pSmad2/3 policlonal de conejo: Santa Cruz Biotechnology Inc, CA, USA a una dilución 1:1000.

- WT-1: anticuerpo policlonal de conejo: Santa Cruz Biotechnology Inc, CA, USA a una dilución 1:500.

El procedimiento de visualización se realizó, también de forma automatizada, utilizando el Novolink Polymer Detection System ${ }^{\circledR}($ RE7140-K) con una incubación con post-primario de 8 minutos, polímero durante 8 minutos y Diaminobencidina (DAB) durante 10 minutos. Por último se realizó una tinción de contraste de la muestra con hematoxilina.

\section{Captura y digitalización de imágenes.}

La captura de imagen tanto de los cortes teñidos con hematoxilina-eosina, tricrómico de Mason e inmunohistoquímica se realizó con el siguiente equipo:

- Microscopio óptico modelo Nikon eclipse 50i.

- Dispositivo de captación de imágenes: videocámara de alta resolución Sony DFW-X710 
- Ordenador personal para transformar, manipular y almacenar la imagen (CPU 486 DX$100 \mathrm{MHz})$.

- Dispositivo de presentación de la imagen (monitor de alta resolución Sony).

- Se capturaron y digitalizaron imágenes con el programa VISILOG 6.2® (Noesis, Francia).

- El análisis y cuantificación de las imágenes digitalizadas se realizó con el programa Image J $(139,140)$.

\section{Procesado de muestras para microscopía electrónica.}

Las piezas de los animales perfundidos, según describimos anteriormente en el apartado de "recogida de muestras", fueron talladas en bloques de, aproximadamente, $1 \mathrm{~mm}^{3} \mathrm{y}$ sumergidas en una solución de glutaraldehido al 2,5\% en tampón fosfato $0,1 \mathrm{M}$ pH 7,4 durante un mínimo de dos horas.

A continuación, se pasaron a tampón fosfato $0,1 \mathrm{M}$ pH 7,4 con Sacarosa al 6,84\% y $1 \mathrm{ml}$ de Cloruro cálcico al 1\%, donde se efectuaron cambios de tampón sucesivos durante dos horas.

Finalmente, fueron postfijadas en tetróxido de osmio al 1\% en tampón fosfato 0,1M pH 7,4 a 4 grados durante $1 \mathrm{~h}$.

Tras el lavado con agua destilada se inició su deshidratación según el siguiente procedimiento:

- Acetona $30 \%$ durante $10 \mathrm{~min}$.

- Acetona 50\% durante $10 \mathrm{~min}$.

- Acetato de uranilo al 2\% en acetona $70 \%$ durante toda la noche.

- Acetona $90 \%$ durante $20 \mathrm{~min}$.

- Acetona $100 \%$ durante $20 \mathrm{~min}$.

- Acetona pura 2 pases de $30 \mathrm{~min}$. 
- Óxido de propileno 2 pases de $15 \mathrm{~min}$.

Finalmente, se procedió a la inclusión de las muestras en resina Durcupán progresivamente en soluciones de concentración creciente con óxido de propileno como sigue:

- Óxido de propileno/resina en proporción 3:1 durante 30 min.

- Óxido de propileno/resina en proporción 1:1 durante 30 min.

- Óxido de propileno/resina en proporción 1:3 durante 30 min.

- Resina pura durante toda la noche.

- Resina pura nueva durante $1 \mathrm{~h}$ a $60^{\circ}$.

- Resina pura nueva durante 30 minutos a $60^{\circ}$.

- Inclusión en cápsulas de gelatina que se rellenaron con resina durante toda la noche.

Las cápsulas así preparadas se polimerizaron durante $48 \mathrm{~h}$ en estufa a $60^{\circ} \mathrm{C}$.

Tras ese tiempo se dejaron atemperar y se procedió a su tallado y corte en secciones semifinas de $0,55 \mu \mathrm{m}$ que fueron teñidas con azul de toluidina para la localización con el microscopio óptico de las áreas de interés que contuviesen corpúsculos. Posteriormente se cortaron secciones finas de, aproximadamente, $60 \mathrm{~nm}$ que fueron depositadas sobre rejillas de cobre revestidas de formvar, y las mismas contrastadas con acetato de uranilo $2 \%$ y citrato de plomo, para su correcta visualización con el microscopio electrónico.

Las rejillas fueron estudiadas en un Microscopio Zeiss EM902, donde, además de visualizar la ultraestructura de los cortes, se realizó un estudio cuantitativo del grosor de la Membrana basal glomerular y de la anchura de la base de los pedicelos. Para ello se capturaron 10 imágenes de cada caso, en diferentes puntos de cada corpúsculo, mediante una cámara CCD SlowScan ${ }^{\circledR}$ que fueron analizadas mediante el programa de digitalización de imagen ImageSP ${ }^{\circledR}$. El programa permite 
obtener de forma automática los datos de los parámetros a analizar y lo deja reflejado en la imagen, como se puede observar en el ejemplo que insertamos a continuación:

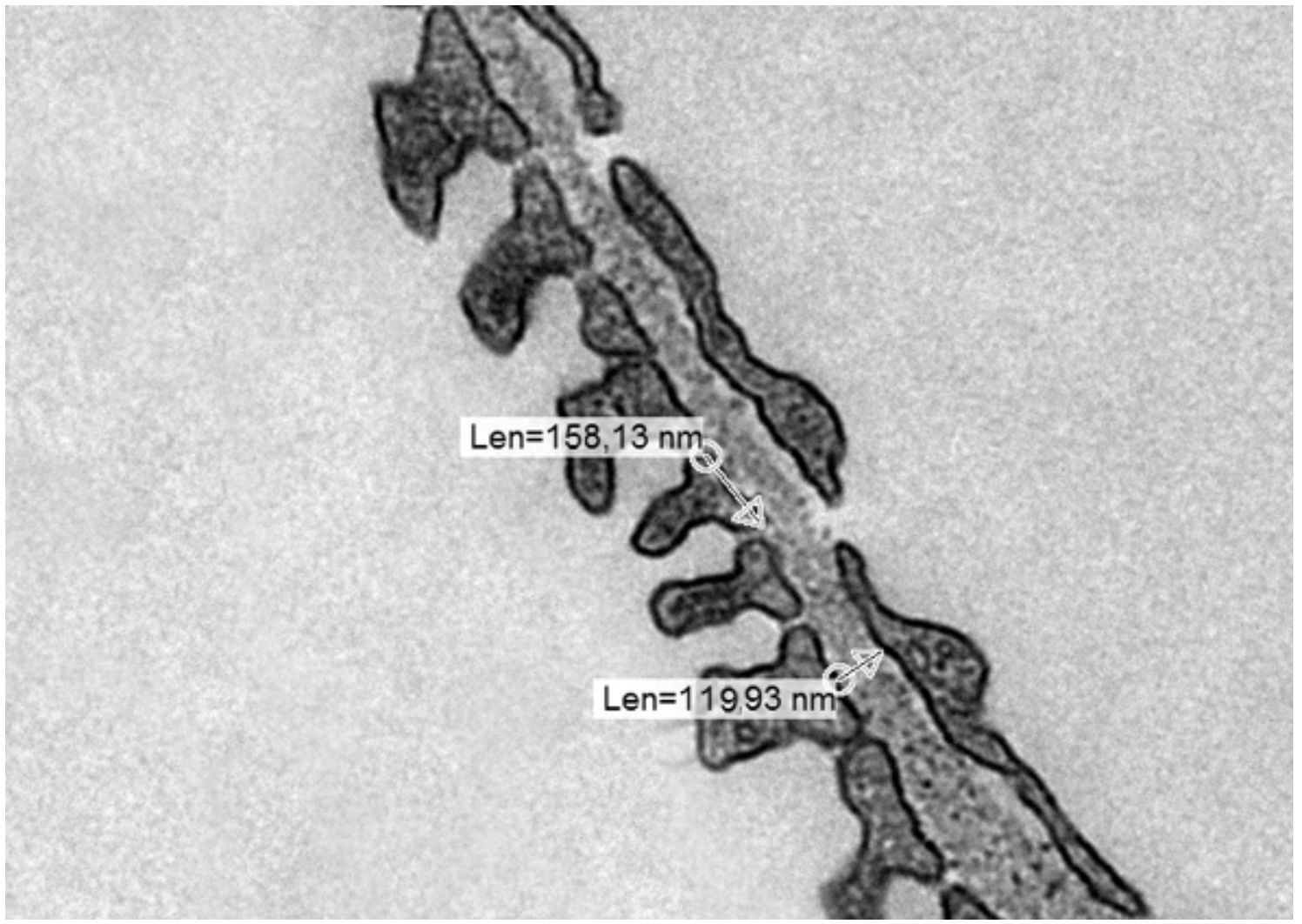

Figura 4: Microfotografía tomada con TEM en la que se muestran los parámetros empleados para los análisis de imagen.

\section{Tratamiento estadístico.}

Los datos obtenidos en los diferentes experimentos se almacenaron en una hoja de cálculo (Microsoft Excel 2010 para Windows ${ }^{\circledR}$ ) y se realizó un análisis de parámetros descriptivos básicos a partir de los cuales se elaboraron histogramas de Barras a partir de las medias correspondientes y su error típico.

Los datos almacenados en las correspondientes hojas de cálculo fueron exportados a la aplicación estadística SPSS statistics ${ }^{\circledR}$. Para evaluar la normalidad de los datos se aplicó el test Kolmogorov-Smirnov obteníendose un p valor mayor de 0,05 con lo cual se asume que la variable se ajusta a la normalidad. El análisis estadístico se llevó a cabo mediante el análisis de la varianza de una entrada (ANOVA1). A continuación, se aplicó el test de Tukey que permite comparar las 
medias de los t niveles de un factor después de haber rechazado la hipótesis nula de igualdad de medias mediante la técnica ANOVA. Se consideró significativo un valor de p menor que 0,05

Los resultados se expresaron como media más menos error estándar de la media (EEM). 


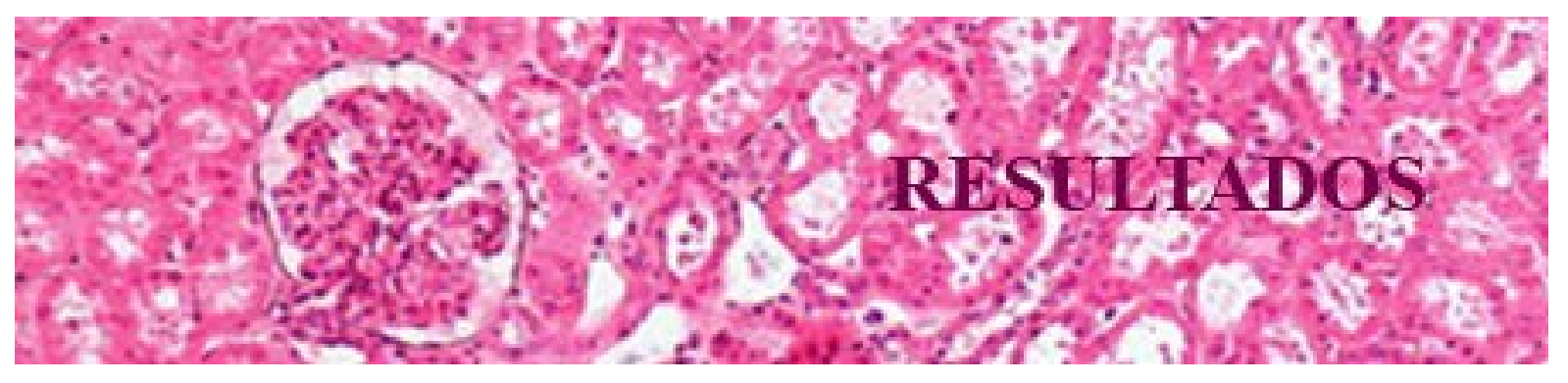




\section{ESTUDIO HISTOLÓGICO.}

\section{Hematoxilina-eosina.}

Transcurridos 15 días desde la ligadura del uréter, los animales ligados desarrollaron una hidronefrosis grave y la tinción con hematoxilina-eosina reveló las características típicas de una nefropatía obstructiva. Así, el espesor total de la corteza y la médula estaba disminuido y se evidenció una compresión medular importante. En la corteza, los túbulos mostraban cambios que iban desde una luz dilatada con un epitelio aplanado, a diferentes grados de necrosis (Figura 5). En la mayoría de los casos, se observó un infiltrado inflamatorio intersticial, principalmente en las zonas perivasculares. Aparentemente, los corpúsculos renales no presentaron grandes alteraciones detectables con esta tinción (Figura 6), aunque fue posible observar las estructuras glomerulares más compactadas y, en un gran porcentaje de corpúsculos, se observó tubularización del epitelio parietal de la cápsula de Bowman. En los riñones contralaterales no ligados no se detectaron alteraciones estructurales relevantes ni en el túbulo-intersticio ni en los corpúsculos. Los riñones de los animales Sham y Control no presentaron alteraciones.

\section{Tricrómico de Mason.}

Para observar la presencia de tejido conjuntivo en las muestras se efectuó una tinción estándar con Tricrómico de Masson, donde se observó un aumento de tejido conectivo en los intersticios tubulares de los animales ligados. En los riñones no ligados no se evidenció aumento importante de tejido conectivo, al igual que en los animales Sham y Control (Figura 7). En el caso de los corpúsculos pudo observarse un aumento de la matriz mesangial en los riñones ligados y ligero aumento en los no ligados, no encontrándose dicho aumento en el caso de los animales Sham y Control (Figura 8). 

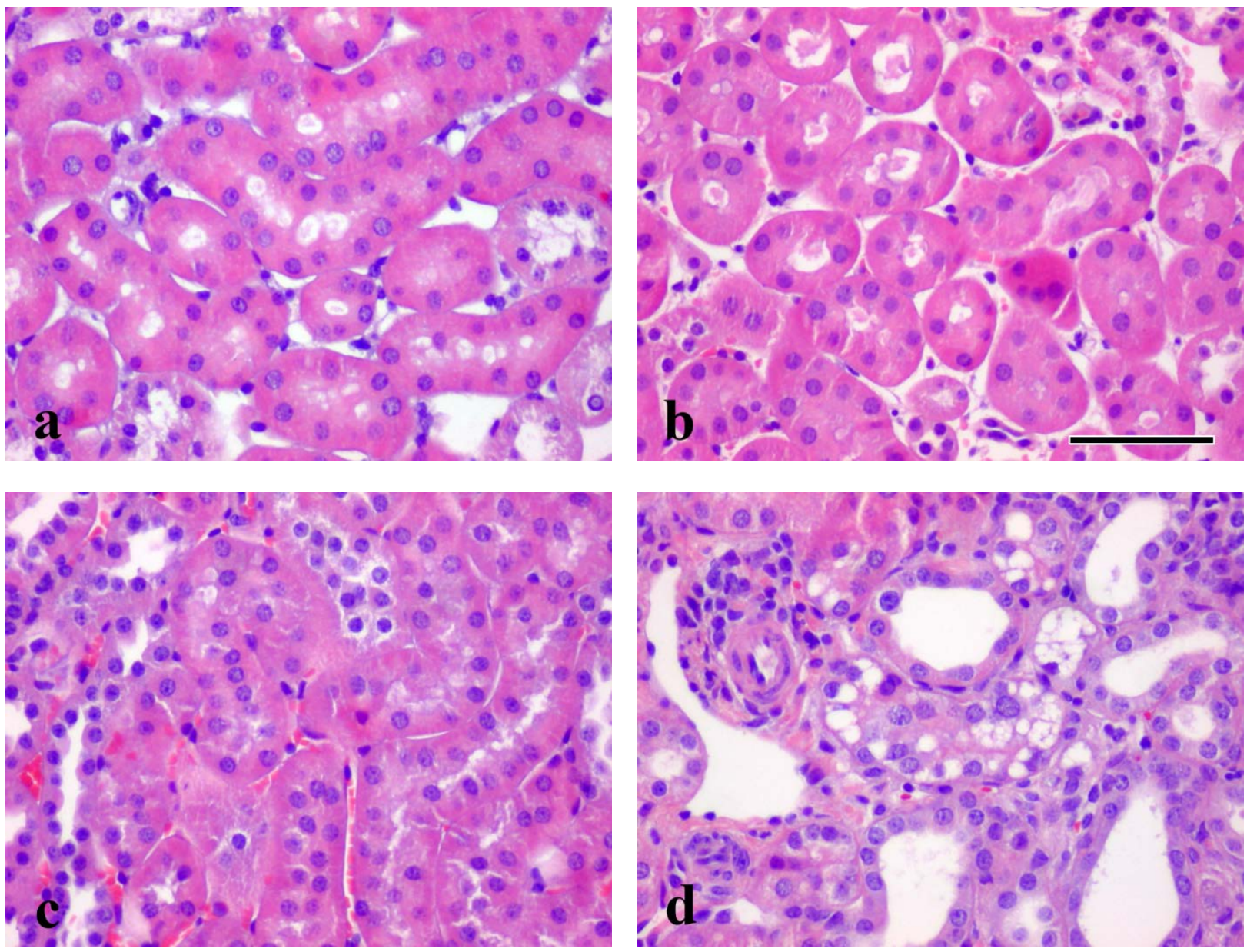

Figura 5: Micrografías representativas de muestras de intersticio cortical renal teñidas con Hematoxilina-Eosina procedentes de riñones de ratones pertenecientes al grupo control (a), grupo sham (b), riñón contralateral no ligado (c) y riñón con ligadura de uréter (d). Barra= $50 \mu \mathrm{m}$. 

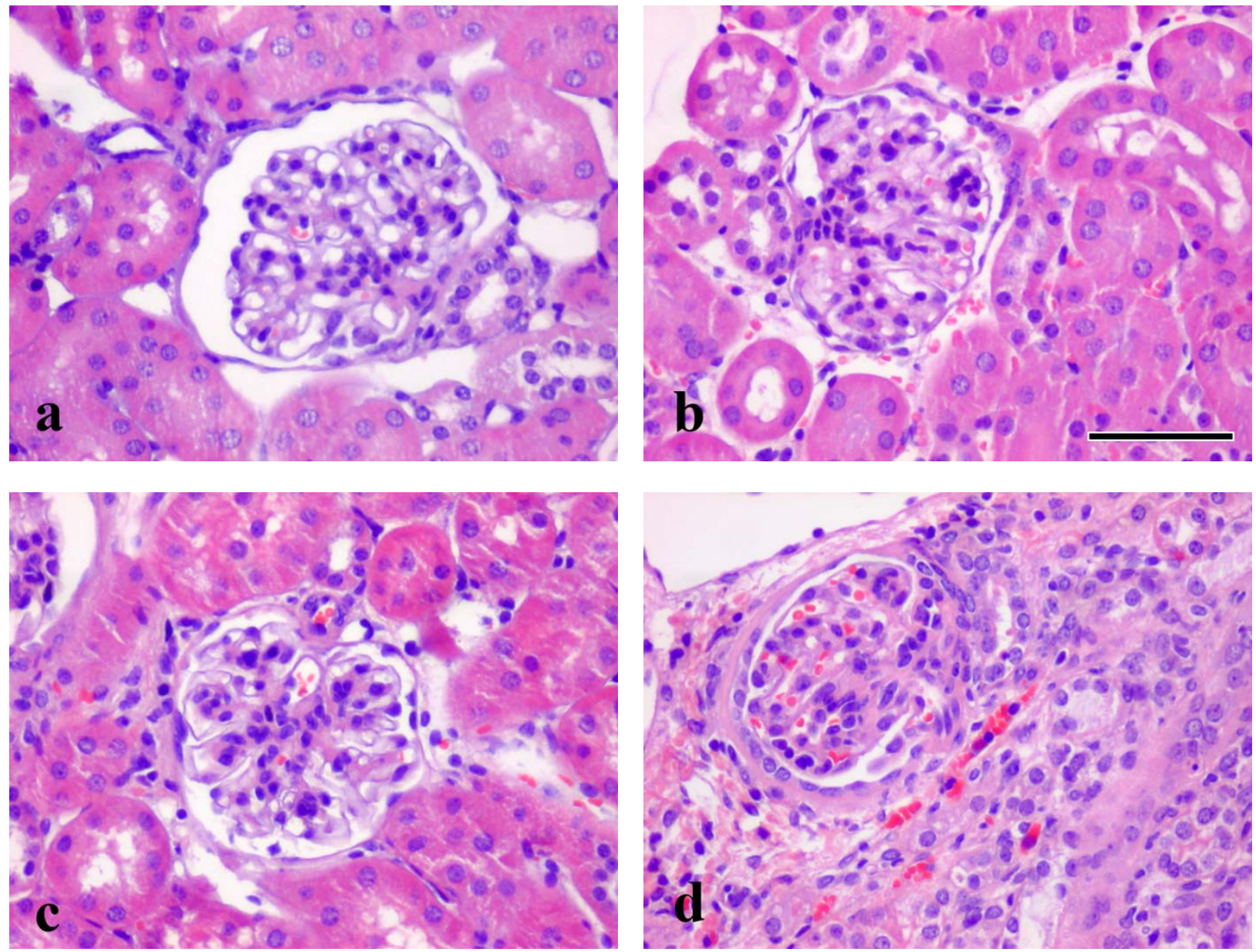

Figura 6: Micrografías representativas de muestras renales con corpúsculos, teñidas con Hematoxilina-Eosina, procedentes de riñones pertenecientes al grupo control (a), grupo sham (b), riñón contralateral no ligado (c) y riñón con ligadura de uréter (d). Barra= $50 \mu \mathrm{m}$. 

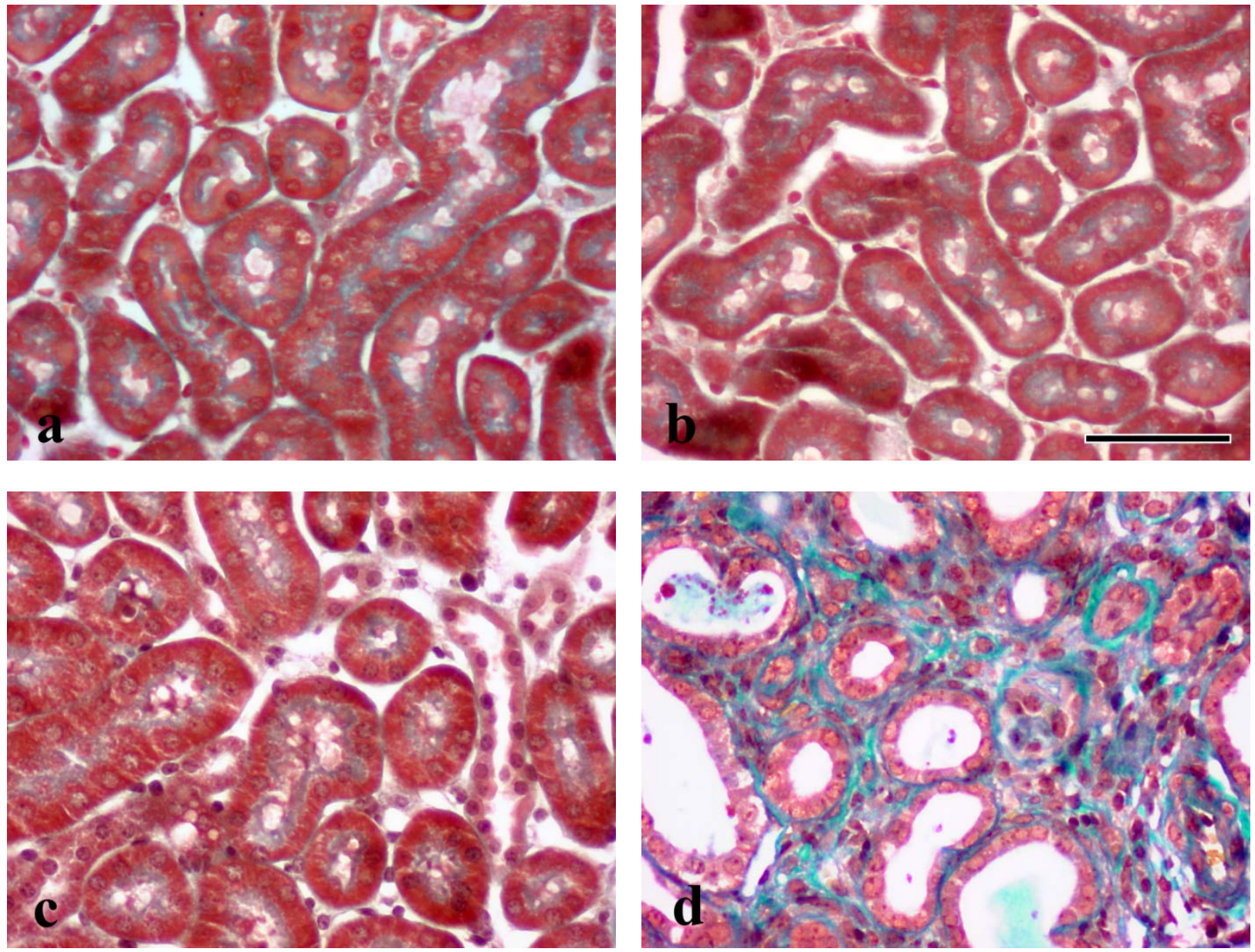

Figura 7: Micrografías representativas de muestras de intersticio renal teñidas con Tricrómico de Masson procedentes de riñones pertenecientes al grupo control (a), grupo sham (b), riñón contralateral no ligado (c) y riñón con ligadura de uréter. Barra $=50 \mu \mathrm{m}$. 

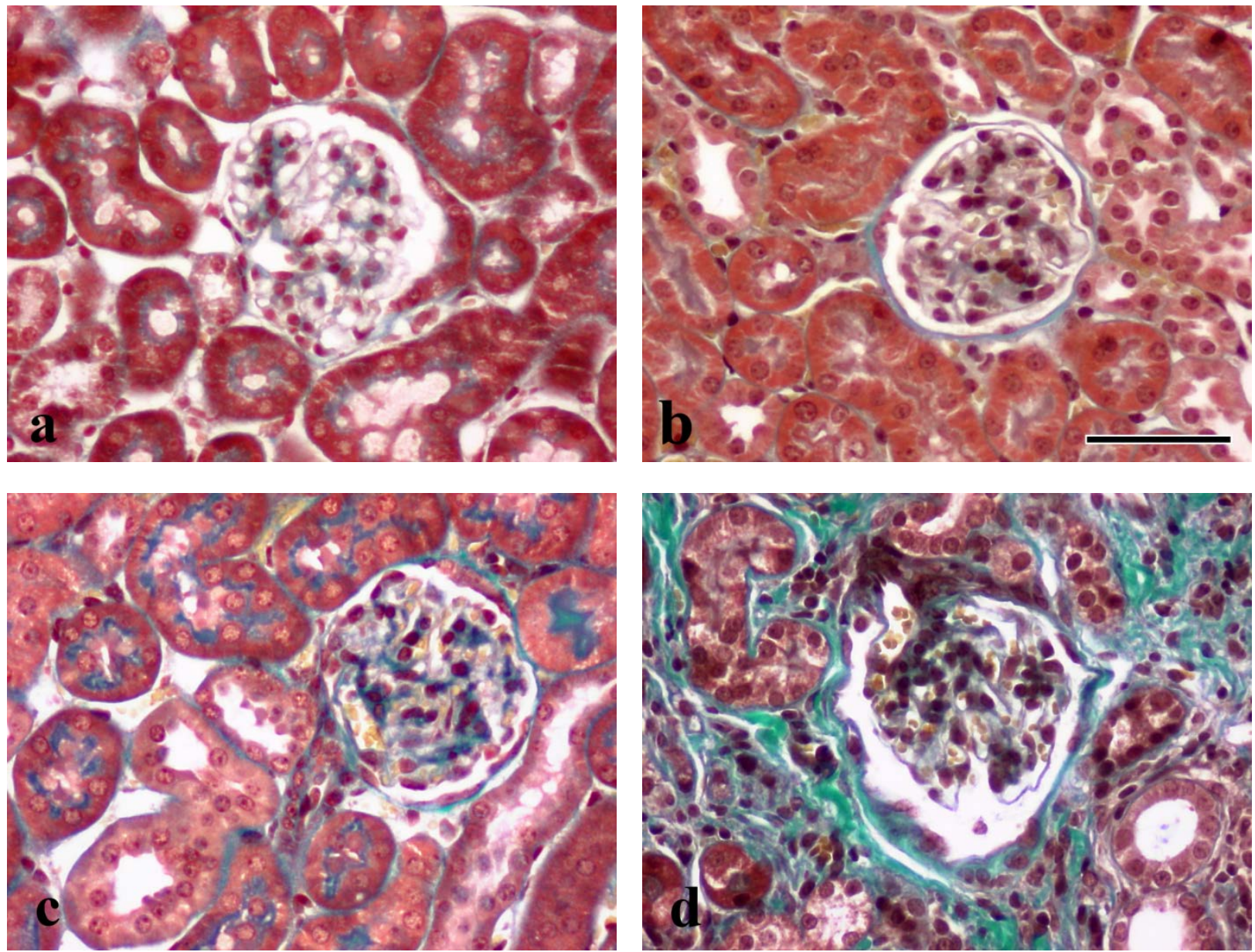

Figura 8: Micrografías representativas de muestras de corpúsculos renales teñidas con Tricrómico de Masson en las que se aprecian corpúsculos renales procedentes de riñones pertenecientes al grupo control (a), grupo sham (b), riñón contralateral no ligado (c) y riñón con ligadura de uréter. Barra= 50 $\mu \mathrm{m}$. 


\section{ESTUDIO MORFOMÉTRICO: TINCIÓN CON ROJO SIRIO.}

Para la evaluación del área corpuscular y cuantificar la posible existencia de fibrosis tanto intersticial como glomerular, se realizó un estudio mediante un sistema de análisis de imagen asistido por ordenador, en preparaciones teñidas con rojo sirio. Los parámetros analizados fueron: área intersticial, área corpuscular y área mesangial.

\section{Intersticio.}

En el caso del intersticio se evidenciaron diferencias significativas en el área ocupada por colágeno entre los riñones ligados (L) y los otros grupos de estudio (NL, Sh y C), siendo ésta significativamente mayor en el caso de los ligados. Como puede verse en la Figura 9, se observaron también diferencias significativas entre NL y C, siendo mayor la fibrosis en el caso de los NL.

\section{Área Corpuscular}

En la Figura 10 se observan los resultados del análisis cuantitativo del área corpuscular. Se aprecia una disminución significativa del tamaño de los corpúsculos en los riñones Ligados (L) con respecto a los otros tres grupos de estudio: no ligados (NL), sham (Sh) y control (C). Cabe señalar que el mayor área corpuscular media de todos los grupos se observó en los riñones NL siendo la diferencia, como ya hemos señalado, significativa con respecto a los riñones L, aunque no lo fue con los NL y Sh. 
A
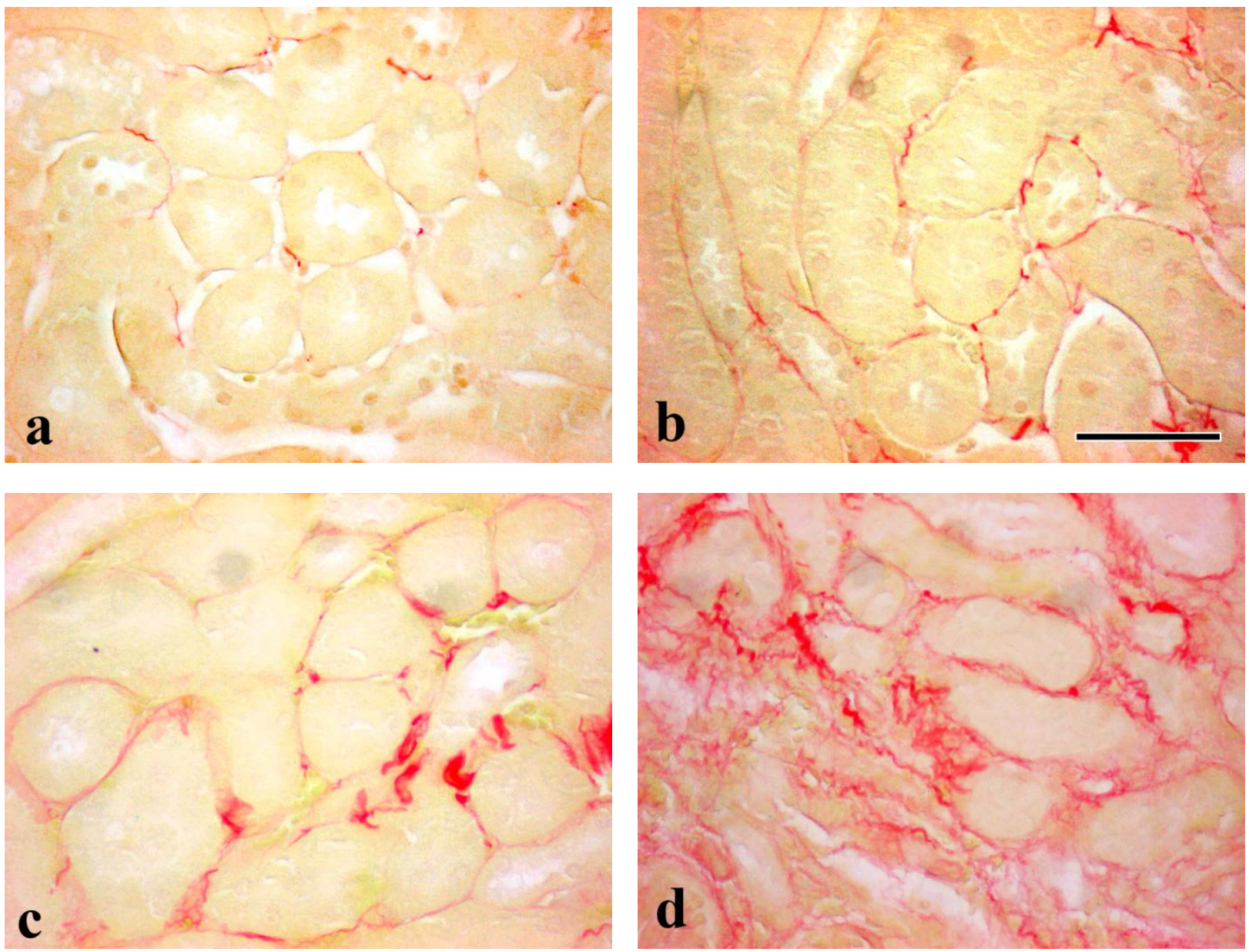

B

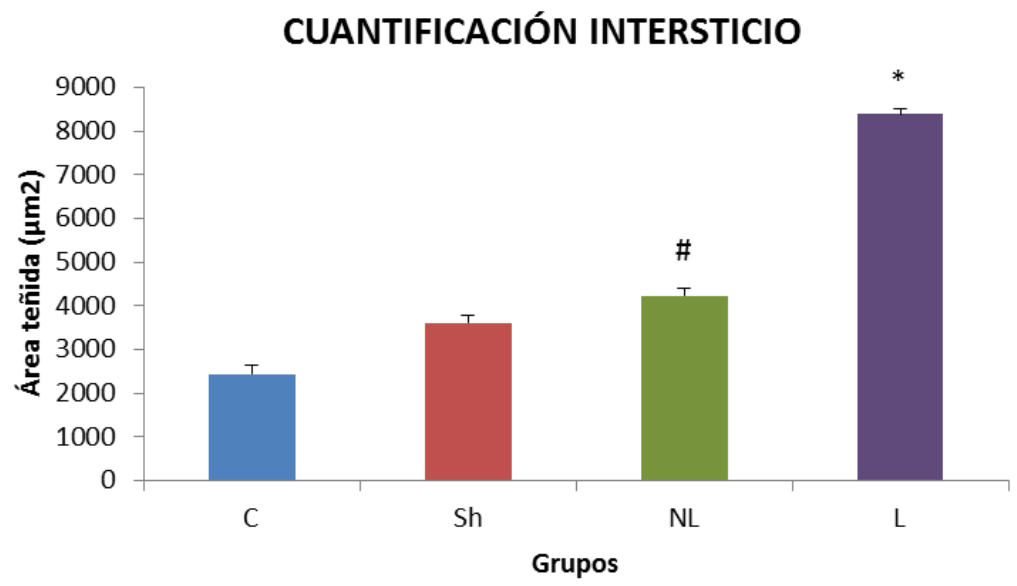

Figura 9: Estudio morfométrico del intersticio (A) Micrografías representativas de muestras de intersticio tubular cortical teñidas con Rojo Sirio en ratones (a) control, (b) grupo sham, (c) riñón contralateral no ligado y (d) riñón con ligadura de uréter. Barra $=50 \mu \mathrm{m}$. (B) Gráfica representativa del análisis de imagen que muestra la cuantificación de rojo sirio intersticial. Los valores representan la media \pm e.e.m. Significación estadística: *p<0,005 vs. NL, Sh y C; \# p<0,005 vs L y C. 
A
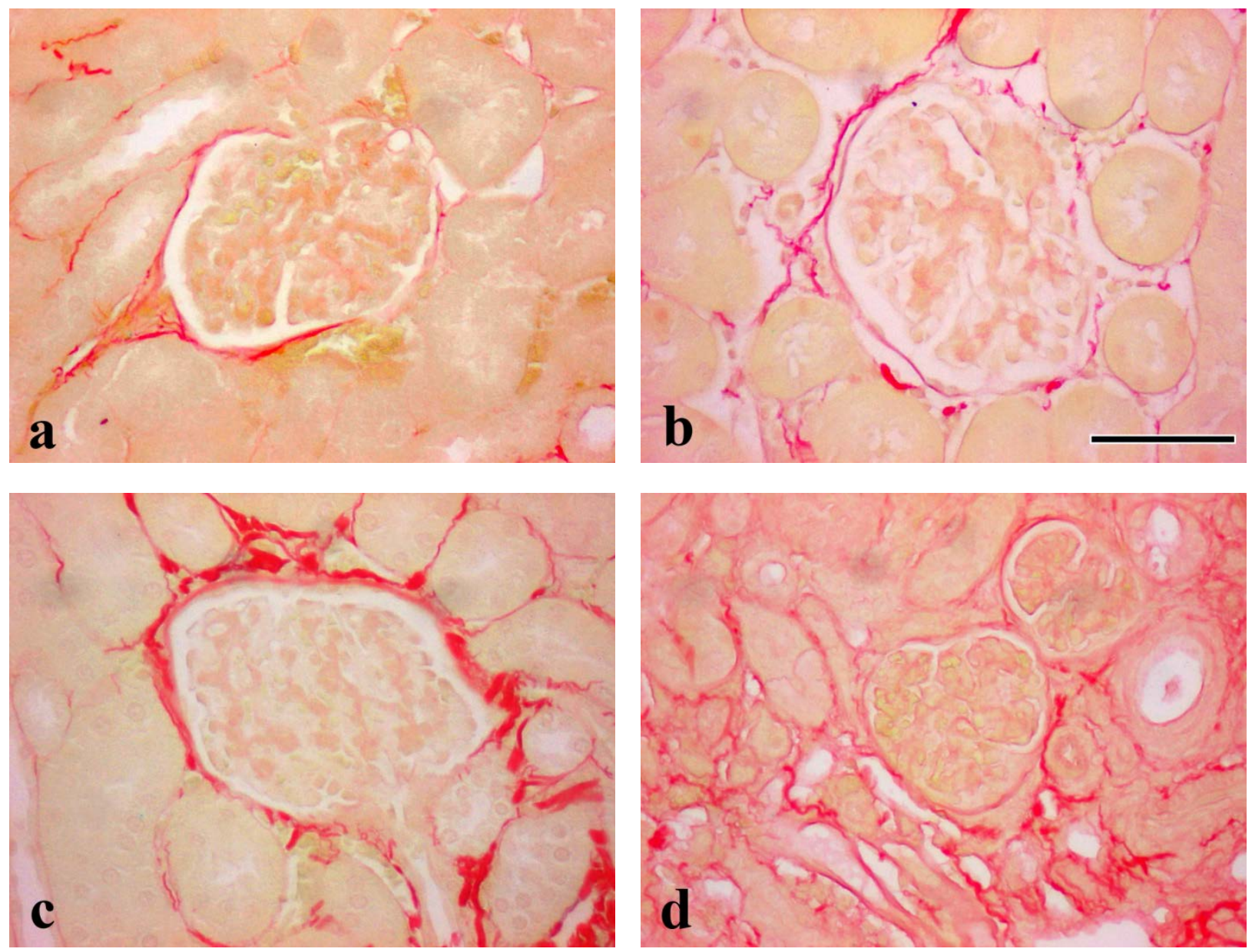

B

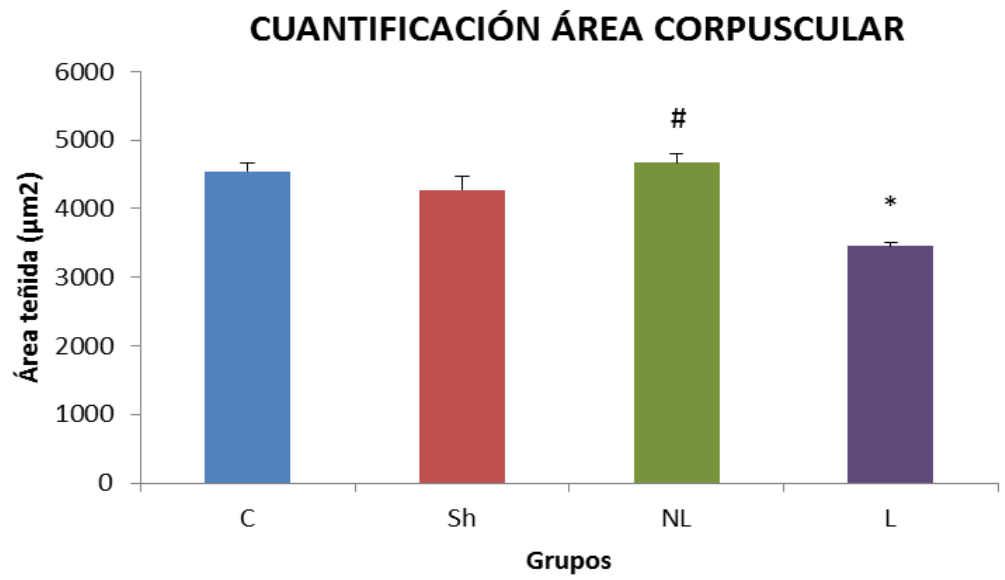

Figura 10: Estudio morfométrico del área corpuscular (A) Micrografías representativas de muestras de corteza renal teñidas con Rojo Sirio procedentes de riñones (a) control, (b) grupo sham, (c) riñón contralateral no ligado y (d) riñón con ligadura de uréter. Barra $=20 \mu \mathrm{m}$. (B) Gráfica representativa del análisis de imagen que muestra el área corpuscular. Los valores representan la media \pm e.e.m. Significación estadística: ${ }^{*} \mathbf{p}<0,005$ vs. NL, Sh y C. ${ }^{\#}$ < $<0,005$ vs. L. 


\section{Mesangio.}

En la Figura 11 se ilustran los resultados de la cuantificación mesangial, donde se apreciaron valores significativamente mayores en el área teñida con rojo sirio en el caso de los riñones $L$ respecto a los otros tres grupos de estudio.

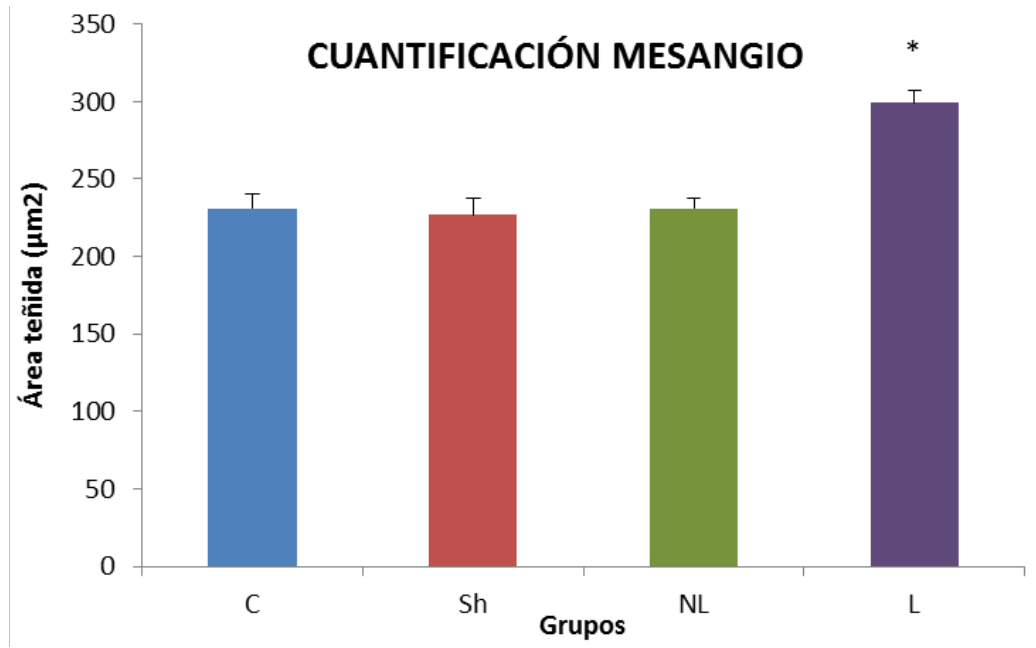

Figura 11: Gráfica representativa del análisis de imagen que muestra la cuantificación mesangial. Los valores representan la media \pm e.e.m. Significación estadística: *p<0,005 vs. L, Nl, Sh y C. 


\section{ESTUDIO INMUNOHISTOQUÍMICO.}

\section{Estudio de las proteínas de matriz extracelular.}

La fibrosis túbulo-intersticial inducida por OUU se caracteriza por aumento de la acumulación de las proteínas de la matriz extracelular en el intersticio renal, por lo que para corroborar los datos obtenidos con el análisis de imagen en preparaciones teñidas con rojo sirio y situar exactamente la localización de proteínas se efectuó un estudio inmunohistoquímico contra Colágeno I y Fibronectina en los corpúsculos renales de los riñones pertenecientes a los grupos de estudio.

\section{Detección de colágeno I.}

Cuando se observaron las preparaciones de inmunohistoquímica contra Colágeno I, se encontró en el intersticio renal una expresión claramente más alta en el caso del riñón L (Figura 12) y en mucha menor medida en el riñón NL, que en los riñones procedentes de los grupos Sh y C. En los corpúsculos se constató igualmente la misma correlación. Como se puede ver en la Figura 13 los ratones con OUU presentaron una expresión significativamente mayor, y de gran intensidad, que el grupo NL donde solo se aprecia una ligera expresión. Los grupos C y Sh prácticamente no mostraron expresión de Colágeno I en el interior de los corpúsculos. 

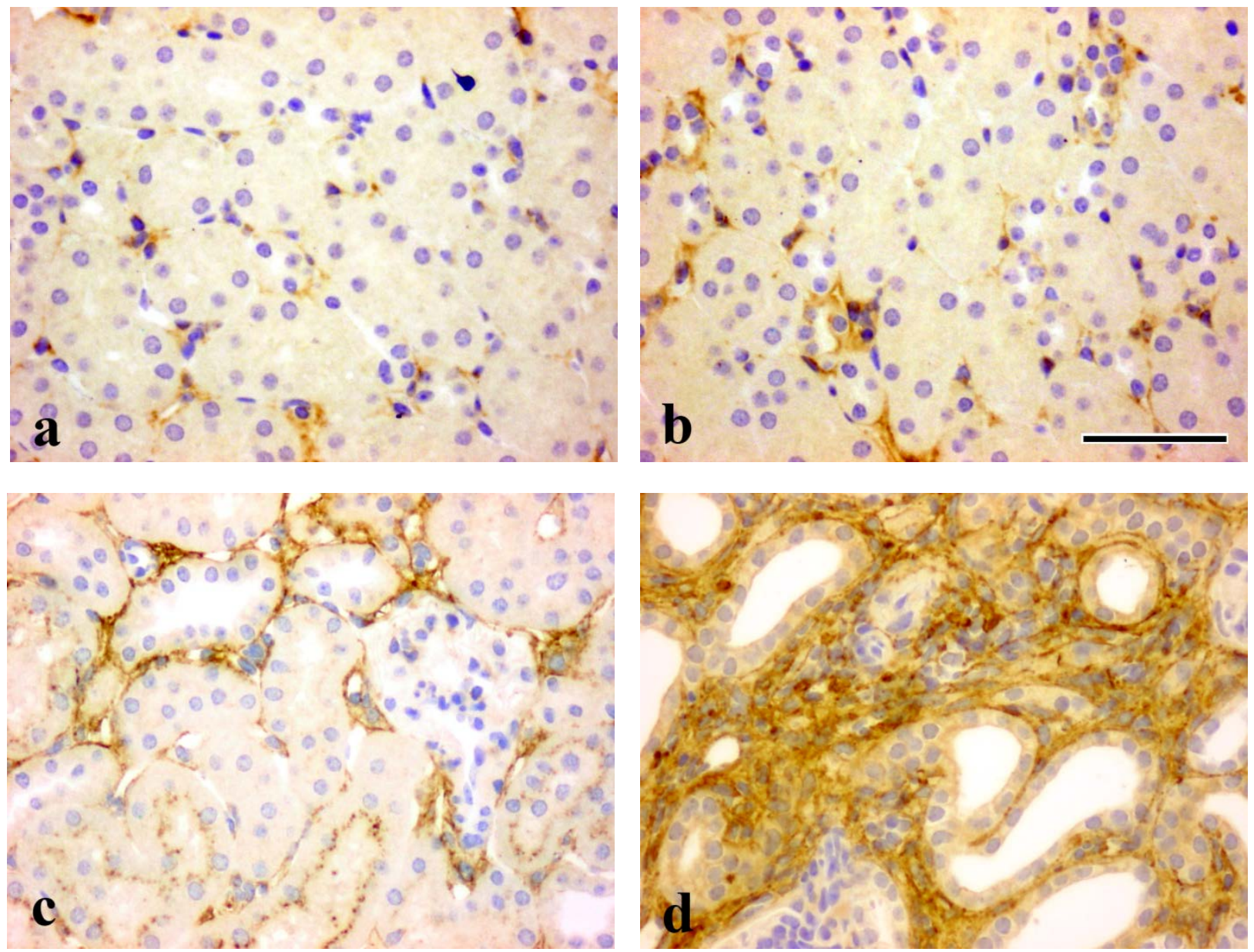

Figura 12: Micrografías que muestran la expresión de colágeno I en intersticio tubular cortical de ratones (a) control, (b) grupo sham, (c) riñón contralateral no ligado y (d) riñón con ligadura de uréter. Barra $=50 \mu \mathrm{m}$. 
A
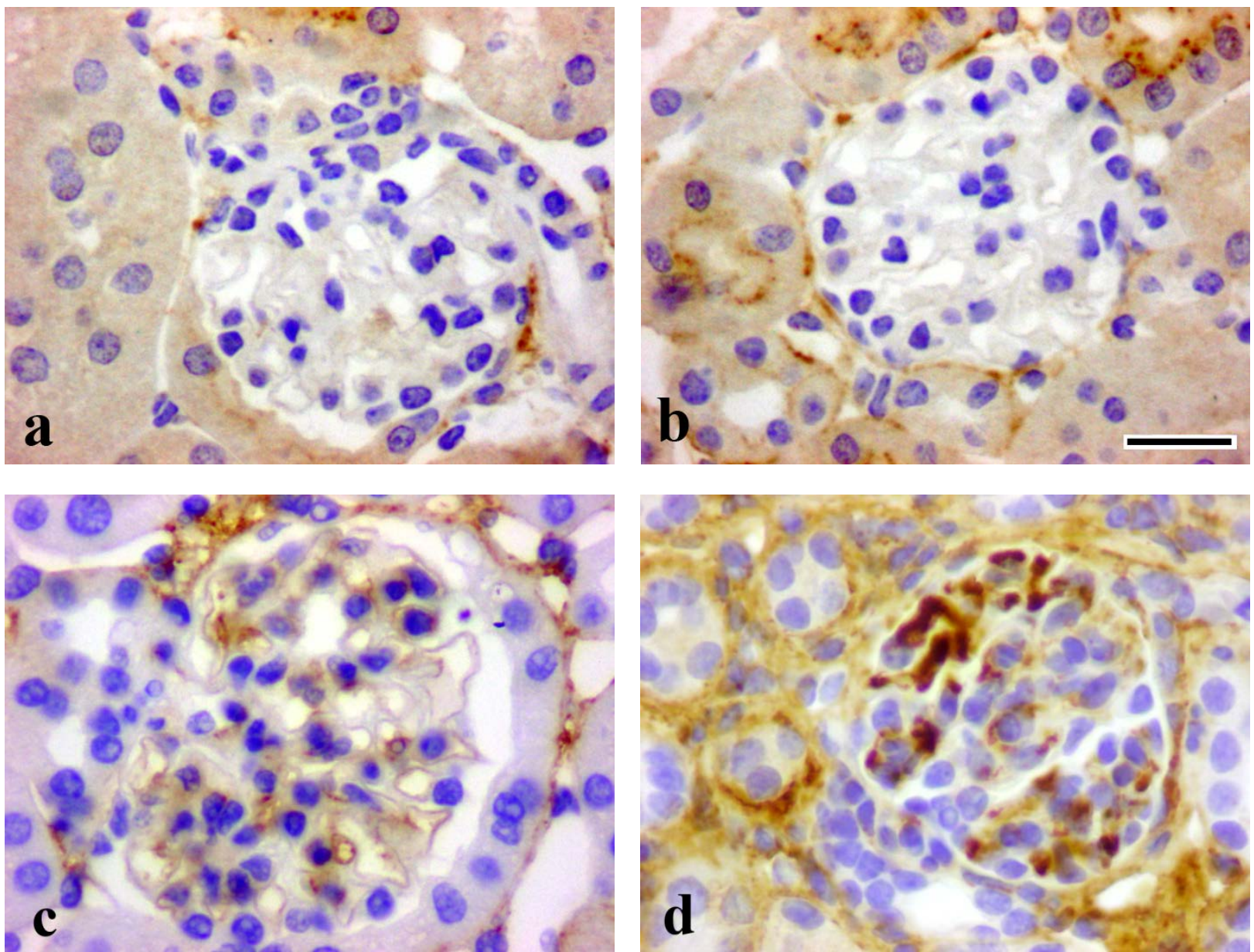

B

\section{CUANTIFICACIÓN COLAGENO I}

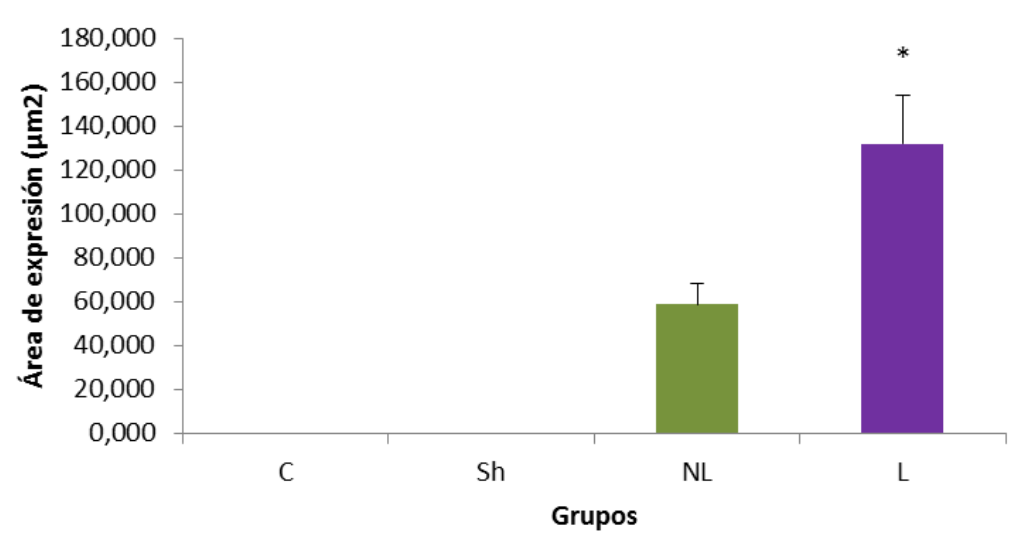

Figura 13: (A) Micrografías que muestran la expresión de colágeno I en corpúsculos de ratones (a) control, (b) grupo sham, (c) riñón contralateral no ligado y (d) riñón con ligadura de uréter. Barra= $20 \mu \mathrm{m}$. (B) Gráfica representativa del análisis de imagen que muestra la cuantificación del colágeno I. Los valores representan la media \pm e.e.m. Significación estadística: *p<0,005 vs. NL. 


\section{Detección de fibronectina.}

Como puede observarse en las imágenes de intersticio renal de la Figura 14, se encontró una expresión de la fibronectina más intensa en el caso del riñón L, disminuyendo su expresión en los otros tres grupos, donde prácticamente se circunscribía a las membranas basales tubulares. Paralelamente, la expresión en los glomérulos también fue mayor y de más intensidad en el caso de los riñones ligados, aunque, por la constitución glomerular también es evidente la expresión de fibronectina en los otros tres grupos de estudio (Figura 15). En la misma figura se representa la cuantificación de fibronectina, en la que se evidenciaron diferencias significativas en el caso de los riñones L respecto a los grupos restantes. Fue notable también la expresión en los animales NL, pero sin que se observaran diferencias significativas respecto a los Sh y C.
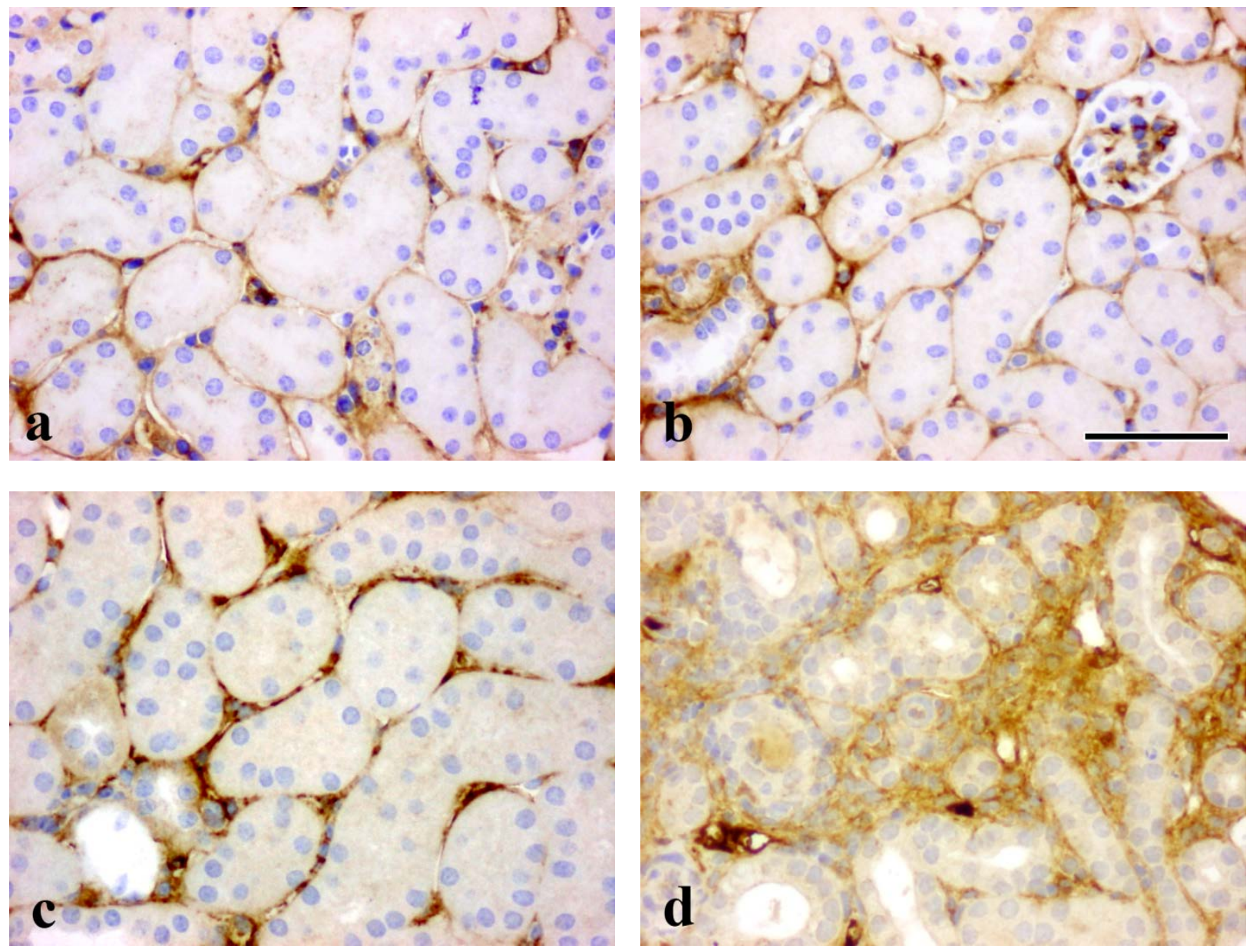

Figura 14: Micrografías que muestran la expresión de fibronectina en intersticio tubular cortical de ratones (a) control, (b) grupo sham, (c) riñón contralateral no ligado y (d) riñón con ligadura de uréter. Barra $=\mathbf{5 0} \boldsymbol{\mu m}$. 
A
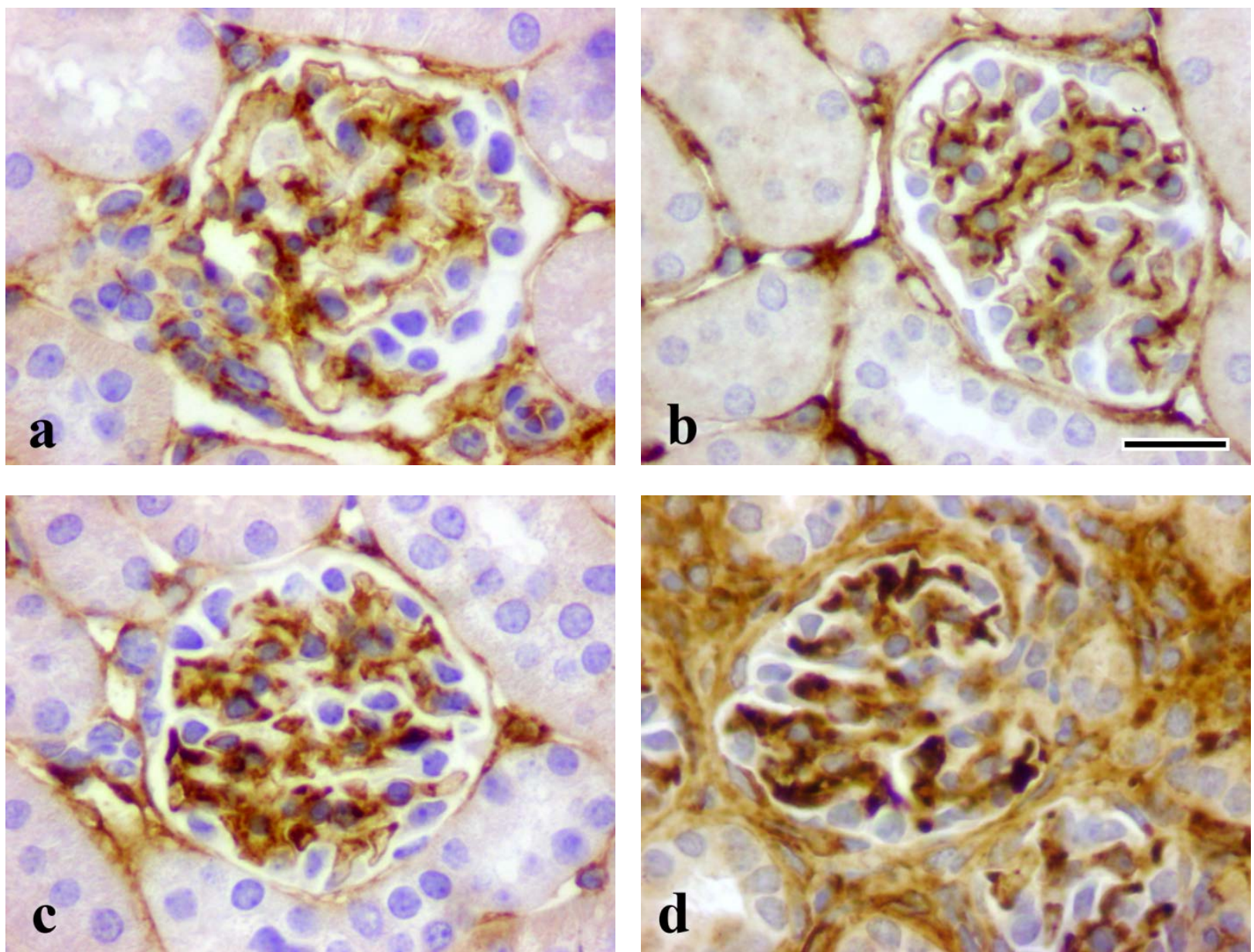

B

\section{CUANTIFICACIÓN FIBRONECTINA}

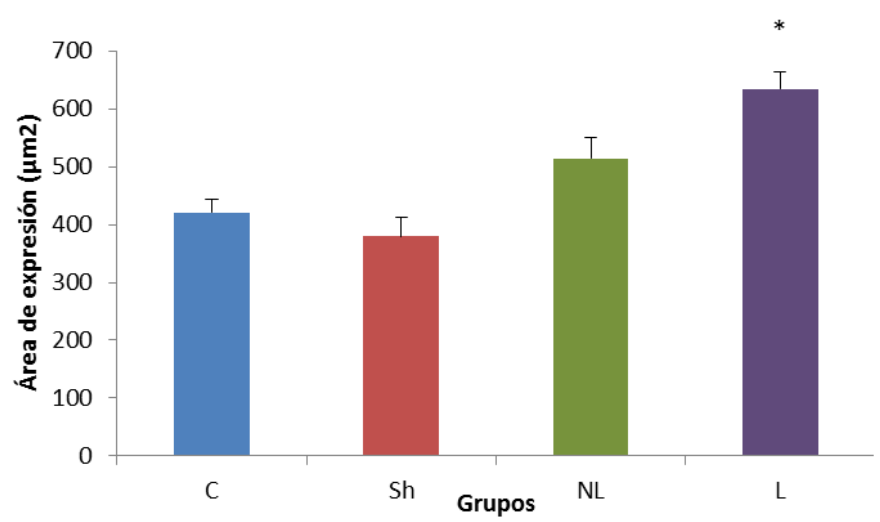

Figura 15: (A) Micrografías que muestran la expresión de fibronectina en corpúsculos de ratones (a) control, (b) grupo sham, (c) riñón contralateral no ligado y (d) riñón con ligadura de uréter. Barra= $20 \mu \mathrm{m}$. (B) Gráfica representativa del análisis de imagen que muestra la cuantificación de la fibronectina. Los valores representan la media \pm e.e.m. Significación estadística: ${ }^{*} \mathbf{p}<0,005$ vs. NL, Sh y C. 


\section{Estudio de la vía de señalización TGF- $\beta$ /pSmad2_3.}

Para analizar la contribución de la vía de señalización TGF- $\beta /$ Smad en las posibles alteraciones renales tras la OUU, se efectuó un estudio de la fosforilación de Smad 2/3.

Como puede verse en la Figura 16, el intersticio renal mostró al microscopio una expresión de pSmad2/3 más alta en los riñones L, seguida por los NL, y descendiendo ésta en los grupos Sh y C. En el caso de los corpúsculos (Figura 17), en las preparaciones se observó una expresión mayor en el grupo de los riñones L frente a los otros tres grupos, NL, Sh y C. La gráfica de la cuantificación correspondiente corrobora dichas diferencias en las que los ratones L presentaron una expresión de núcleos marcados en relación con el número de núcleos totales, significativamente mayor que los grupos NL, C y Sh que no evidenciaron diferencias significativas entre ellos.
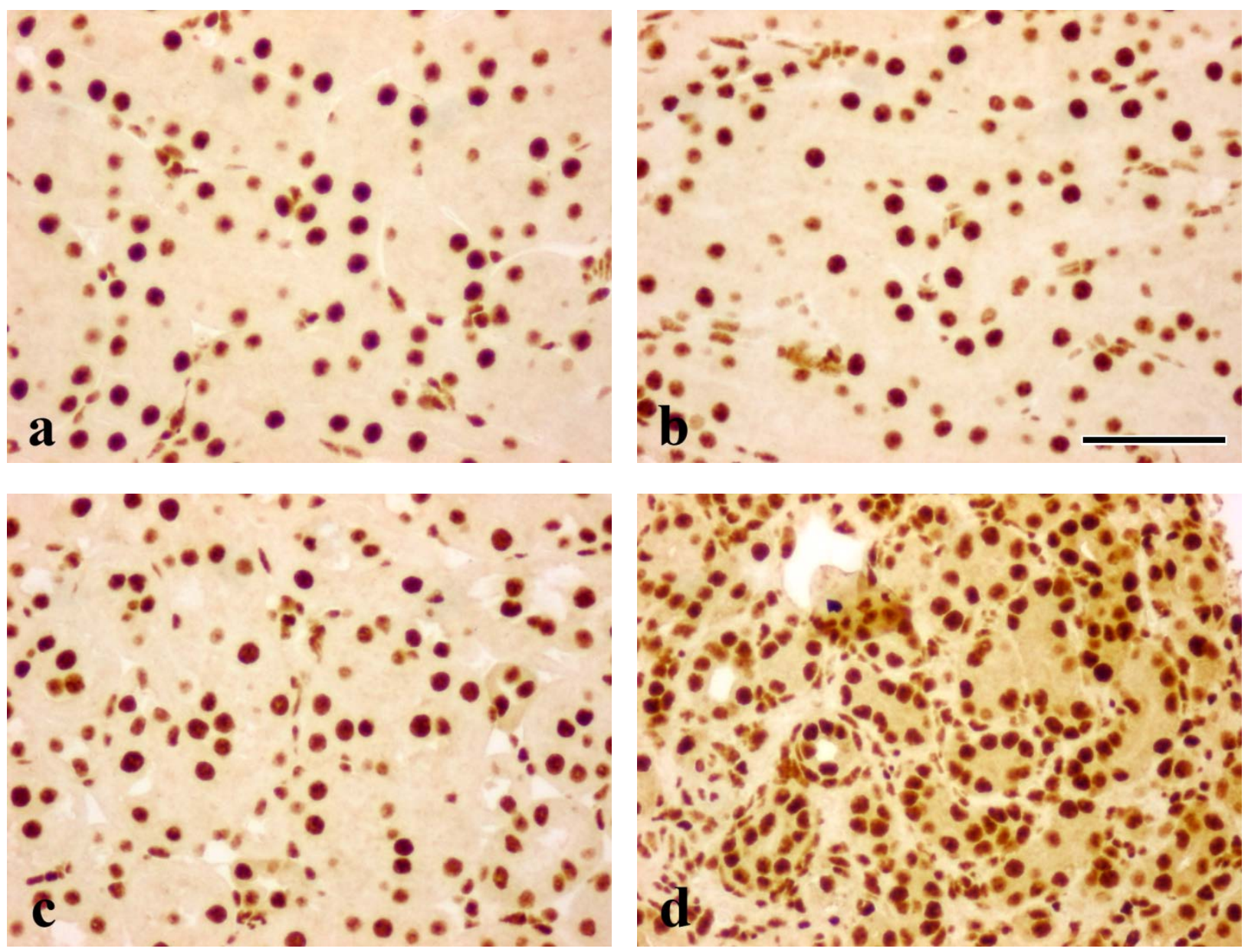

Figura 16: (A) Micrografías que muestran la expresión de pSmad 2_3 en intersticio tubular cortical de ratones (a) control, (b) grupo sham, (c) riñón contralateral no ligado y (d) riñón con ligadura de uréter. Barra $=\mathbf{5 0} \mu \mathrm{m}$. 
A
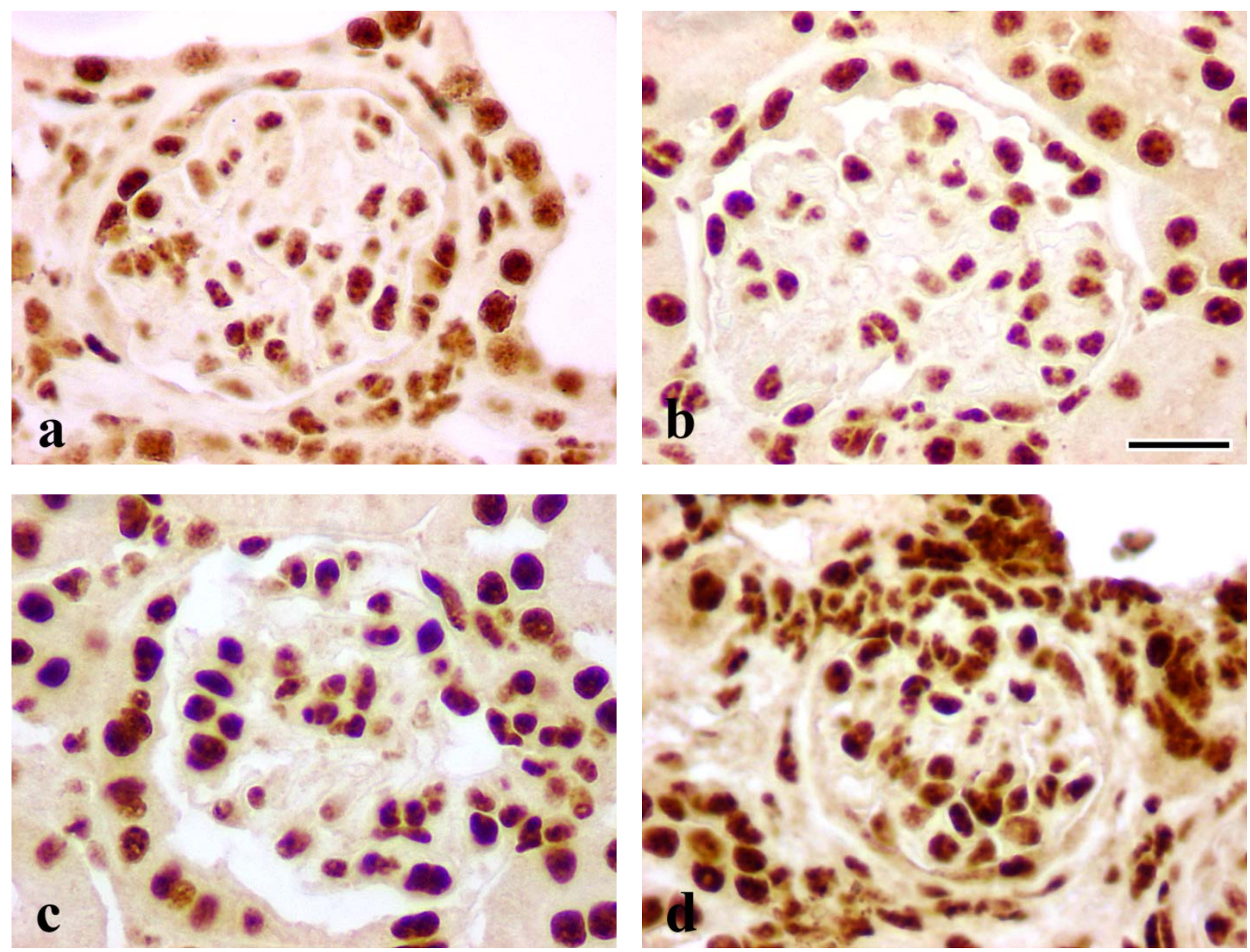

B

CUANTIFICACIÓN pSmad 2/3

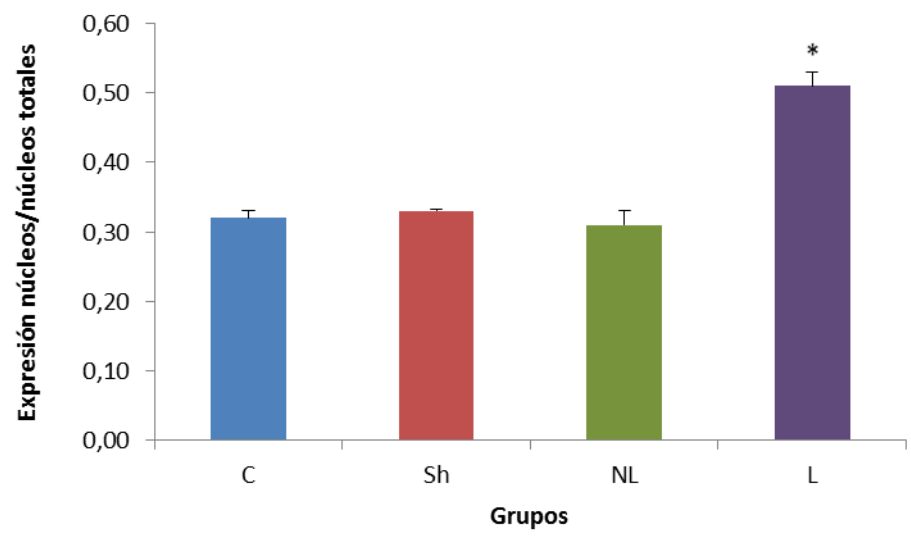

Figura 17: (A) Micrografías que muestran la expresión de pSmad 2_3 en corpúsculos de ratones (a) control, (b) grupo sham, (c) riñón contralateral no ligado y (d) riñón con ligadura de uréter. Barra= $20 \mu \mathrm{m}$. (B) Gráfica representativa del análisis de imagen que muestra la cuantificación de la pSmad 2_3. Los valores representan la media \pm e.e.m. Significación estadística: *p<0,005 vs. NL, Sh y C. 


\section{Detección de $\alpha$-actina.}

Para analizar la posible activación de células implicadas en el aumento de matriz extracelular se realizó un estudio inmunohistoquímico de la expresión de novo de alfa actina del músculo liso ( $\alpha$-SMA). En el intersticio renal se encontró una expresión de $\alpha$-actina más alta en el caso del riñón L, seguido en orden por los NL, siendo menor en los grupos Sh y C (Figura 18). En los corpúsculos se observó una expresión claramente mayor en los correspondientes a animales L y NL, estando prácticamente ausente la actina en los de los animales Sh y C (Figura 19). Como se puede ver en la gráfica de cuantificación de la misma figura, la expresión fue significativamente mayor en los L con respecto a los NL, estando prácticamente ausente en los grupos Sh y C.
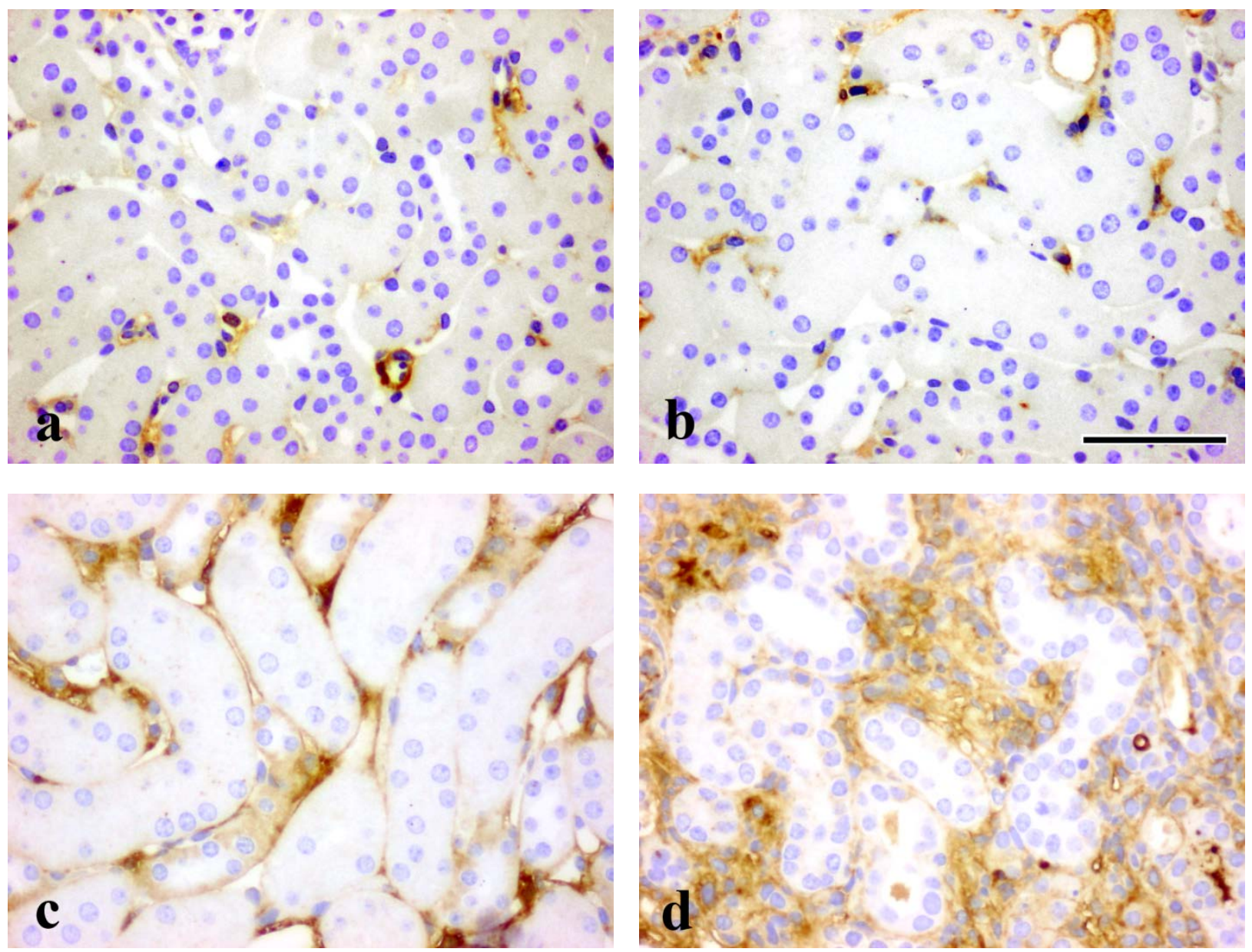

Figura 18: (A) Micrografías que muestran la expresión de $\alpha$-actina de músculo liso vascular en intersticio tubular cortical de ratones (a) control, (b) grupo sham, (c) riñón contralateral no ligado y (d) riñón con ligadura de uréter. Barra $=100 \mu \mathrm{m}$. 
A
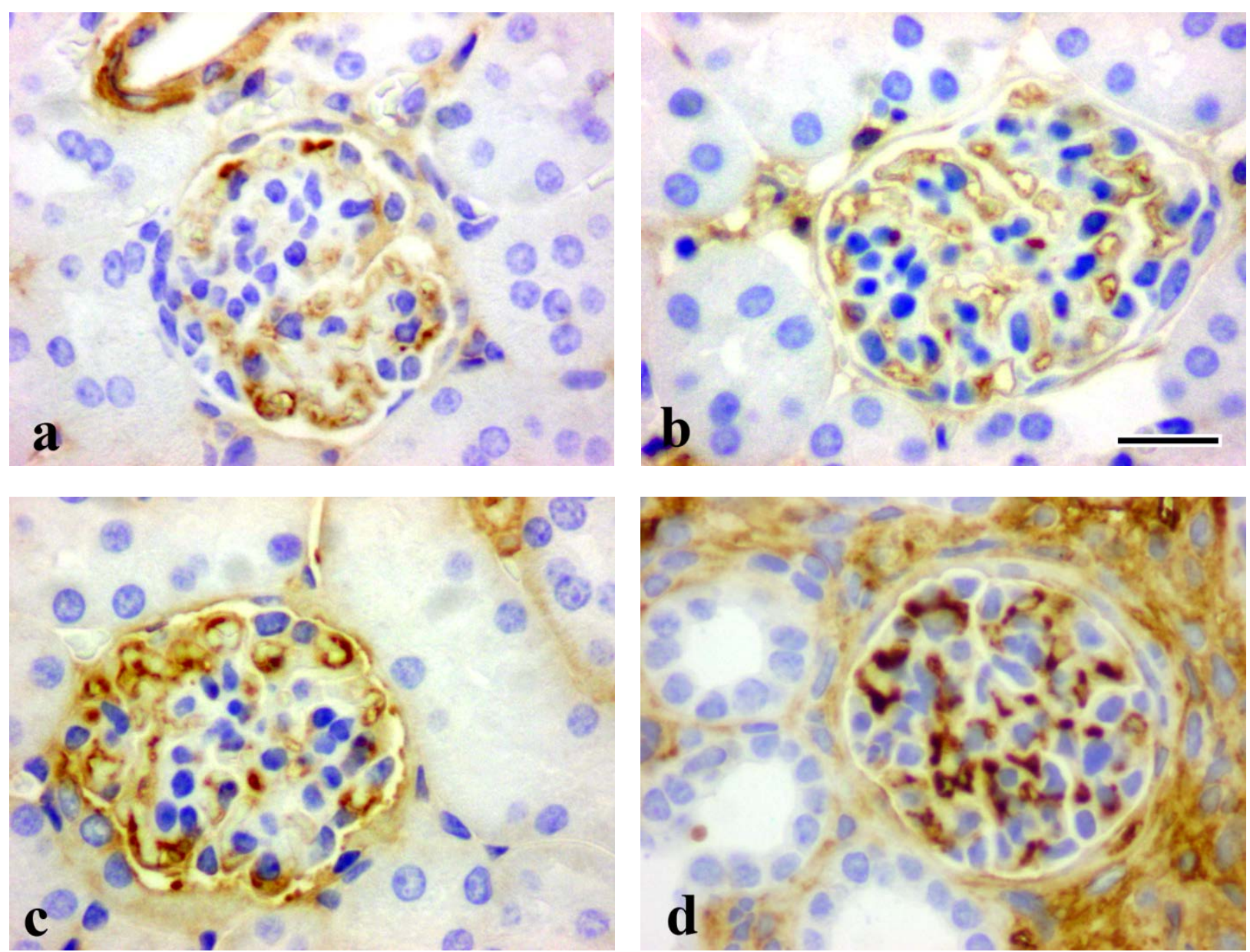

B

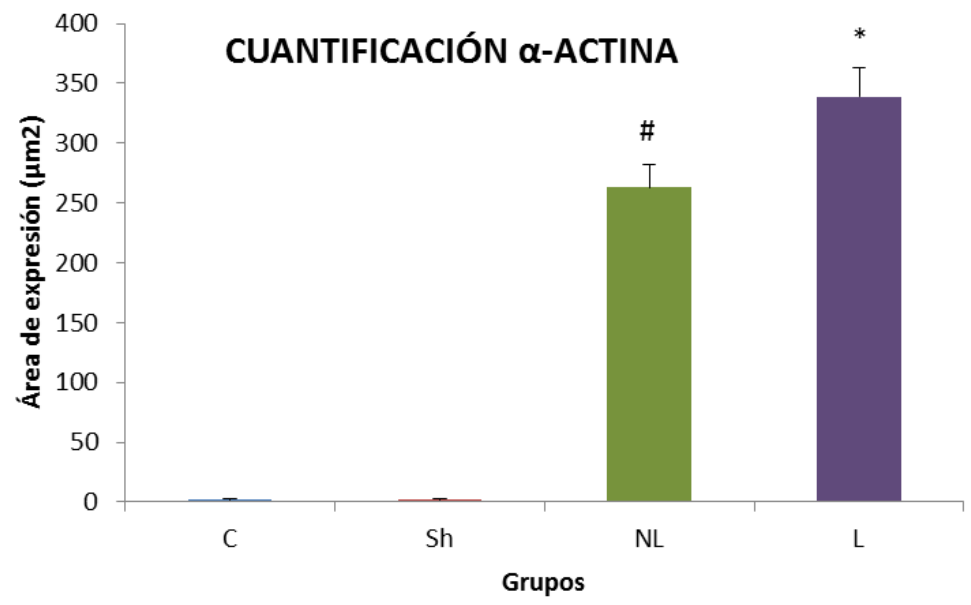

Figura 19: (A) Micrografías que muestran la expresión de $\alpha$-actina de músculo liso vascular en corpúsculos de ratones (a) control, (b) grupo sham, (c) riñón contralateral no ligado y (d) riñón con ligadura de uréter. Barra $=20 \mu \mathrm{m}$. (B) Gráfica representativa del análisis de imagen que muestra la cuantificación de la $\alpha$-actina. Los valores representan la media \pm e.e.m. Significación estadística: ${ }^{*} \mathbf{p}<0,005$ vs. NL, Sh y C; ${ }^{\# p<0,005 ~ v s . ~ L, ~ S h ~ y ~ C . ~}$ 


\section{Estudio de la proliferación celular: detección de Ki67.}

Con objeto de estudiar la posible proliferación celular que se produjese en este proceso de nefropatía obstructiva se efectuó un estudio inmunohistoquímico del antígeno de proliferación Ki67, usando para ello el anticuerpo monoclonal Mib-1.

Al observar al microscopio las preparaciones se apreció en el intersticio renal una expresión más alta de Mib1 en el caso del riñón L, seguido en orden por los NL, siendo menor en los grupos Sh y C (Figura 20). En el caso de los glomérulos, la estimación obtenida fue que la proliferación aumentaba en el caso de los L respecto a los otros tres grupos. Al realizar la cuantificación de los núcleos positivos, se constató lo anteriormente dicho, como se puede ver en la gráfica de la Figura 21, los animales sometidos a OUU presentaron una proliferación significativamente mayor, aproximadamente del doble, que los grupos NL, Sh y C, no existiendo diferencias significativas entre estos tres últimos grupos 

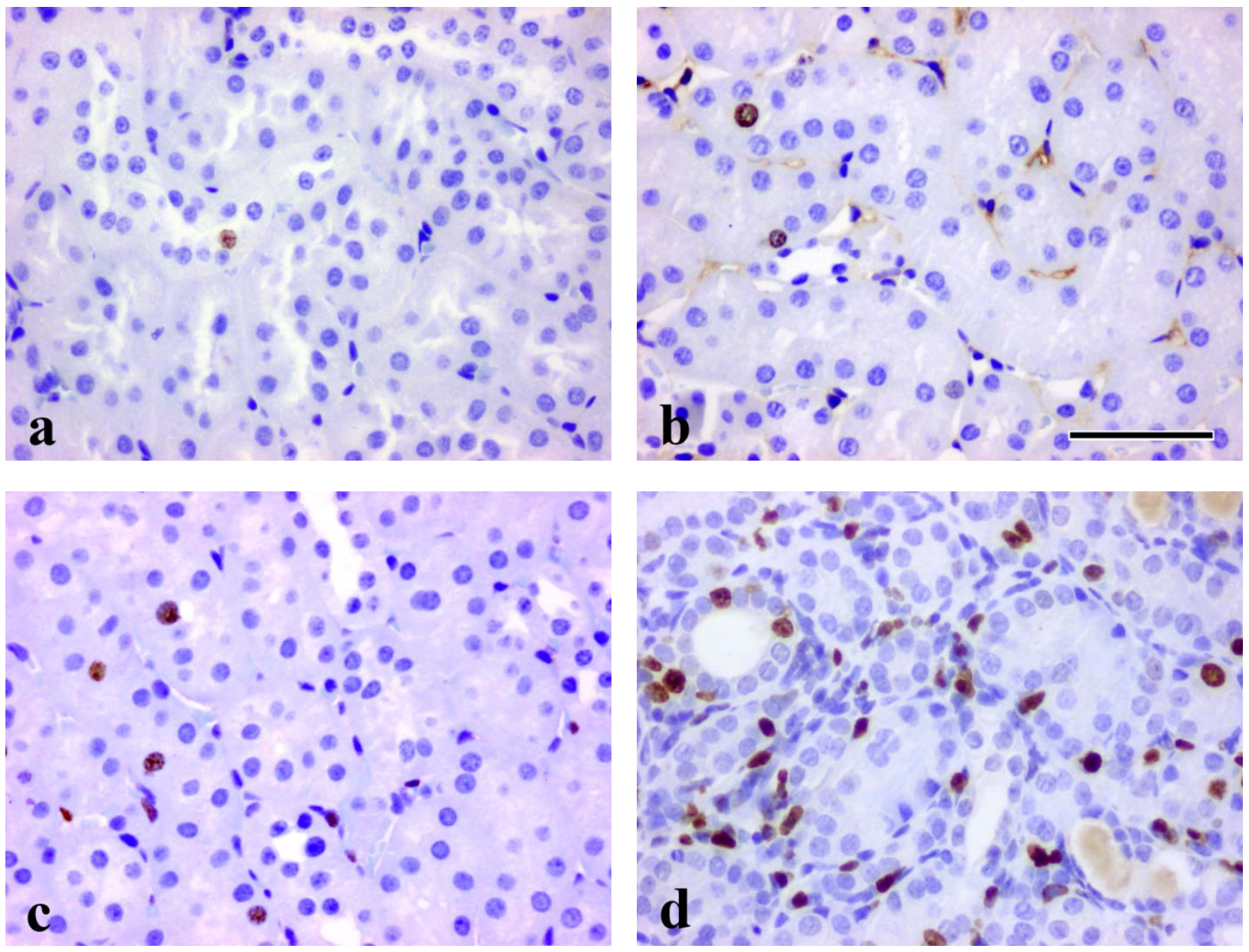

Figura 20: Micrografías que muestran la expresión de Mib1 en intersticio tubular cortical de ratones (a) control, (b) grupo sham, (c) riñón contralateral no ligado y (d) riñón con ligadura de uréter. Barra $=50 \mu \mathrm{m}$. 
A
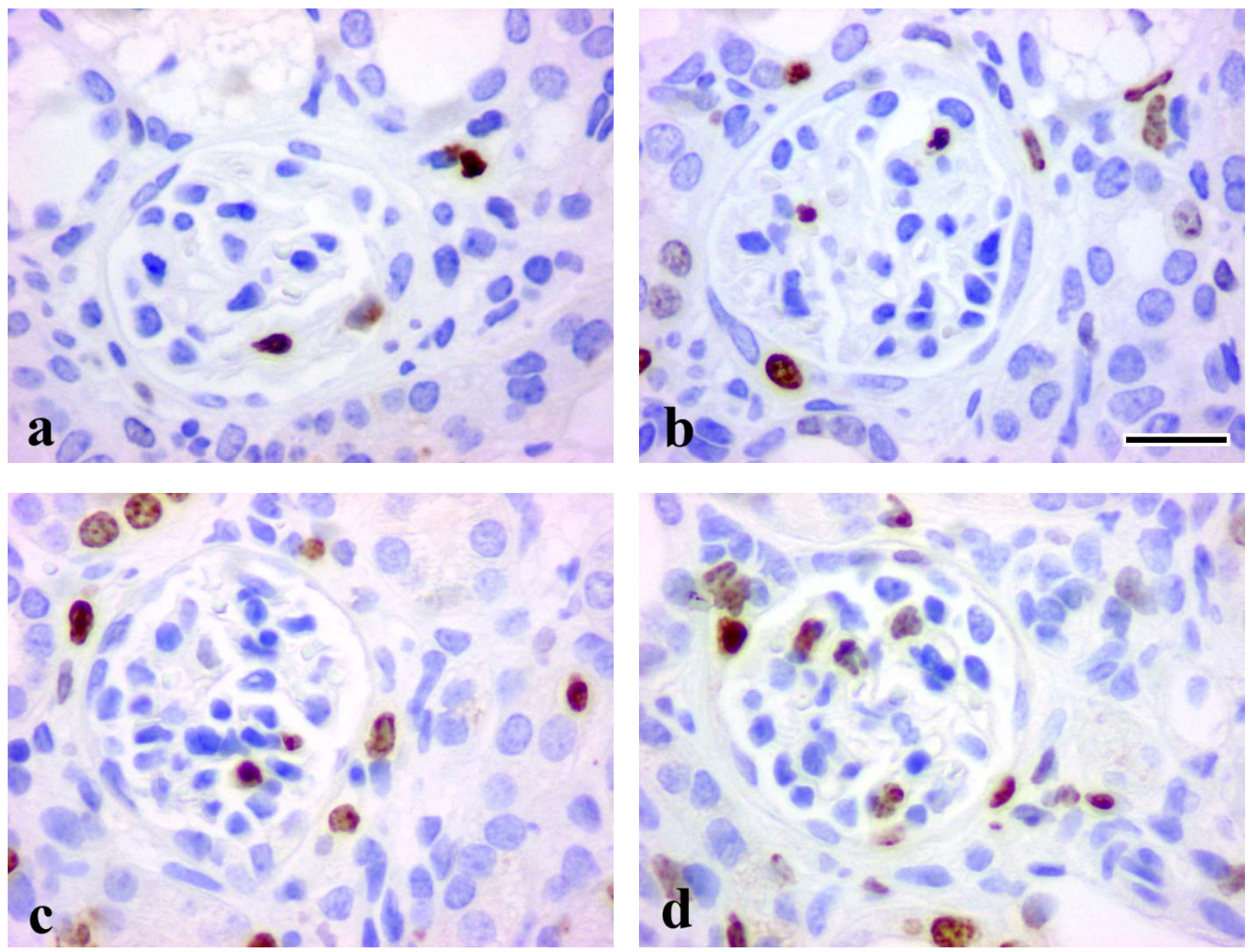

B

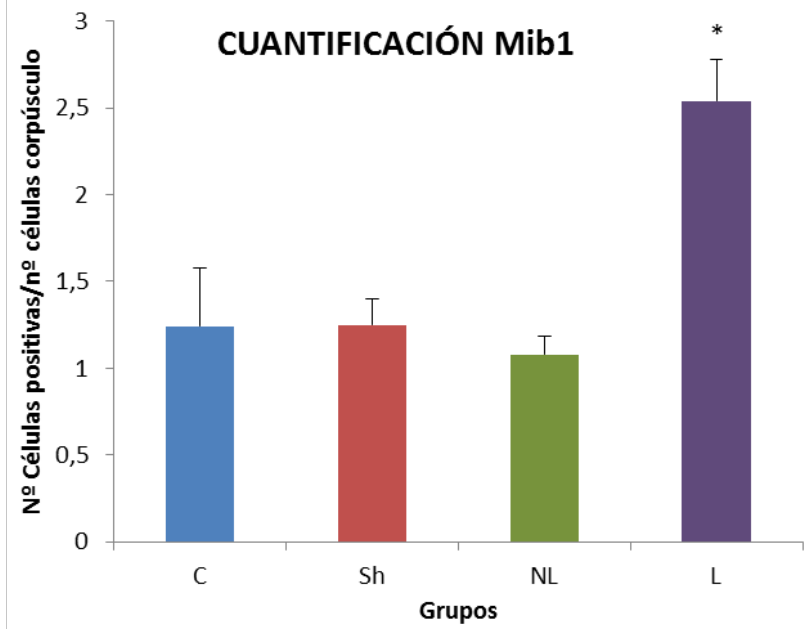

Figura 21: (A) Micrografías que muestran la expresión de Mib1 en corpúsculos de ratones (a) control, (b) grupo sham, (c) riñón contralateral no ligado y (d) riñón con ligadura de uréter. Barra= $20 \mu \mathrm{m}$. (B) Gráfica representativa del análisis de imagen que muestra la cuantificación de Mib1. Los valores representan la media \pm e.e.m. Significación estadística: *p<0,005 vs. NL, Sh y C. 


\section{Estudio de la apoptosis.}

La progresión del daño renal está asociada con la eliminación progresiva de las células renales junto con la fibrosis del riñón. Para la comprobación de la posible apoptosis se utilizó como referencia la expresión inmunohistoquímica de Caspasa 3 activada.

En el intersticio renal se apreció una expresión de Caspasa 3 activada que parecía más alta en el caso del riñón L respecto a los otros tres grupos NL, Sh y C (Figura 22). En el caso de los glomérulos, el estudio al microscopio de las preparaciones indicaba la misma tendencia (Figura 23). El posterior análisis cuantitativo demostró que los ratones L, presentan una expresión significativamente mayor que los grupos NL, Sh y C. (Gráfica Figura 23).
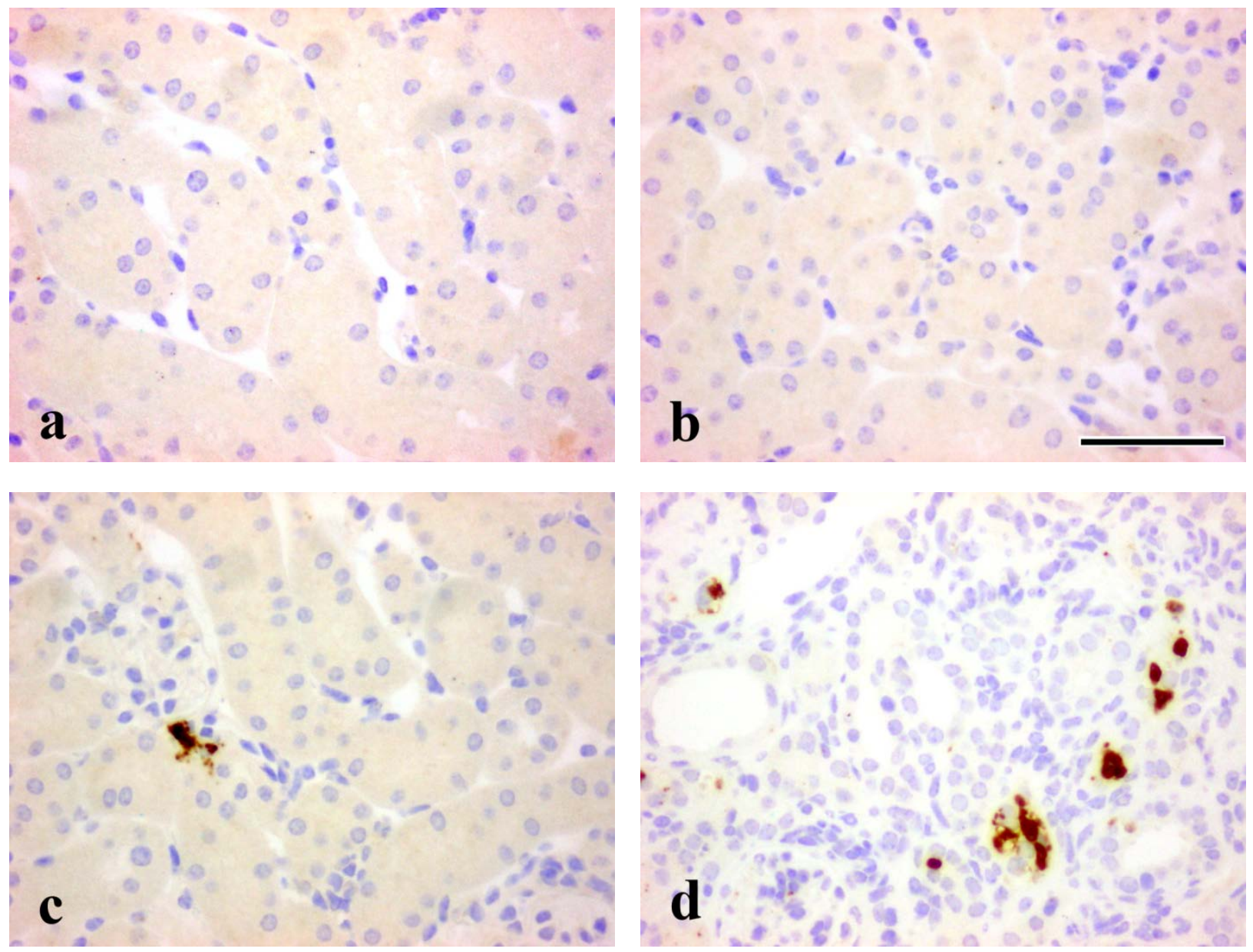

Figura 22: Micrografías que muestran la expresión de caspasa 3 activada en intersticio tubular cortical de ratones (a) control, (b) grupo sham, (c) riñón contralateral no ligado y (d) riñón con ligadura de uréter. Barra $=\mathbf{5 0} \boldsymbol{\mu m}$. 
A
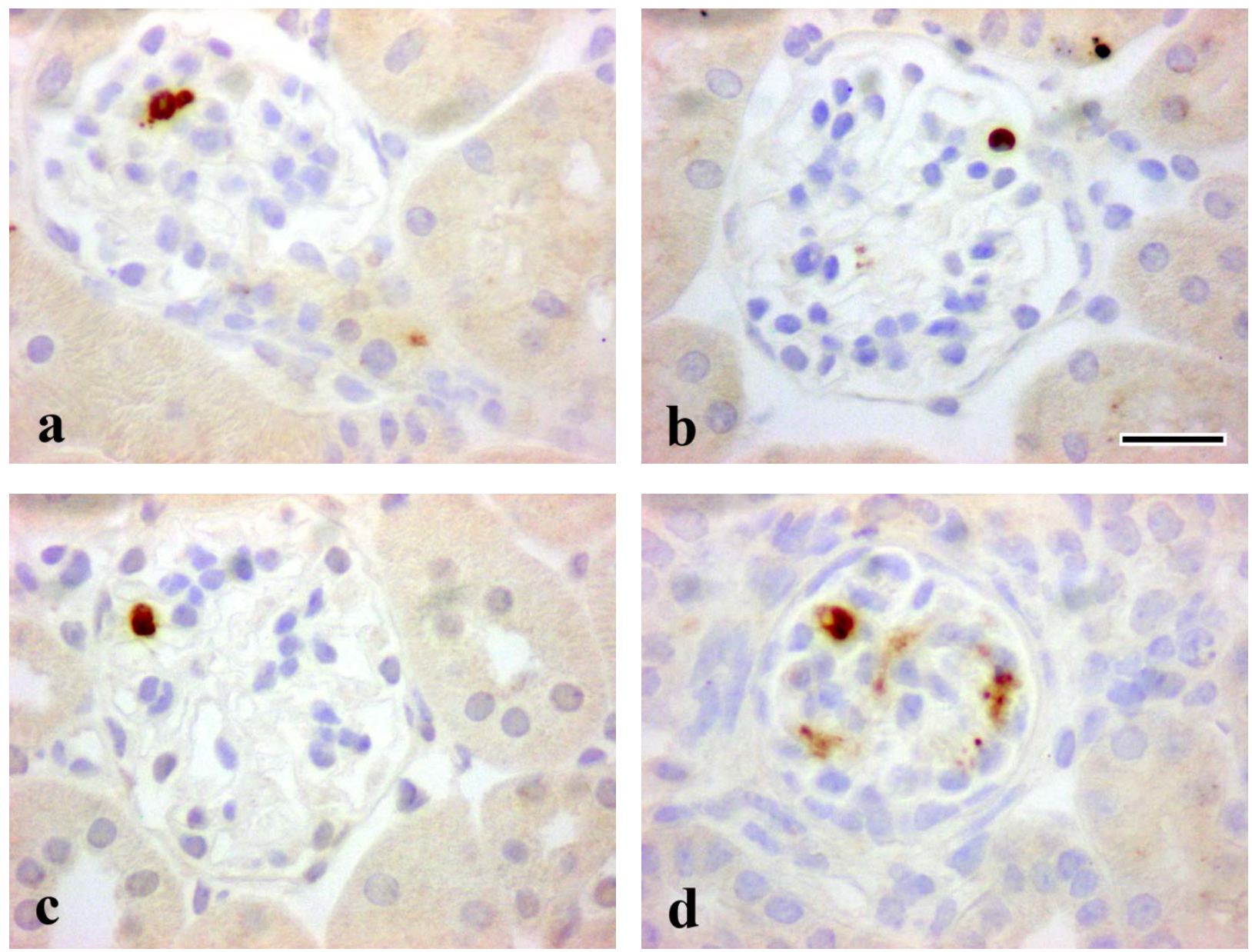

B

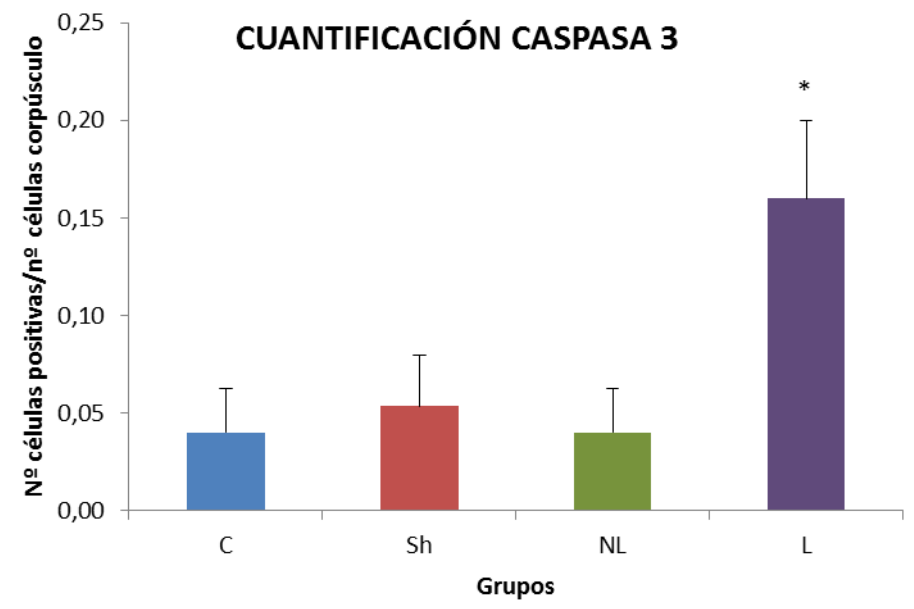

Figura 23: (A) Micrografías que muestran la expresión de caspasa 3 activada en corpúsculos renales de ratones (a) control, (b) grupo sham, (c) riñón contralateral no ligado y (d) riñón con ligadura de uréter. Barra $=20 \mu \mathrm{m}$. (B) Gráfica representativa del análisis de imagen que muestra la cuantificación de la caspasa 3 activada. Los valores representan la media \pm e.e.m. Significación estadística: ${ }^{*} \mathbf{p}<0,005$ vs. NL y C. 


\section{Estudio de podocitos.}

Para analizar la posible pérdida de podocitos se realizó un estudio cuantitativo mediante inmunomarcaje con el anticuerpo contra células de tumor de Willms (WT-1), comúnmente utilizado para estos propósitos. Para la evaluación se cuantificó el número de células que mantenían expresión nuclear de WT-1 en cada glomérulo. El análisis cuantitativo de células con núcleo positivo en relación al número total de células por glomérulo mostró una reducción significativa en los grupos L y NL en comparación con las ratas control y sham, como puede verse en la gráfica de Figura 24. No se constataron diferencias significativas entre L y NL ni entre Sh y C. 
A
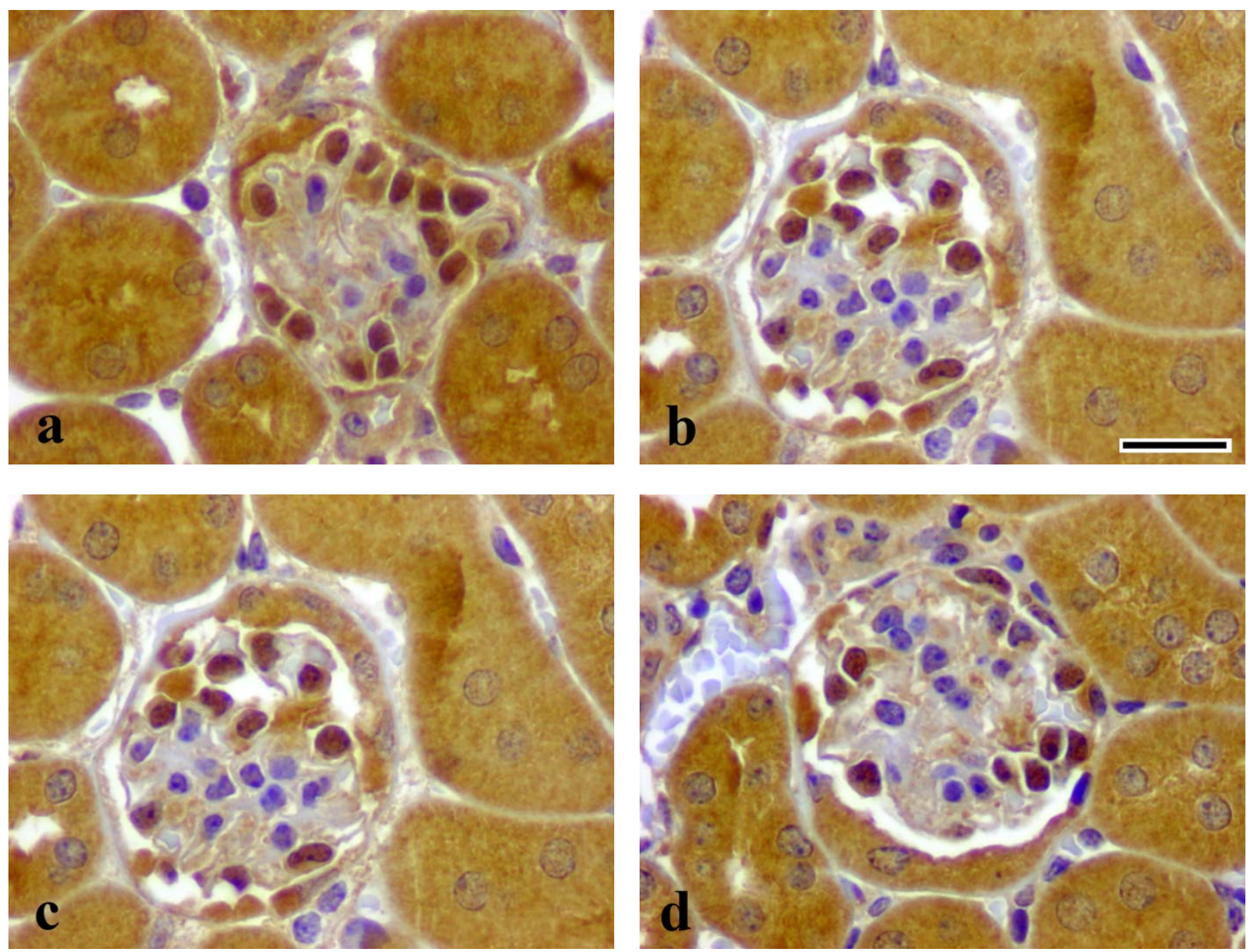

B

\section{CUANTIFICACIÓN WT-1}

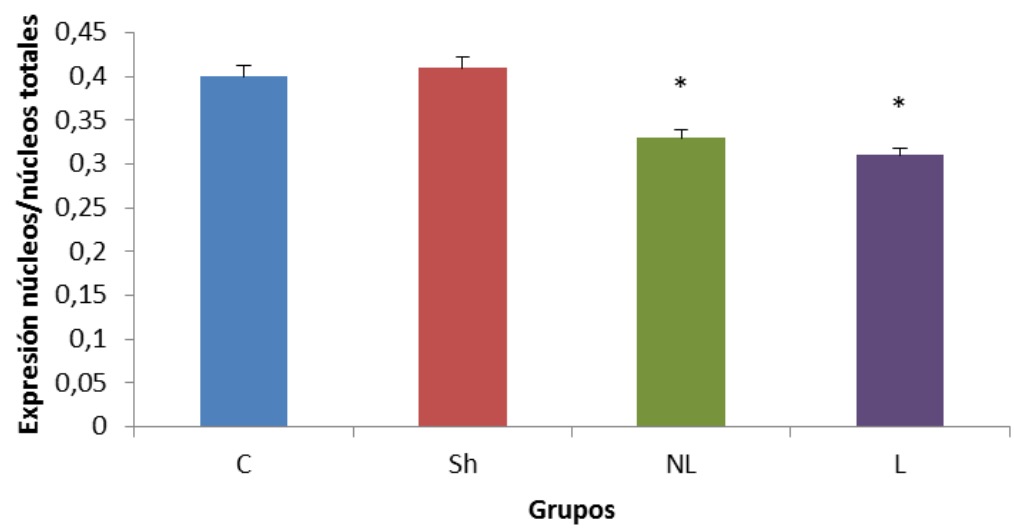

Figura 24: (A) Micrografías que muestran la expresión de WT-1 en corpúsculos renales de ratones (a) control, (b) grupo sham, (c) riñón contralateral no ligado y (d) riñón con ligadura de uréter. Barra $=20 \mu \mathrm{m}$. (B) Gráfica representativa del análisis de imagen que muestra la cuantificación de WT1. Los valores representan la media \pm e.e.m. Significación estadística: ${ }^{*} p<0,005$ vs. Sh y $C$. 


\section{ESTUDIOS CON MICROSCOPÍA ELECTRÓNICA DE TRANSMISIÓN.}

Al observar las rejillas de los bloques correspondientes a los grupos de estudio, no se apreciaron alteraciones ultraestructurales destacables, salvo un aparente incremento de matriz mesangial o el colapso de algunas luces capilares en el grupo de animales sometidos a la ligadura, circunstancia que no se observó en el resto de grupos NL, Sh y C. No se observaron alteraciones nucleares o citoplasmáticas en ninguno de los grupos.

De esta manera, al microscopio, las membranas basales glomerulares no ofrecían signos de engrosamiento anormal ni depósitos electrodensos en los grupos de estudio. Tampoco se encontraron lesiones generales que implicaran pérdida o fusión de los pedicelos de los podocitos que parecían estar bien conservados. Las asas capilares conservaban su arquitectura normal, con las fenestraciones conservadas y las células y matriz mesangiales no presentaban signos de anormalidad. No se observó la presencia de ningún tipo de material extraño o celular en los espacios urinarios, y en el epitelio parietal de la cápsula de Bowman solo fue posible observar, fundamentalmente en los animales L, pero también en algunos corpúsculos de NL, la tubularización de dicho epitelio (Figura 25).

Con el fin de analizar posibles alteraciones en el grosor de la MBG o de los pedicelos que escapasen a la observación directa al microscopio, se efectuó un estudio cuantitativo de estos parámetros. Los resultados de la cuantificación no mostraron diferencias significativas entre los distintos grupos de estudio, como queda reflejado en la gráfica de cuantificación de la Figura 27. 

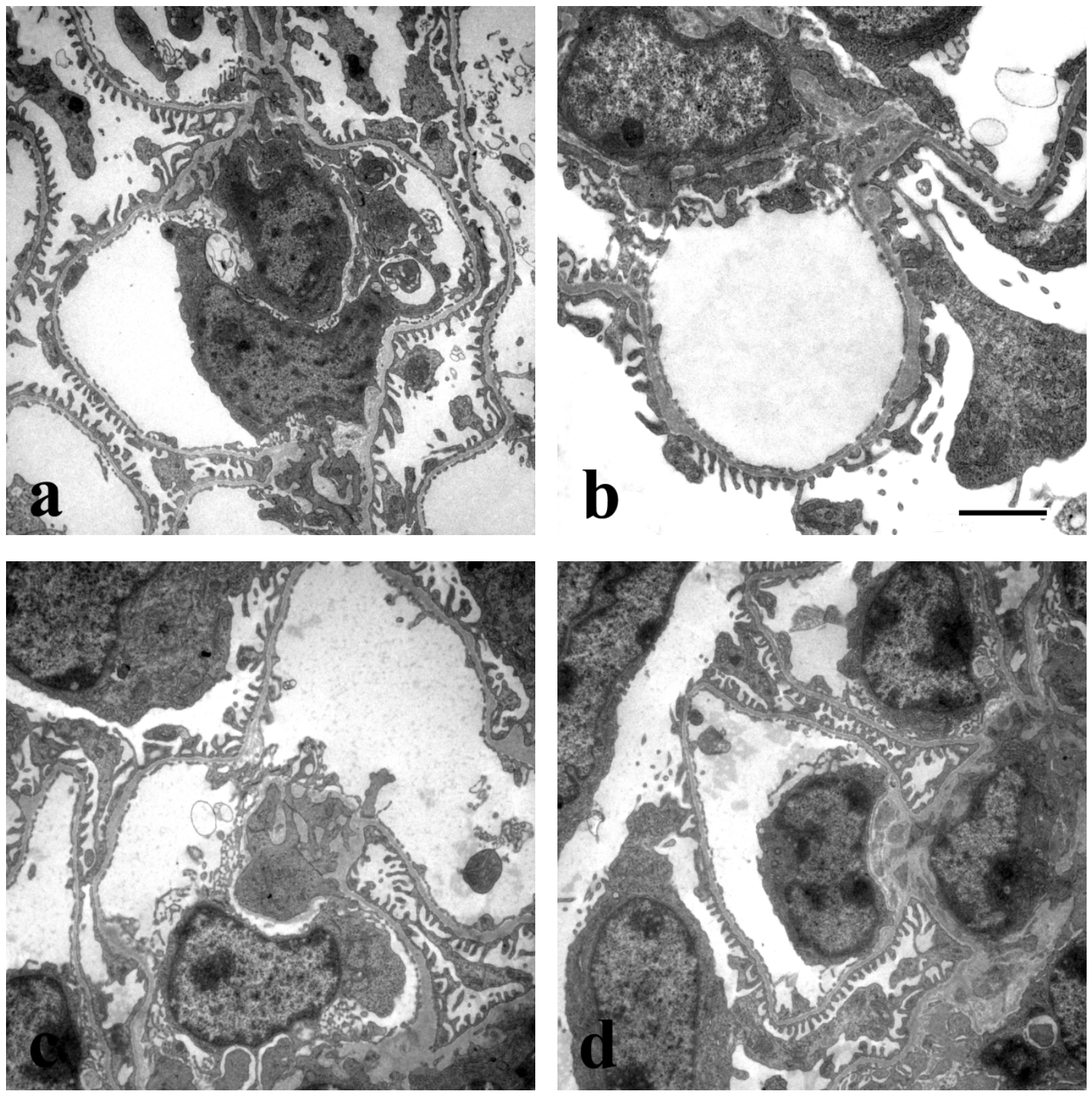

Figura 25: Microfotografías tomadas mediante microscopía electrónica de transmisión en corpúsculos renales de ratones (a) control, (b) grupo sham, (c) riñón contralateral no ligado y (d) riñón con ligadura de uréter. Barra $=2500 \mathrm{~nm}$. 
A
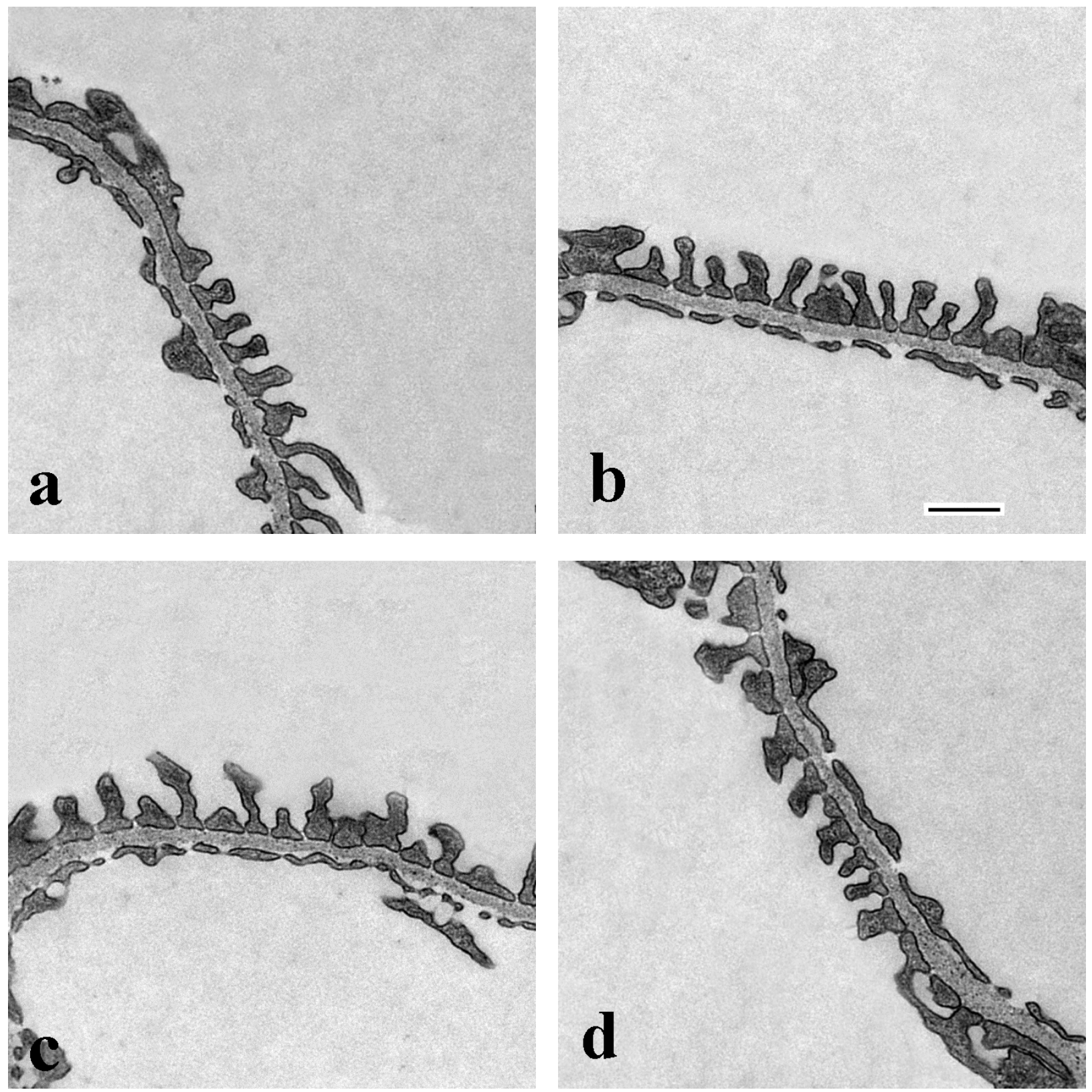

Figura 26: Ultramicrofotografías tomadas mediante microscopía electrónica de transmisión en corpúsculos renales de ratones (a) control, (b) grupo sham, (c) riñón contralateral no ligado y (d) riñón con ligadura de uréter. Barra $=500 \mathrm{~nm}$ 
A

\section{CUANTIFICACIÓN DEL GROSOR DE LA \\ MEMBRANA BASAL}

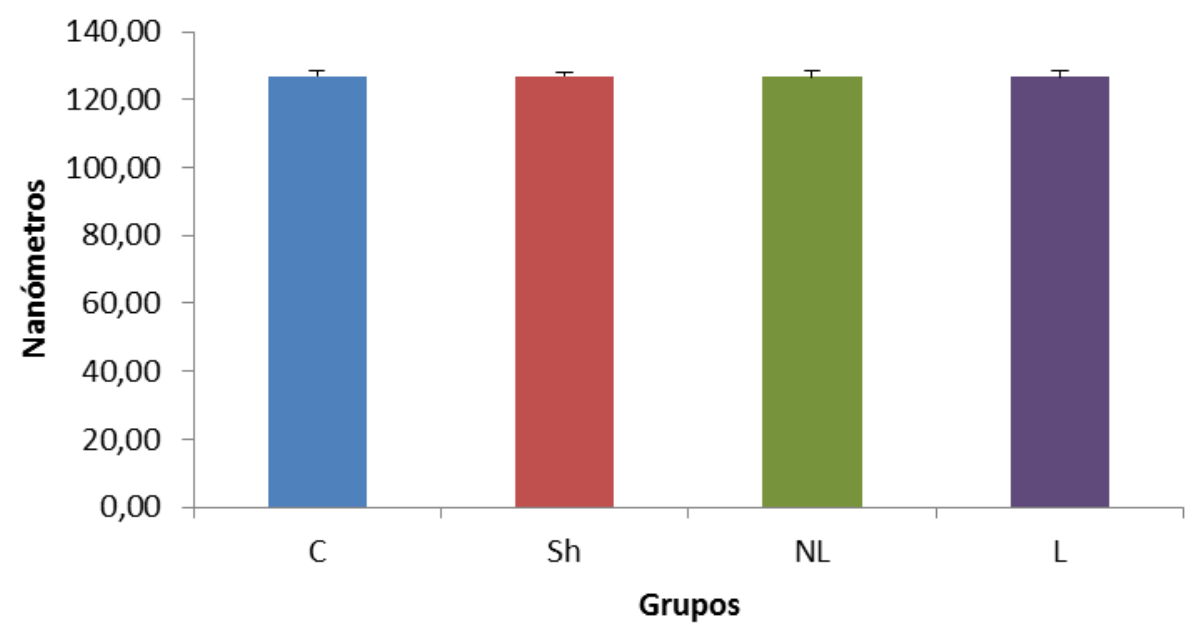

B

\section{CUANTIFICACIÓN DE LA ANCHURA DE LA BASE DE LOS PEDICELOS}

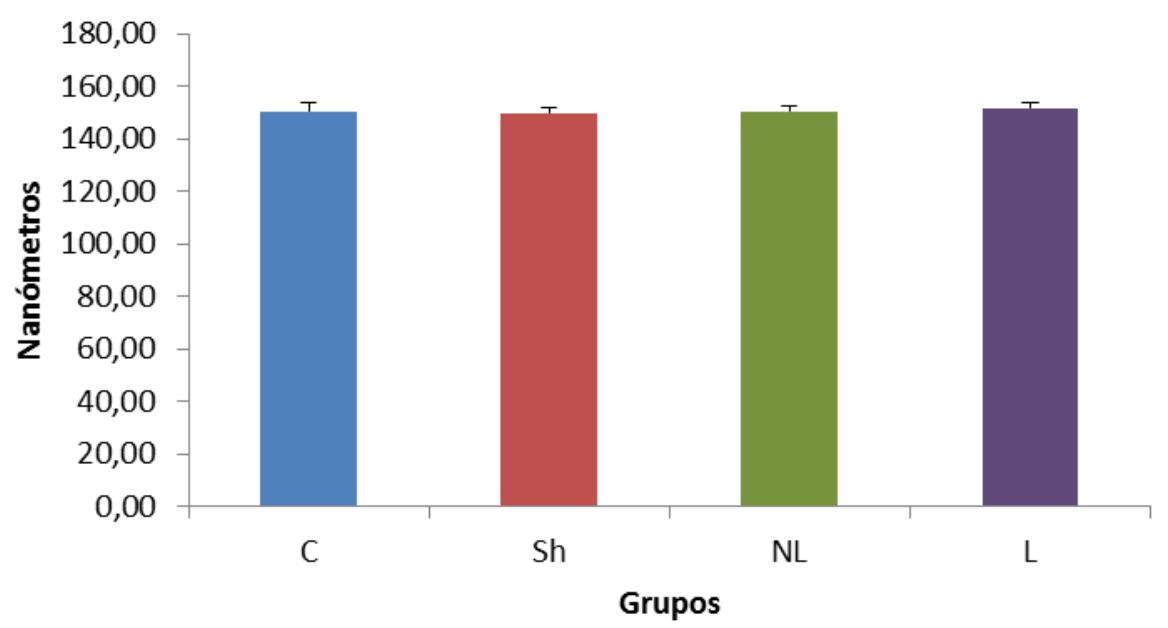

Figura 27: (A) Gráfica representativa del análisis de imagen que muestra la cuantificación del grosor de la membrana basal glomerular. Los valores representan la media \pm e.e.m. (B) Gráfica representativa del análisis de imagen que muestra la cuantificación del grosor de la base de los pedicelos. Los valores representan la media \pm e.e.m. 


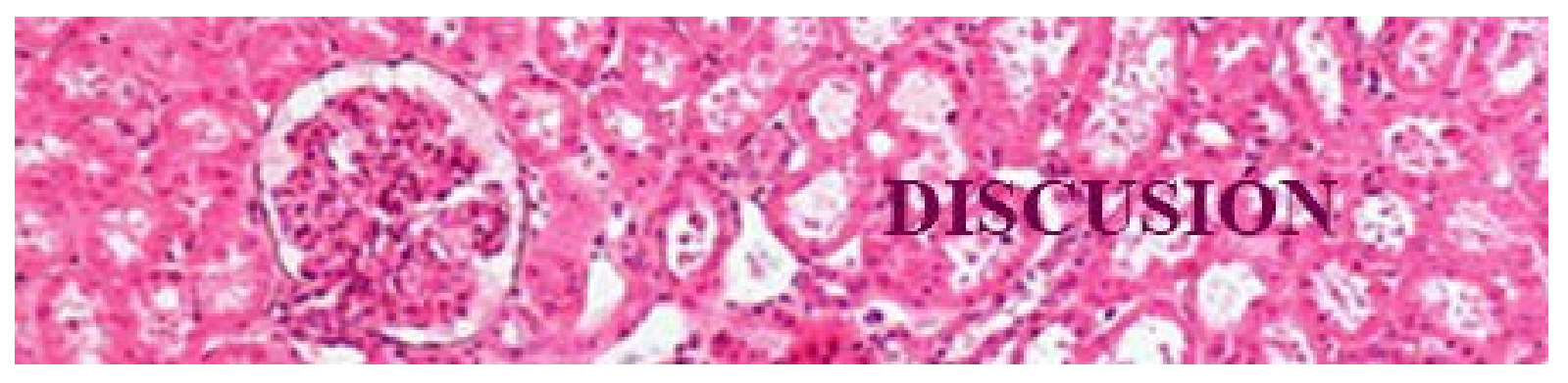


El objetivo principal de nuestro trabajo ha sido el estudio de las posibles alteraciones del corpúsculo renal en procesos de nefropatía obstructiva que conllevan la aparición de fibrosis renal $y$, finalmente, desembocan en insuficiencia renal $(1,31,35,37,60,141)$.

Para reproducir una uropatía obstructiva similar a la que sucede en el humano, hemos utilizado ratones de la cepa C57BL/6 a los que se sometió a una ligadura unilateral de uréter, modelo ampliamente descrito en la literatura $(102,103,128)$ y que se suele utilizar para analizar los fenómenos fisiopatológicos que acaecen en procesos de insuficiencia renal crónica que cursan con fibrosis renal. (142-144)

Al realizar la correspondiente revisión bibliográfica, pudimos constatar que prácticamente todos los estudios realizados hasta el momento se limitaban a describir las alteraciones que suceden en el espacio túbulo-intersticial en el modelo de OUU, no existiendo hasta la fecha estudios relativos al corpúsculo renal, salvo alguna pequeña mención sin detallar $(12,145)$. Sin embargo, en estudios previos de nuestro grupo de investigación ya detectamos hace algún tiempo que, si bien no se observan alteraciones llamativas de los corpúsculos renales, estos no eran absolutamente normales (146) lo que nos ha impulsado a realizar la presente tesis doctoral.

El modelo de obstrucción ureteral por ligadura del uréter ha demostrado ser un buen modelo experimental para inducir daño renal caracterizado por lesión de las células tubulares, inflamación intersticial y fibrosis $(102-104,106)$. El procedimiento de la ligadura causa la obstrucción completa del uréter de forma aguda y tiene como ventaja que las lesiones evolucionan de manera altamente reproducible, reflejando de forma acelerada la secuencia de acontecimientos patogénicos de la nefropatía obstructiva. Clínicamente, se caracteriza por una uremia ligera y transitoria y la ausencia de hipertensión. Histológicamente se define por un aumento de infiltrado intersticial de células, fundamentalmente macrófagos, seguidos en número por linfocitos T, aunque también pueden encontrarse neutrófilos ya desde el día 1 tras la obstrucción. Al mismo tiempo, se produce una proliferación de células intersticiales y dilatación tubular durante los primeros días 
después de la obstrucción ureteral $(103,104,106,147)$. Entre los días 4-10 ya es constatable la proliferación de miofibroblastos, apoptosis tubular y comienzo de la atrofia, iniciándose un exceso de deposición de matriz extracelular.

En nuestro trabajo, el tiempo de evolución de los riñones tras la ligadura ha sido de 15 días ya que, si bien la fibrosis empieza a ser apreciable a partir del día 8, es a partir del día 15 el tiempo estimado en el que son plenamente verificables las alteraciones descritas para este modelo con clara acumulación de matriz extracelular, extensa atrofia tubular y afluencia de células inflamatorias, especialmente macrófagos $(102-104,106,148,149)$. Si el proceso se mantiene la fibrosis evoluciona y, con el tiempo, el riñón se ve abocado a un colapso crónico.

Tras la obstrucción ureteral, lógicamente, se produce un estasis urinario que lleva a un proceso de hidronefrosis, originándose, en primer lugar, el aplastamiento mecánico, tanto de la médula como de la corteza renal, lo que provoca la casi total desaparición de la papila y la mayoría de los componentes medulares, conservándose en mayor medida la corteza, si bien ésta aparece comprimida (150). Esos fenómenos fueron perfectamente constatados en nuestro trabajo cuando se examinaron preparaciones teñidas con la técnica estándar de hematoxilina-eosina.

Igualmente, en nuestras preparaciones se observaron cambios túbulo-intersticiales importantes en los riñones ligados. Así, los túbulos proximales mostraron numerosas alteraciones, desde el lumen dilatado y el epitelio aplanado hasta necrosis en diferentes grados. En el intersticio tubular se observó infiltrado inflamatorio, el cual era más intenso en las áreas profundas de la corteza, en lo que queda de médula, y alrededor de los vasos. Estas alteraciones coinciden plenamente con lo descrito en la bibliografía para este modelo experimental.

Muy poco se dice en la literatura de lo que se observa en los corpúsculos renales tras la OUU, sin embargo, ya con la técnica histológica de hematoxilina-eosina, nos llamó la atención la diferencia de tamaño y el abigarramiento celular que se observaba en los riñones ligados cuando se comparaban con los no ligados o los controles. Por ello se efectuó un estudio cuantitativo del área 
corpuscular en las preparaciones teñidas con rojo sirio ya que en las mismas se facilita el aislamiento del glomérulo al existir una pequeña cantidad de colágeno rodeando la periferia de la cápsula de Bowman y, por tanto se tiñe con rojo sirio, de tal manera que el glomérulo queda, en la mayoría de los casos, bien delimitado.

En estos estudios se observó que el área corpuscular media de los riñones de animales ligados era significativamente menor que en sus correspondientes contralaterales e, incluso que los sham y controles. Este hecho, que es de lo poco que se puede encontrar en la literatura $(12,145)$, podría ser consecuencia de la variación del volumen renal observado en los animales L debido a la compresión que sufre el tejido por la hidronefrosis que provocaría una disminución del calibre de las luces vasculares y del corpúsculo en sí.

Llama la atención también que los riñones de los animales NL presentaran el área corpuscular de mayor tamaño medio de todos los grupos de estudio, circunstancia que podría deberse a que este riñón no ligado sufre una hipertrofia compensadora tras la ligadura de su contralateral, fenómeno que sucede habitualmente cuando una de las dos vísceras renales se ve afectada morfo funcionalmente. (145)

Una de las primeras alteraciones observadas en nuestro trabajo fue la tubularización del epitelio parietal de la cápsula de Bowman, fundamentalmente en los animales L, pero también en algunos corpúsculos de NL sin que apareciese en prácticamente ningún caso de los ejemplares Sh y C. Este fenómeno ocurre como respuesta a diferentes agresiones a la víscera renal, entre ellas la obstrucción y, debido a él, las células parietales de la Cápsula de Bowman adquieren un aspecto similar al de las células del túbulo contorneado proximal (TCP). Se cree que constituye una respuesta adaptativa a la proteinuria, y, debido a esto, no sólo el TCP participaría de la reabsorción proteica sino también las células parietales glomerulares (151). La aparición de tubularización en los animales de nuestro estudio supondría ya una alteración de los corpúsculos fácilmente detectable, aunque la misma no tenga una repercusión en la funcionalidad glomerular intrínseca. 
Los hechos citados, nos indujeron a pensar que posiblemente estuvieran ocurriendo en los corpúsculos otras circunstancias de difícil visualización mediante técnicas estándar de microscopía óptica, por lo que resultaba de gran interés realizar un estudio más amplio, con técnicas más específicas, tanto de microscopía óptica como de microscopía electrónica, para confirmar o no las posibles alteraciones corpusculares y su correlación con lo que ocurre a nivel intersticial.

La fibrosis intersticial es el resultado final de todas las formas de enfermedad renal crónica, habiéndose observado también en procesos de daño renal agudo grave $(152,153)$.

En la OUU, la fibrosis intersticial es su consecuencia más dramática (144). La fibrosis se caracteriza por el incremento del número de fibroblastos activados y la acumulación de componentes de la matriz extracelular. En la OUU se producen ya a los 3 días de la obstrucción cambios en la expresión génica relacionada con la activación de fibroblastos, además de procesos de transformación epitelio mesenquimal y acúmulo de matriz extracelular $(28,62$, 125). El aumento del número de fibroblastos es evidente ya el día 7 de OUU y a partir de los quince días de ligadura, los riñones obstruidos desarrollan fibrosis intersticial demostrado por el aumento de proteínas de matriz extracelular, como son, entre otras, colágeno tipo I y III y fibronectina (106, 150).

Por ello, realizamos una tinción con la técnica de Tricrómico de Masson para ver si aparecía un aumento de matriz extracelular en los corpúsculos renales. Efectivamente, con esta técnica pudo observarse un aumento de la matriz mesangial en los riñones ligados y un ligero aumento en los riñones contralaterales no ligados, no encontrándose dicho incremento en el caso de los animales Sham y Control. La expansión mesangial, se correlaciona con el aumento de tejido conectivo observado en los riñones L y NL en la zona túbulo-intersticial, y en coincidencia con lo descrito clásicamente para este modelo de OUU en el intersticio $(106,150)$.

La tinción de Masson es útil para un análisis cualitativo o semicuantitativo, pero esta técnica presenta variaciones tintoriales entre las distintas preparaciones que la hacen poco exacta a 
la hora de cuantificar densitométricamente y conducen a una imprecisión de los resultados. Por ello, para un análisis cuantitativo se hacía necesario buscar otra tinción más estable y reproducible que permitiera obtener preparaciones uniformes y por tanto comparables y se optó por el rojo sirio que es una técnica muy reproducible, ocasiona escasos artefactos y tinción de fondo, y, además, los núcleos no se contrastan, con lo que se evitan interferencias en la cuantificación. Las preparaciones teñidas con rojo sirio se analizaron mediante un sistema de cuantificación asistido por ordenador mediante el software específico Fibrosis $\mathrm{HR}^{\circledR}$. Este procedimiento ha sido perfectamente validado, obteniéndose resultados objetivos, precisos y reproducibles (138).

Con la técnica de rojo sirio y el análisis de las preparaciones mediante ordenador, se corrobora cuantitativamente que los animales L tienen una mayor cantidad de matriz extracelular en los corpúsculos que los NL, Sh y controles y que este aumento se produce fundamentalmente en el área mesangial.

Es bien conocido que muchos de los procesos patológicos que afectan al corpúsculo renal provocan una expansión de matriz extracelular, iniciándose la misma con una acumulación de tejido conectivo en el mesangio. Estos procesos pueden acabar en una glomeruloesclerosis que altera seriamente la funcionalidad corpuscular $(33,34)$. En los animales L de nuestro estudio, si bien se observa este aumento de matriz mesangial, esta no llega nunca al estado de glomeruloesclerosis que pudiera comprometer el funcionalismo glomerular. En otros procesos que cursan con el desarrollo de glomeruloesclerosis como la hipertensión arterial, las células mesangiales responden al aumento de presión produciendo una mayor cantidad de matriz mesangial (154). El modelo de OUU no conlleva un incremento de la presión arterial en los animales, por lo que la expansión mesangial observada debe ocurrir por otros motivos. Como hemos observado, los animales L desarrollan, ya a los 15 días, un franco proceso de fibrosis en el intersticio y se ha descrito, también en modelos de hipertensión arterial, que, si bien la fibrosis túbulo-intersticial podría ser consecuencia en ellos de una inicial alteración en el glomérulo, ésta provocaría, una vez establecida, un mayor daño glomerular (155) por lo que el aumento de 
mesangio observado en nuestros animales podría ser consecuencia de un daño secundario a la fibrosis establecida previamente en el intersticio.

Se puede decir que las células mesangiales son una especie de pericitos, similares a miocitos lisos, que son primordiales para el mantenimiento de la homeostasis glomerular. Estas células sintetizan y regulan el recambio de la matriz extracelular que soporta las asas capilares glomerulares, regula la superficie de ultrafiltración y actúan también como auténticos fagocitos (156). Al igual que sucede en el intersticio con la activación fibroblástica, ante diferentes agresiones que afectan al glomérulo, las células mesangiales responden produciendo un exceso de proteínas de la matriz extracelular. Sin embargo, poco se sabe acerca de los mecanismos moleculares que median en la acumulación de MEC glomerular. En nuestro trabajo hemos efectuado un estudio inmunohistoquímico de dos de las proteínas más importantes en los fenómenos de esclerosis glomerular como son el Colágeno I, y la Fibronectina.

En el intersticio renal, tanto el colágeno I como la fibronectina aparecen con el patrón clásicamente descrito para el modelo de $\operatorname{OUU}(60,145,157)$, es decir, una expresión intensa peritubular y perivascular en los riñones L, mientras que en los riñones NL la expresión era muy pequeña. En los riñones de animales Sh y C la expresión fue muy débil, circunscribiéndose solo a algunas zonas perivasculares.

Cuando se observaron las inmunotinciones para Colágeno I y Fibronectina en los corpúsculos renales, se pudo apreciar una correlación con lo que aparecía en el intersticio, si bien con mucha menos intensidad. De esta manera, en los riñones L, se encontró una expresión pequeña pero intensa en la matriz mesangial, tanto en colágeno como en Fibronectina, que resultó significativamente mayor con respecto al grupo NL y más con los grupos Sh y C. Estos resultados permiten decir que, para el tiempo de OUU efectuado, también existen alteraciones referidas a la matriz extracelular en los corpúsculos renales de riñones sometidos a ligadura, si bien la expansión 
mesangial no llega a ser tan llamativa como la observada en el túbulo-intersticio, ni a comprometer seriamente la viabilidad glomerular.

En procesos que cursan con fibrosis intersticial, los miofibroblastos que se generan expresan alfa actina de músculo liso ( $\alpha$-SMA) que es considerada con un marcador de este tipo celular $(158,159)$. De hecho, en nuestro trabajo hemos podido observar en el intersticio renal una expresión de $\alpha$-SMA aumentada en el caso del riñón L, seguido en orden por los NL, siendo notablemente menor en los grupos Sh y C. Resultados que están en consonancia con en estudios previos de otros autores (125). Dado que las células mesangiales expresan en su citoesqueleto $\alpha$ SMA, y que esta aumenta considerablemente en procesos de expansión mesangial, se considera también esta molécula como un buen marcador para estas células en los procesos de fibrosis. Por ello se realizó un estudio inmunohistoquímico de la expresión de novo de $\alpha$-SMA, observando en los corpúsculos una expresión evidente en los correspondientes a animales L y, en menor medida, en NL.

El incremento de la expresión de $\alpha$-SMA en las células mesangiales es un paso importante en los cambios fenotípicos que se producen desde su estado no activado hacia el estado proliferativo y secretorio. Las células mesangiales activadas incrementan la producción de matriz extracelular, aumentan la respuesta inflamatoria, al mismo tiempo que incrementan su propia proliferación que puede desembocar en glomeruloesclerosis $(160,161)$. El aumento de $\alpha$-SMA detectado en nuestro trabajo permitiría decir que las células mesangiales se activan tras la OUU, no solo en el riñón obstruido, sino también, aunque en menor medida, en su correspondiente contralateral no obstruido. El aumento de $\alpha$-SMA en los riñones NL podría deberse a la hipertrofia compensadora de estos riñones, como hemos comentado más arriba.

Se considera al TGF- $\beta 1$ como el mediador más importante en la enfermedad renal crónica $(162,163)$. Este factor de crecimiento contribuye al desarrollo de glomeruloesclerosis en los procesos renales progresivos mediante la inducción de acumulación de matriz extracelular 
glomerular. Numerosos estudios constatan que la sobreexpresión del TGF- $\beta 1$ en respuesta a estímulos perjudiciales, entre los que se incluye la OUU incrementa la transcripción, síntesis y secreción de proteínas de matriz extracelular causando fibrosis $(145,164-166)$. En diversos modelos experimentales de fibrosis renal se ha demostrado un aumento de la producción renal de TGF- $\beta 1$ así como de su mRNA $(167,168)$. Isaka y cols.(169) encontraron que la inyección en el riñón de cDNA para TGF- $\beta$ producía glomeruloesclerosis en ratas. Igualmente, los ratones transgénicos que sobrexpresan TGF- $\beta 1$ desarrollan esclerosis renal espontánea (170). Todas estas evidencias sugieren una implicación directa del TGF- $\beta$ en el desarrollo de la patología renal.

También se sabe que TGF- $\beta 1$ inhibe la degradación por las células mesangiales de varios componentes de la matriz mesangial (156). Bajo condiciones de estímulo en cultivos, las células mesangiales adquieren un fenotipo similar a los miofibroblastos, que se asemejan a las encontradas en procesos de glomeruloesclerosis (171). Por tanto, actuarían de una manera similar a los miofibroblastos del túbulo-intersticio.

Está muy bien documentado que TGF- $\beta 1$ promueve la fibrosis activando la fosforilación y movilización específica de los factores de trascripción denominados Smad. Las Smad son proteínas intracelulares que una vez activadas interactúan con la co-Smad4 formando complejos que se trasladan al núcleo donde activan la transcripción en cascada de diversos genes relacionados con la vía TGF- $\beta$. La participación concreta de la de la vía TGF- $\beta / S m a d 2 / 3$ en la fibrosis renal ha sido ampliamente descrita (172-175) y se ha observado que la OUU induce un incremento en la fosforilación de Smad2 y Smad3 (176).

Por lo anteriormente expuesto se realizó un estudio de la fosforilación de Smad 2/3, mediante inmunohistoquímica, con objeto de analizar la contribución de la vía de señalización TGF- $\beta$ /Smad en las posibles alteraciones ocurridas tras la OUU.

Así, se pudo observar cómo se produce un aumento de la expresión y la intensidad de pSmad2/3 en el túbulo-intersticio de los riñones obstruidos, corroborando los descrito en la 
literatura $(143,164)$. Y cuando analizamos lo que aparece en los corpúsculos renales se observó un paralelismo a lo indicado para el túbulo-intersticio, es decir, una expresión significativamente mayor en el riñón obstruido respecto a los grupos NL, C y Sh, circunstancia no descrita hasta el momento y que nos sugiere que el incremento de Colágeno I y fibronectina observado en los glomérulos de los animales ligados puede estar relacionado con una mayor activación de la vía de Smad 2/3, implicando, por consiguiente, al TGF- $\beta 1$ en la expansión mesangial observada en nuestro estudio.

Como ya hemos comentado, ante distintas agresiones que afectan al riñón, las células mesangiales responden de diferentes maneras que, además de la secreción de citoquinas proinflamatorias y el desarrollo de fibrosis, la capacidad de proliferar, y el desarrollo de procesos de muerte celular por, apoptosis (177-181).

Por ello, hemos realizado un estudio de la posible proliferación y la apoptosis que pudieran tener lugar tras la OUU. En primer lugar, para la comprobación de los fenómenos proliferativos se efectuó un estudio inmunohistoquímico del antígeno de proliferación Ki67, usando para ello el anticuerpo monoclonal Mib-1 que detecta un epítopo distinto del mismo antígeno, pero que es más fácilmente detectable en muestras incluidas en parafina. Los anticuerpos monoclonales Ki-67 y Mib-1 son marcadores del ciclo celular y del crecimiento tumoral que pueden detectarse fácilmente utilizando métodos de inmunocitoquímica. Son antígenos nucleares presentes sólo en los núcleos de las células que se dividen y se dirigen contra diferentes determinantes antigénicos del mismo antígeno relacionado con la proliferación.

Ki-67 y Mib-1 pueden utilizarse en secciones fijadas. Mib-1 se utiliza en aplicaciones clínicas para determinar el índice de marcaje de Ki-67 y una de sus principales ventajas sobre el anticuerpo original Ki-67 (y la razón por la que ha sus sustituido al anticuerpo original para uso clínico) es que se puede utilizar en secciones embebidas en parafina fijadas con formalina, después de la 
recuperación de antígeno mediada por calor. En nuestro caso se utilizó Ki67 (clon Mib-1) monoclonal de conejo.

En el intersticio renal se observó una expresión alta de Mib-1 en el caso del riñón L, con una menor proporción en el NL, siendo prácticamente testimonial en los grupos Sh y C. Estos datos están en consonancia con lo descrito en la literatura hasta la fecha $(182,183)$.

En el caso de los corpúsculos renales, el resultado obtenido fue una proliferación netamente superior en el caso de los riñones L respecto a los otros tres grupos de estudio. Solo hemos encontrado en la literatura un estudio bastante antiguo sobre proliferación en el corpúsculo tras la OUU (12). Estos autores no encontraron prácticamente proliferación ni diferencias significativas entre animales ligados y no ligados a lo largo del experimento en células glomerulares, en contraposición a nuestros resultados donde, a pesar de ser escasa, 2,5 células/glomérulo de media en animales L, sí que se observa claramente.

Como se indicó anteriormente, la progresión del daño renal está asociada con la eliminación progresiva de las células renales junto con la fibrosis del riñón. Se ha descrito que la apoptosis es la primera causa de muerte celular en la OUU, siempre referido al intersticio renal (184). La muerte celular tubular se puede observar ya tras 24 horas de OUU (185) y alcanzaría un pico a las dos semanas en los túbulos distales y colectores tanto en la corteza como en la médula renales, sugiriendo que la pérdida celular contribuye a la resolución de la inflamación, la regulación del número de fibroblastos y el daño microvascular.

Está bien establecido, por tanto, que a partir de los 15 días, la dilatación tubular y la apoptosis experimentan un alza en túbulos y conductos colectores y las células intersticiales experimentan la apoptosis $(3,86,186-188)$.

Las caspasas son mediadores esenciales de los procesos de apoptosis y de muerte celular programada entre otras funciones. Debido a ello, para la comprobación de la posible apoptosis en nuestro trabajo se utilizó como referencia la expresión inmunohistoquímica de Caspasa 3 activada. 
Los resultados obtenidos cuando se estudió la apoptosis en el túbulo-intersticio, fueron análogos a lo descrito en la literatura, es decir, se encontró una expresión de Caspasa 3 activada más alta en el caso del riñón L respecto a los otros tres grupos NL, Sh y C. Una correlación similar del anticuerpo fue encontrada en el corpúsculo renal, en oposición a lo descrito por Truong y cols. (12), que raramente encontraron células apoptóticas en glomérulos de riñones ligados aunque hemos de mencionar que estos autores llevaron a cabo su trabajo en ratas. En nuestro caso, si bien se encontraron pocos glomérulos con apoptosis y el número absoluto de células marcadas fue escaso, las diferencias entre los grupos si resultaron significativas.

Se ha postulado que la aparición de apoptosis de las células mesangiales varía de acuerdo al grado de desarrollo de la enfermedad renal crónica. De esta manera, en estadios iniciales la apoptosis se inhibiría favoreciendo la transdiferenciación de las células mesangiales en miofibroblastos e iniciando, por tanto el proceso fibrogénico y la consiguiente expansión mesangial (189) Por otro lado, en fases finales de glomeruloesclerosis la apoptosis se asocia con la deposición de matriz extracelular y contribuye a la disminución de la celularidad mesangial (188). Se cree que los cambios cualitativos y cuantitativos de matriz extracelular del corpúsculo renal interrumpen los estímulos pro-supervivencia de las células mesangiales, exponiéndolas a los estímulos proapoptóticos presentes durante el desarrollo de glomeruloesclerosis (186).

La proliferación celular y la apoptosis suelen ir asociadas (187). Nuestros resultados en ambos casos indican un aumento de ambas, con un ligero predominio en las cifras de proliferación con respecto a la apoptosis, aunque en ambos casos los niveles son pequeños. Esto podría ser debido a la duración del periodo de evolución desde que se practicó la OUU hasta la recogida de las muestras.

Se ha considerado durante décadas a las células mesangiales como el foco de interés en la investigación de los fenómenos que se producían tras diferentes procesos que provocan daño renal, sin embargo, algunos fenómenos como la génesis de la proteinuria que suele suceder en muchas de 
las alteraciones que cursan con expansión mesangial no son fácilmente explicables por dicho aumento del mesangio (190). Por tanto, la atención se ha centrado en la barrera de filtración glomerular (BFG) compuesta por los capilares endoteliales fenestrados, la membrana basal glomerular (MBG) y las células del epitelio visceral de la cápsula de Bowman, conocidas como podocitos.

Aunque se sabe que los tres componentes de la BFG son esenciales para la filtración renal normal, siempre ha existido un gran debate sobre el papel de cada uno de ellos en la patogénesis de la proteinuria, atribuyéndose por parte de algunos autores la pérdida de proteínas a la disfunción endotelial, por ejemplo, la microangiopatía que sucede en la diabetes mellitus (191). Otros refieren que es el engrosamiento de la MBG y la alteración de sus propiedades electrostáticas $(192,193)$ aunque se sabe que esto sucede mucho después de que haya microalbuminuria (194).

En el caso de la OUU no hay nada escrito sobre posibles alteraciones tanto del endotelio, como de la MBG. Por ello efectuamos un estudio con microscopía electrónica de transmisión en el que solamente se pudo apreciar un ligero incremento de matriz mesangial o el colapso de algunas luces capilares en el grupo de animales sometidos a la ligadura, no percibiéndose, ni en los riñones ligados ni ninguno del resto de los grupos, más alteraciones estructurales nucleares o citoplasmáticas. Tampoco se apreciaron depósitos electrondensos ni presencia de ningún tipo de material extraño o celular en los espacios urinarios. En la observación inicial tampoco se apreció engrosamiento anormal de la membrana basal ni procesos de fusión o pérdida de podocitos. La arquitectura de las asas capilares no presentaba tampoco alteraciones. Tan solo llamaba la atención la circunstancia, ya descrita en los estudios con microscopía óptica, de la tubularización del epitelio parietal de la cápsula de Bowman, circunstancia que podemos atribuir a la transformación compensatoria de estas células debido a la disminución de la celularidad de los túbulos alterados tras la OUU. 
Para observar si pudiesen existir alteraciones no detectables a simple vista, realizamos un estudio morfométrico sobre las muestras de microscopía electrónica del grosor de la membrana basal, objetivando que no existían diferencias significativas entre los distintos grupos de estudio, por lo que no se puede atribuir al endotelio o a la MBG ningún papel aparente en las alteraciones que hemos encontrado en los corpúsculos tras la OUU.

En cuanto al tercer componente de la BFG, es decir, los podocitos, que suponen la última barrera que restringe el paso de proteínas a la orina, el estudio con microscopía electrónica de transmisión tampoco demostró lesiones generales que implicaran alteración citoplásmica o pérdida o fusión de los pedicelos de los podocitos que parecían estar bien conservados. No obstante, también realizamos un estudio morfométrico de la anchura de los pedicelos por si pudiese revelar alguna alteración los mismos, no objetivando tampoco diferencias significativas entre los distintos grupos de estudio.

No obstante, en diversas enfermedades relativas al riñón se ha descrito que la alteración en el número de podocitos supone un importante mediador en la progresión del daño glomerular $(190,195,196)$ Los podocitos cumplen un papel fundamental en el mantenimiento de la estructura y función de la barrera de filtración glomerular, por lo tanto, la pérdida de estas células condiciona el desarrollo progresivo de disfunción renal. Diversos estudios clínicos y experimentales de daño glomerular han demostrado que la reducción progresiva en el número de podocitos precede al desarrollo de glomeruloesclerosis (195-197). Debido a su limitada capacidad proliferativa, el desprendimiento de podocitos de la MBG conduce a la depleción celular, iniciando el desarrollo de glomeruloesclerosis (197).

Por lo anteriormente expuesto en nuestro trabajo hemos realizado un estudio para analizar la posible lesión o pérdida de podocitos mediante inmunomarcaje con el anticuerpo (WT-1). En el mismo, Se pudo constatar una reducción significativa en el número de núcleos positivos tanto en 
los grupos L como en los NL, no observándose diferencia entre ellos, comparado con los grupos Sh y C entre los cuales tampoco se observaron diferencias significativas.

Los podocitos son células diferenciadas terminales que tienen un fenotipo quiescente, por lo que se ha propuesto la hipótesis de que tras la pérdida crítica de una población de podocitos glomerulares, el resto de células de los mismos no podrían compensar la función de filtración glomerular y que este hecho desembocaría en el desarrollo de glomeruloesclerosis (198). Se han propuesto dos mecanismos para explicar la pérdida podocitaria, por un lado, la apoptosis y por otro, la denudación o desprendimiento desde su localización sobre la membrana basal. En ambos casos, se sabe que TGF- $\beta 1$ juega un papel relevante. Así, TGF- $\beta 1$ induce apoptosis por la activación de p38 (MAP Kinasa) y de Caspasa-3 (199). Por otro lado, en pacientes con enfermedades progresivas que afectan a los podocitos como la glomeruloesclerosis focal y segmentaria y la nefropatía membranosa, la expresión de TGF- $\beta 1$ aparece aumentada en podocitos. Este aumento en la actividad de TGF- $\beta 1$ por los podocitos podría inducir la apoptosis y el desprendimiento de los mismos (197). Aunque se ha visto in vivo e in vitro que TGF- $\beta$ induce apoptosis podocitaria, las tasas de apoptosis in vivo son muy bajas (200). Por otro lado, se ha demostrado que son necesarias tasas altas de pérdida podocitaria, más del 40 por ciento, para que se produzca macroalbuminuria y glomeruloesclerosis (201).

Si tenemos en cuenta que en nuestro estudio hemos observado que, tras la ligadura unilateral del uréter y la consiguiente uropatía obstructiva, se ven incrementadas las proteínas de matriz, el TGF- $\beta 1$, vía Smad2/3, participa en los procesos de expansión mesangial detectados, que, además, existe apoptosis, aunque esta sea en una proporción pequeña, se detectan fenómenos proliferativos y que hay disminución del número de podocitos, podemos concluir que, tras la OUU los corpúsculos renales se ven afectados, aunque no se compromta su viabilidad. 


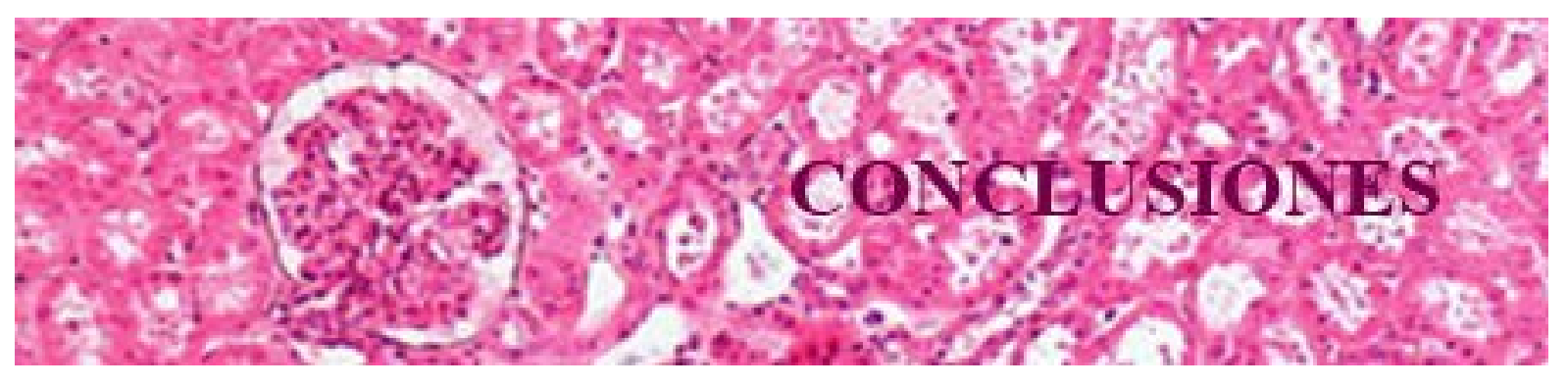


1. Tras la ligadura unilateral del uréter los corpúsculos renales no presentan lesiones estructurales relevantes cuando se observan con las técnicas histológicas habituales de microscopía óptica y electrónica. Sin embargo, al efectuar un estudio con técnicas más específicas como son las morfométricas o inmunohistoquímicas, sí que es posible detectar alteraciones evidentes.

2. La obstrucción ureteral provoca la disminución del área corpuscular en el riñón obstruido y una hipertrofia, posiblemente compensadora, en el riñón contralateral.

3. Se observan numerosos casos de tubularización del epitelio parietal de la cápsula de Bowman en ambos riñones, aunque es mayor en los ligados que en los no ligados. Este fenómeno sería consecuencia del déficit túbulo-intersticial renal e intentaría aumentar la superficie de reabsorción alterada.

4. La obstrucción ureteral provoca una expansión de la matriz mesangial en los glomérulos, aunque éste incremento no llega a tener una magnitud suficiente como para comprometer la viabilidad de la función glomerular. Este aumento de la matriz extracelular podría ser consecuencia de un daño secundario a la fibrosis establecida previamente en el intersticio.

5. El incremento de la matriz mesangial estaría mediado por TGF- $\beta 1$, puesto de manifiesto por la activación de la vía canónica de señalización de TGF- $\beta 1$.

6. La obstrucción ureteral provoca en los glomérulos la aparición de procesos proliferativos y apoptóticos que, aunque en niveles pequeños, resultan significativos.

7. Aunque no se observan alteraciones significativas relacionadas con el grosor de la MBG o la anchura de los pedicelos, ni procesos de fusión o pérdida de los mismos, si se evidenció una reducción significativa del número de podocitos en los riñones obstruidos, así como en sus contralaterales.

8. Como conclusión general se puede decir que la OUU afecta a los corpúsculos renales, aunque no podemos decir cómo afecta a su funcionalidad. 


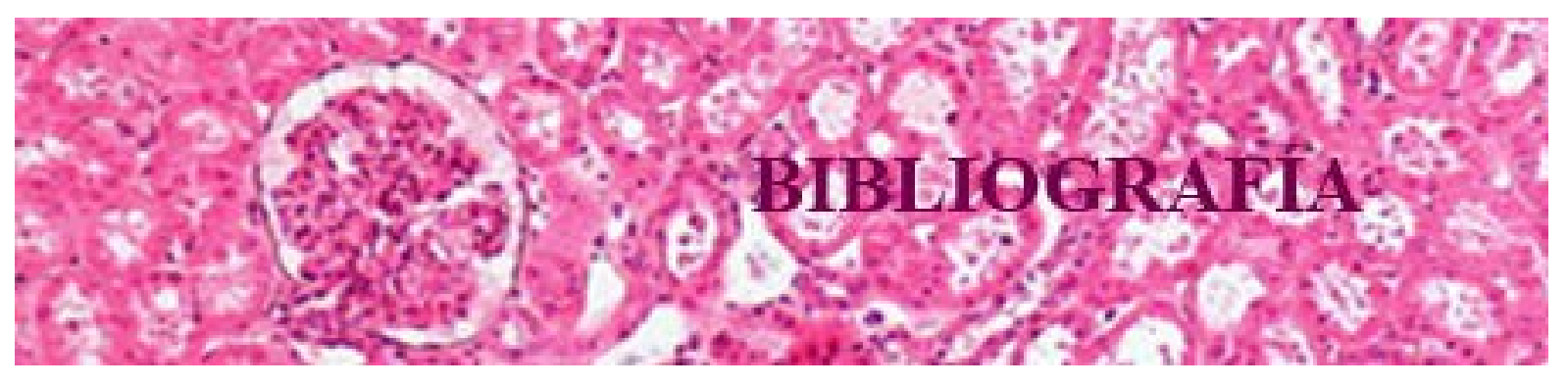


1. Boor P, Ostendorf T, Floege J. Renal fibrosis: novel insights into mechanisms and therapeutic targets. Nat Rev Nephrol. 2010;6:643-56.

2. Diamond JR. Macrophages and progressive renal disease in experimental hydronephrosis. Am J Kidney Dis. 1995;26:133-40.

3. Manucha W, Carrizo L, Ruete C, Vallés PG. Apoptosis induction is associated with decreased NHE1 expression in neonatal unilateral ureteric obstruction. BJU Int. 2007;100(1):191-8.

4. Allen AM, Zhuo J, Mendelsohn FA. Localization and function of angiotensin ATI receptors. Am J Hypertens. 2000;13:31S-8S.

5. Ardaillou R. Angiotensina II receptors. J Am Soc Nephrol. 1999;10 suppl 11:S30-9.

6. Attisano L, Wrana JL, Lopez-Casillas F, Massague J. TGF-beta receptors and actions. Biochim Biophys Acta. 1994;1222:71-80.

7. Cheifetz S, Bellón T, Calés C, Vera S, Bernabeu C, Massagué J, et al. Endoglin is a component of the transforming growth factor-beta receptor system in human endothelial cells. J Biol Chem. 1992;267:19027-30.

8. Guerrero-Esteo M, Lastres P, Letamendia A, Perez-Alvarez MJ, Langa C, Lopez LA, et al. Endoglin overexpression modulates cellular morphology, migration and adhesion of mouse fibroblasts. Eur J Cell Biol. 1999;78:614-23.

9. Kingsley DM. The TGF-beta superfamily: new members, new receptors, and new genetic test of function in different organims. Pharmacol. 1994;8(133-146).

10. Obreo J, Díez-Marques L, Lamas S, Düwell A, Eleno N, Bernabéu C, et al. Endoglin expression regulates basal and TGF-beta1-induced extracellular matrix synthesis in cultured L6E9 myoblasts. Cell Physiol Biochem. 2004;14(301-10).

11. Wrana JL, Attisano L, Wieser R, Ventura F, Massague J. Mechanism of activation of the TGFbeta receptor. Nature. 1994;370:341-7.

12. Truong LD, Petrusevska G, Yang G, Gurpinar T, Shappell S, Lechago J, et al. Cell apoptosis and proliferation in experimental chronic obstructive uropathy. Kidney Int. 1996;50:200-7.

13. Bulger RE, Dobyan DC. Recent adbances in renal morphology. Annu Rev Physiol. 1982;44:14779.

14. Tischer CC. Anatomy of the kidney. Brenner BM, Rector FC, editors. Philadepphia: Saunders; g1976. 3-64 p.

15. Arévalo M, En Avendaño LH. Nefrología clínica. 2014;Cap.2:13-20.

16. Beeuwkes R. The vascular organization of the kidney. Annu Rev Physiol. 1980;42:531-42.

17. Barajas L, Liu L, Powers K. Anatomy of the renal innervation: intrarenal aspects and ganglia of origin. Can J Physiol Pharmacol. 1992;70(5):735-49. 
18. Albertine KH, O'Morchoe CC. Distribution and density of the canine renl cortical lymphatic system. Kidney Int. 1979;16:470-80.

19. Schreiner GF, Unanue ER. Origin of the rat mesangial phagocyte and its expression of the leukocyte common antigen. Lab Invest. 1984;5:889-93.

20. Veis JH. An overview of mesangial cell biology. Contrib Nephrol. 1993;104:115-26.

21. Engel J, Odermatt A, Madri JA, Furthmayr H, Rohde H, Timpl R. Shapes, domain organizations and flexibility of laminin and fibronectin, two multifunctional proteins of the extracellular matrix. J Mol Biol. 1981;150:97-120.

22. Eddy AA. Experimental insights into the tubulointestitial disease accompanying primary glomerular lesions. J Am Soc Nephrol. 1994;5:1273-87.

23. Yurchenko PD, Schittny JC. Molecular architecture of basement membranes. Faseb J. 1990;4:1577-90.

24. Tomasini BR, Mosher DF. On the identity of vitronectin and S-protein: immunological crossreactivity and functional studies. Blood. 1986;68(737-742).

25. Zeisberg M, Strutz F, Muller GA. Role of fibrobast activation in inducing interstitial fibrosis. J Nephrol Suppl. 2000;13:S11-120.

26. Leblond CP, Inoue S. Structure, composition, and assembly of basement membrane. Am J Anat. 1989;185:367-90.

27. Border WA, Noble NA. TGF-beta in kidney fibrosis: a target for gene therapy. Kidney Int. 1997;51:1388-96.

28. Yang J, Liu Y. Blockage of tubular epithelial to myofibroblst transition vy hepatocyte growth factor prevents renal interstitial fibrosis. J Am Soc Nephrol. 2002;13:96-107.

29. Zeisberg M, Bonner G, Maeshima Y, Colorado P, Muller GA, Strutz F, et al. Renal fibrosis: collagen composition and assembly regulates epithelial-mesenchymal trasdifferentiation. Am J Pathol. 2001a;159:1313-21.

30. Davies M, Martin J, Thomas GJ, Lovett DH. Proteinases and glomerular matrix turnover. Kidney Int. 1992;41:671-8.

31. Eddy AA. Molecular basis of renal fibrosis. Pediatr Nephrol. 2000;15:290-301.

32. Guyton AC. Tratado de Fisiología Médica: Interamericana-McGraw-Hill. 2011;Cap. 26:303-22.

33. Lopez-Novoa JM, Martinez-Salgado C, Rodriguez-Pena AB, Lopez-Hernandez FJ. Common pathophysiological mechanisms of chronic kidney disease: therapeutic perspectives. Pharmacol Ther. 2010;128:61-81. 
34. Lopez-Novoa JM, Rodriguez-Pena AB, Ortiz A, Martinez-Salgado C, Lopez Hernandez FJ. Etiopathology of chronic tubular, glomerular and renovascular nephropathies: clinical implications. $\mathrm{J}$ Transl Med. 2011:9-13.

35. Bohle A, Muller GA, Wehrmann M, Mackensen-Haen S, Xiao JC. Phatogenesis of chronic renal failure in the primary glomerulopathies, renal vasculopathies, and chronic interstitial nephritides. Kidney Int Suppl. 1996b;54:S2-9.

36. Barnes JL, Gorin Y. Myofibroblast differentiation during fibrosis: role of NAD(P)H oxidases. Kidney Int. 2011;79:944-56.

37. Chatziantoniou C, Boffa JJ, Tharaux PL, Ronco P, Dussaule JC. Progression and regression in renal vascular and glomerular fibrosis. 2004;85(1):1-11.

38. Liu Y. New insights into epithelial-mesenchymal transition in kidney fibrosis. J Am Soc Nephrol. 2010;21:212-22.

39. Pohlers D, Brenmoehl J, Loffler I, al. e. TGF-beta and fibrosis in different organs - molecular pathway imprints. Biochim Biophys Acta. 2009;7(12):684-96.

40. $\quad$ LeBleu VT, g.; O’Connell, J.; Teng, Y.; Cooke, V.G.; Woda, C.; Sugimoto, H.; Kalluri,R. Origin and function of myofibroblasts in kedney fibrosis. Nat Med. 2013;19(8):1047-53.

41. Lange-Sperandio B, Trautmann A, Eickelberg O, Jayachandran A, Oberle S, Schmidutz F, et al. Leukocytes Induce Epithelial to Mesenchymal Transition after Unilateral Ureteral Obstruction in Neonatal Mice. Am J Pathol. 2007;171(3):861-71.

42. Grande MT, Fuentes-Calvo I, Arevalo M, Heredia F, Santos E, Martinez-Salgado C, et al. Deletion of H-Ras decreases renal fibrosis and myofibroblast activation following ureteral obstruction in mice. Kidney Int. 2010;77(6):509-18.

43. Chuang PY, Menon MC, He JC. Molecular targets for treatment of kidney fibrosis. J Mol Med. 2012;91(5):549-59.

44. Ricard-Blum S. The Collagen Family. Cold Spring Harb Perspect Biol. 2011;3(1):a004978.

45. Sanz AB, Santamaría B, Ruiz-Ortega M, Egido J, Ortiz A. Mechanisms of renal apoptosis in health and disease. J Am Soc Nephrol. 2008;19(9)(1634-42).

46. Grande MT, Lopez-Novoa JM. Fibroblast activation and myofibroblast generation in obstructive nephropathy. Nat Rev Nephrol. 2009;5:319-28.

47. Strutz F, Muller GA. Renal fibrosis and the origin of the renal fibroblast. Nephrol Dial Transplant. 2006;21:3368-70.

48. Strutz F, Zeisberg M. Renal fibroblasts and myofibroblasts in chronic kidney disease. J Am Soc Nephrol. 2006;17:2992-8. 
49. Acloque H, Adams MS, Fishwick K, Bronner-Fraser M, Nieto MA. Epithelial-mesenchymal transitions: the importance of changing cell state in development and disease. J Clin Invest. 2009;119:1438-49.

50. Kriz W, Kaissling B, Le Hir M. Epithelial-mesenchymal transition (EMT) in kidney fibrosis: fact or fantasy? J Clin Invest. 2011;121:468-74.

51. Li Y. Epithelial-to-mesenchymal transition is a potential pathway leading to podocyte dysfunction and proteinuria. Am J Pathol. 2008;172:299-308.

52. Liu Y. Epithelial to mesenchymal transition in renal fibrogenesis: pathologic significance, molecular mechanism, and therapeutic intervention. J Am Soc Nephrol. 2004;15:1-12.

53. Steffes MW, Osterby R, Chavers B, Mauer SM. Mesangial expansion as a central mechanism for loss of kidney function in diabetic patients. Diabetes. 1989;38(1077-81).

54. Lopez-Hernandez FJ, Lopez-Novoa JM. Role of TGF-beta in chronic kidney disease: an integration of tubular, glomerular and vascular effects. Cell Tissue Res. 2012;347:141-54.

55. Cogan MG. Medical Staff Conference. Tubulo-interstitial nephropathies--a pathophysiologic approach. West JMed. 1980;132:134-40.

56. Blythe WB. Natural history of hypertension in renal parenchymal disease. Am J Kidney Dis. 1985;5:A50-6.

57. Johnson DW, Saunders HJ, Baxter RC, Field MJ, Pollock CA. Paracrine stimulation of human renal fibroblasts by proximal tubule cells. Kidney Int. 1998;54:747-57.

58. Norman JT, Fine LG. Profressive renal disease: fibroblasts, extracellular matrix, and integrins. Exp Nephrol. 1999;7:167-77.

59. Kelly CJ. Cellular immunity and the tubulointerstitium. Semin Nephrol. 1999;19:182-7.

60. Becker GJ, Hewitson TD. The role of tubulointerstitial injury in chronic renal failure. Curr Opin Nephrol Hypertens. 2000;9:133-8.

61. Gobe GC, Axelsen RA. Genesis of renal tubular atrophy in experimental hydronephrosis in the rat. Role of apoptosis. Lab Invest. 1987;56:273-81.

62. Iwano M, Plieth D, Danoff TM, Xue C, Okada H, Neilson EG. Evidence that fibroblasts derive from epithelium during tissue fibrosis. J Clin Invest. 2002;110:341-50.

63. Zeisberg M, Duffield JS. Resolved: EMT produces fibroblasts in the kidney. J Am Soc Nephrol. 2010;21:1247-53.

64. Lan HY, Nikolic-Paterson DJ, Mu W, Atkins RC. Local macrophage proliferation in the progression of glomerular and tubulointerstitial injury in rat anti-BM glomerulonephritis. Kidney Int. 1995;48:753-60.

65. Nath KA. The tubulointerstitium in progressive renal disease. Kidney Int. 1998;54:992-4. 
66. Nath KA. Tubulointerstitial chan ges as a major determinant in the progression of renal damage. Am J Kidney Dis. 1992;20:1-17.

67. Hewitson TD, Darby LA, Bisucci T, Jones CL, Becker GJ. Evolution of tubulointerstitial fibrosis in experimental renal infection and scarring. J Am Soc Nephrol. 1998;9:632-42.

68. Basile DP. The transforming growth factor beta system in kidney disease and repair: recent progress and future directions. Curr Opin Nephrol Hypertens. 1999;8:21-30.

69. El Nahas AM. Growth factors and glomerular sclerosis. Kidney Int Suppl. 1992;36:S15-20.

70. Schondorff D, Striker GE, Cutler RE, Bemditt EP. The role of chemokines in thyeinitiation and progression of renal disease. Kidney Int Suppl. 1995;47:S44-S7.

71. Bohle A, Mackensen-Haen S, Wehrmann M. Significance of postglomerular capillaries in the pathogenesis of chronic renal failure. Kidney Blood Press Res. 1996a;19:191-5.

72. Eddy AA. Molecular basis of renal fibrosis. Pediatr Nephrol. 2000;15:290-301.

73. Border WA, Noble NA. Transforming growth factor beta in tissue fibrosis. N Engl J Med. 1994;331:1286-92.

74. Eddy AA. Molecular insights into renal intersticial fibrosis. J Am Soc Nephrol. 1996;7:2495-508.

75. Ito Y, Aten J, Bende RJ, Oemar BS, Rabelink TJ, Weening JJ, et al. Expression of connective tissue growth factor in human renal fibrosis. Kidney Int. 1998;53:853-61.

76. Kagami S, Border WA, Miller DE, Noble NA. Angiotensin II stimulates extracellular matrix protein synthesis through indction of transforming growth factor-beta expression in rat glomerular messangial cells. J Urol. 1994;157:2431-7.

77. Fern RJ, Yesko CM, Thornhill BA, H.S. K, Smithies O, Chevalier RI. Reduced angiotensinogen expression attenuates renal interstitial fibrosis in obstructive nephropathy in mice. J Clin Invest. 1999;103:39-46.

78. Hisada Y, Sugaya T, Yamamouchi M, Uchida H, Fujimura H, Sakurai H, et al. Angiotensin II plays a pathogenic role in immune-mediated renal injury in mice. J Clin Invest. 1999;103:627-35.

79. Kriz W, Hahnel B, Rosener S, Elger M. Long-term treatment of rats with FGF-2 results in focal segmental glomerulosclerosis. Kidney Int. 1995b;45:369-76.

80. Mizuno S, Kaurosawa T, Matsumoto K, Mizuno-Horikawa Y, Okamoto M, Nakamura T. Ephatocyte growth factor prevents renal fibrosis and disfunction in a mouse model of chronic renal disease. J Clin Invest. 1998;101:1827-34.

81. Ghraraee-Kermani M, Wiggins R, Wolber F, Goyal M, Phan SH. Fibronetin is the major fibroblast chemoattractant in rabbit anti-glomerular basement membrane disease. Am J Pathol. 1996;148:961-7. 
82. Wells AF, Larsson E, Tengblad A, Fellstrom B, Tufveson G, Klareskog L, et al. The localization of hyaluronan in normal and rejected human kidneys. Transplanttion. 1990;50:24-243.

83. Lane TF, Sage EH. The biology os SPARC, a protein that modulates cell-matrix interactions. Faseb Journal. 1994;8:163-73.

84. Francki A, Bradshaw AD, Bassuk JA, Howe CC, Couser WG, Sage EH. SPARC regulates the expression of collagen type I and transforming growth factor-beta 1 in mesangial cells. J Biol Chem. 1999;274:32145-152.

85. Funabiki K, Horikoshi S, Tomino Y, Nagai Y, Koide H. Immunohistochemical analysis of extracellular components in the glomerular sclerosis of patients with glomerulonephritis. Clin Nephrol. 1990;34:239-46.

86. Makino H, Kashihara N, Sugiyama H, Sekikawa T, Ota Z. Role of apoptosis in the progression of glomerulosclerosis. Contrib Nephrol. 1996;118:41-7.

87. Wesson LG. Physical factors and glomerulosclerosis. Cause or coincidence. Nephron. 1998;78:125-30.

88. Harris RC, Akai Y, Yasuda T, Homma T. The role of physical forces in alterations of mesangial cell function. Kidney Int Suppl. 1994;45:S17-21.

89. Morel-Maroger Striker L, Killen PD, Chi E, Striker GE. The composition of glomerulosclerosis. I. Studies in focal sclerosis, crescentic glomerulonephritis, and membranoproliferative glomerulonephritis. Lab Invest. 1984;51:181-92.

90. Massy ZA, Guijarro C, O'Donnell MP, Kim Y, Kashtan CE, Egido J, et al. The cental role of nuclear factor-kappa B in mesangial cell activation. Kidney Int Suppl. 1999;71:S76-9.

91. Ichikawi I, Harris RC. Angiotensin actions in the kidney: renewed insight into the old hormone. Kidney Int. 1991;40:583-96.

92. Gomez-Garre D, Ruiz-Ortega M, Largo R, Lopez-Armada MJ, Plaza JJ, Gonzalez E, et al. Effects and interactions of endothelin-1 and angiotensis II on matrix protein expression and synthesis and mesangial cell growth. Hypertension. 1996;27:885-92.

93. Hahn S, Krieg RJJ, Hisano S, Chan W, Kuemmerle NB, Saborio P, et al. Vitamin E supresses oxidative stress and glomerulosclerosis in rat remmant kidney. Pediatr Nephrol. 1999;13:195-8.

94. Isaka Y, Akagi Y, Ando Y, Tsujie M, Imai E. Cytokines and glomerulosclerosis. Nephrol Dial Transplant. 1999;14 Supple 1:30-2.

95. Johnson DW, Lida H, Alpers CE, Majesky MW, Schwartz SM, Pritzi P, et al. Expression of smooth muscle cell phenotype by rat mesangial cells in immune ncomplex nephritis. Alpha-smooth muscle actin is a marker of mesangial cell proliferation. J Clin Invest. 1991;87:847-58.

96. Alpers CE, Hudkins KL, Gown AM, Johnson RJ. Enhanced expression of "musclespecific" actin in glomerulonephritis. Kidney Int. 1992;16:1134-42. 
97. Couser WG, Johnson RJ. Mechanisms of progressive renal disease in glomerulonephritis. Am J Kidney Dis. 1994;23:193-8.

98. Dijke P, Hill CS. New insights into TGF-beta-Smad signalling. Trends Biochem Sci. 2004;29(5):265-73.

99. Cheifetz S, Bellon T, Caless C, Vera S, Bernabeu C, Massague J, et al. Endoglin is a component of the transforming growth factor-beta receptor system in human edothelial cells. J Biol Chem. 1992;267:19027-30.

100. Stacey DW. The ras pathway: a model for the control of proliferation in animal cells. Adv Esp Med Biol. 1988;234:141-67.

101. Ludewig D, Kosmehl H, Sommer M, Bohmer FD, Stein G. PDGF receptor kinase blocker AG1295 attenuates interstitial fibrosis in rat kidney after unilateral obstruction. Cell Tissue Res. 2000;299:97-103.

102. Chevalier RL, Forbes MS, Thornhill BA. Ureteral obstruction as a model of renal interstitial fibrosis and obstructive nephropathy. Kidney Int. 2009;75(11):1145-52.

103. Klahr S, Morrissey J. Obstructive nephropathy and renal fibrosis. Am J Physiol Renal Physiol. 2002;283:861-75.

104. Klahr S. Obstructive nephropathy. Kidney Int. 1998;54:286-300.

105. Muñoz-Felix JM, Lopez-Novoa JM, Martinez-Salgado C. Heterozygous disruption of activin receptor-like kinase 1 is associated with increased renal fibrosis in a mouse model of obstructive nephropathy. Kidney Int. 2014;85(2):319-32.

106. Ucero A, Benito-Martin A, Izquierdo MC, Sanchez-Niño MD, Sanz AB, Ramos AM, et al. Unilateral ureteral obstruction: beyond obstruction. Int Urol Nephrol. 2014;46(4):765-76.

107. Benfield MR, McDonald RA, Bartosh S, Ho PL, Harmon W. Changing trends in pediatric transplantation: 2001. Annual Report of the North American Pediatric Renal Trnasplant Cooperative Study. Pediatric Trasplant. 2003;7:321-35.

108. Young LH, Hegarty NJ, Fitzpatrick JM. Obstructive uropathy. Curr Opin Urol. 1998;8(2):119-24.

109. Frokiaer J, Djurhuus JC, Nielsen M, Pedersen EB. Renal hemodynamic response to ureteral obstruction during converting enzyme inhibition. Urol Res. 1996;24(4):217-27.

110. Kahn SA, Gulmi FA, Chou SY, Mooppan UM, Kim H. Contribution of Endothelin-1 to Renal Vasoconstriction in Unilateral Ureteral Obstruction: Reversal by Verapamil. J Urol. 1997;157:1957-62.

111. Schreiner GF, Harris KP, Purkerson ML, Klahr S. Immunological aspects of acute ureteral obstruction: immune cell infiltrate in the kidney. Kidney Int. 1988;34:487-93.

112. Shappell SB, Mendoza LH, Gurpinar T, Smith CW, Suki WN, Truong LD. Expression of adhesion molecules in kidney with experimental chronic obstructive uropathy: the pathogenic role of ICAM-1 and VCAM-1. Neprhron. 2000;85:156-66. 
113. Diamond JR, Kees-Folts D, Ding G, Frye JE, Restrepo NC. Macrophages, monocyte chemoattractant peptide-1, and TGF-beta 1 in experimental hydronephrosis. Am J Physiol. 1994;266:F926-33.

114. Schreiner GF, Kohan DE. Regulation of renal transport processes and hemodynamics by macrophages and lymphocytes. Am J Physiol. 1990;258:F761-7.

115. Ophascharoensuk V, Giachelli CM, Gordon K, Hughes J, Pichler R, Brown P, et al. Obstructive uropathy in the mouse: role of osteopontin in interstitial fibrosis and apoptosis. Kidney Int. 1999;56:57180.

116. Rouschop KM, Sewnath ME, Claessen N, Roelofs JJ, Hoedemaeker I, van der Neut R, et al. CD44 deficiency increases tubular damage but reduces renal fibrosis in obstructive nephropathy. J Am Soc Nephrol. 2004;15:674-86.

117. Lange-Sperandio B, Cachat F, Thornhill BA, Chevalier RL. Selectins mediate macrophage infiltration in obstructive nephropathy in newborn mice. Kidney Int. 2002;61:516-24.

118. Kaneto H, Morrissey J, McCracken R, Reyes A, Klahr S. pEnalapril reduces collagen type IV synthesis and expansion of the interstitium in the obstructed rat kidney. Kidney Int. 1994;45:1637-47.

119. González-Avila G, Vadillo-Ortega F, Pérez-Tamayo R. Experimental diffuse interstitial renal fibrosis. A biochemical approach. Lab Invest. 1988;59:245-52.

120. Davis BB, Thomasson D, Zenser TV. Renal disease profoundly alters cortical interstitial cell function. Kidney Int. 1983;23(458-64).

121. Ophascharoensuk V, Fero ML, Hughes J, Roberts JM, Shankland SJ. The cyclin-dependent kinase inhibitor p27Kip1 safeguards against inflammatory injury. Nat Med. 1998;4:575-80.

122. Hughes J, Brown P, Shankland SJ. Cyclin kinase inhibitor p21CIP1/WAF1 limits interstitial cell proliferation following ureteric obstruction. Am J Physiol. 1999;277(F948-56).

123. Morrissey JJ, Ishidoya S, McCracken R, Klahr S. Control of p53 and p21 (WAF1) expression during unilateral ureteral obstruction. Kidney Int Suppl. 1996;57:S84-92.

124. Choi YJ, Mendoza L, Rha SJ, Sheikh-Hamad D, Baranowska-Daca E, Nguyen V, et al. Role of p53-dependent activation of caspases in chronic obstructive uropathy: evidence from p53 null mutant mice. J Am Soc Nephrol. 2001;12:983-92.

125. Yang J, Liu Y. Dissection of key events in tubular epithelial to myofibroblast transition and its implications in renal interstitial fibrosis. Am J Pathol. 2001;159:1465-75.

126. Yang G, Dai C, Liu Y. Hepatocyte growth factor gene therapy and angiotensin II blockade synergistically attenuate renal interstitial fibrosis in mice. J Am Soc Nephrol. 2002a;13(2464-77).

127. Yang J, Shultz RW, Mars WM, Wegner RE, Li Y, Dai C, et al. Disruption of tissue-type plasminogen activator gene in mice reduces renal interstitial fibrosis in obstructive nephropathy. J Clin Invest. 2002b;110:1525-38. 
128. Klahr S, Morrissey J. The role of growth factors, cytokines, and vasoactive compounds in the obstructive nephropathy. Kidney Int Suppl. 1998;63(S111-114).

129. Ishidoya S, Morrissey J, McCracken R, Reyes A, Klahr S. Angiotensin II receptor antagonist ameliorates renal tubulointerstitial fibrosis caused by unilateral ureteral obstruction. Kidney Int. 1995;47(1285-94).

130. Klahr S, Morrissey J. Comparative study of ACE inhibitors and angiotensin II receptor antagonists in interstitial scarring. Kidney Int Suppl. 1997;63:S111-14.

131. Ma J, Nishimura H, Fogo A, Kon V, Inagami T, Ichikawa I. Accelerated fibrosis and collagen deposition develop in the renal interstitium of angiotensin type 2 receptor null mutant mice during ureteral obstruction. Kidney Int. 1998;53(937-44).

132. Satoh M, Kashihara N, Yamasaki Y, Maruyama K, Okamoto K, Maeshima Y, et al. Renal interstitial fibrosis is reduced in angiotensin II type 1a receptor-deficient mice. J Am Soc Nephrol. 2001;12:317-25.

133. Kaneto H, Morrissey J, Klahr S. Increased expression of TGF-beta1 mRNA in the obstructed kidney of rats with unilateral ureteral ligation. Kidney Int. 1993;44:313-21.

134. Griffin KA, Picken MM, Churchill M, Churchill P, Bidani AK. Functional and structural correlates of glomerulosclerosis after renal mass reduction in the rat. J Am Soc Nephrol. 2000;11:497506.

135. Kim KH, Kim Y, Park HW, Jeong HJ, Mauer M. A re-evaluation of the renal ablation model of progressive renal disease in rats. J Nephrol. 2003;16(196-202).

136. Striker GE, Schainuck LI, Cutler RE, Benditt EP. Structural-functional correlations in renal disease. I. A method for assaying and classifying histopathologic changes in renal disease. Hum Pathol. 1970;1(4):615-30.

137. García del Moral R, editor. Coloraciones para fibras colágenas y elásticas del tejido conjuntivo. Coloraciones para sustancia amiloidea. Laboratorio de Anatomía patológica. 1993.

138. Masseroli M, O’ Valle F, Andújar M, Ramírez C, Gómez-Morales M, DeDios-Luna J, et al. Design and validation of a new image analysis method for automatic quantification of interstitial fibrosis and glomerular morphometry. Lab Invest. 1998;78:511-22.

139. Abramoff MD, Magalhaes PJ, Ram SJ. "Image Processing with ImageJ". Biophotonics International2004. p. 36,42.

140. Rasband WS. ImageJ, U. S.: National Institutes of Health, Bethesda, Maryland, USA; 1997-2014.

141. Liu Y. Renal fibrosis: new insights into the pathogenesis and therapeutics. Kidney Int. 2006;69:213-7.

142. Grande MT, Arévalo M, Núñez A, Cannata-Andía JB, Santos E, López-Novoa JM. Targeted genomic disruption of $\mathrm{H}$-ras and $\mathrm{N}$-ras has no effect on early renal changes after unilateral ureteral ligation. World J Urol. 2009;27(6):787-97. 
143. Oujo B, Muñoz-Félix JM, Arévalo M, Núñez-Gómez E, Pérez-Roque L, Pericacho M, et al. Lendoglin overexpression increases renal fibrosis after unilateral ureteral obstruction. PLoS One. 2014;9(10):e110365.

144. Rodríguez-Peña AB, Fuentes-Calvo I, Docherty NG, Arévalo M, Grande MT, Eleno N, et al. Effect of angiotensin II and small GTPase Ras signaling pathway inhibition on early renal changes in a murine model of obstructive nephropathy. Biomed Res Int. 2014:124902.

145. Prieto M, Rodríguez-Peña AB, Düwel A, Rivas JV, Docherty N, Pérez-Barriocanal F, et al. Temporal changes in renal endoglin and TGF-beta1 expression following ureteral obstruction in rats. J Physiol Biochem. 2005;61(3):457-67.

146. Prieto Vicente M. Expresión de la Endoglina tras la obstrucción unilateral ureteral en rata: Salamanca; 2001.

147. Klahr S. New insights into the consequences and mechanisms of renal impairment in obstructive nephropathy. . Am J Kidney Dis. 1991;18:689-99.

148. Eddy AA, López-Guisa JM, Okamura DM, Yamaguchi I. Investigating mechanisms of chronic kidney disease in mouse models. Pediatr Nephrol. 2012;27(8):1233-47.

149. Ucero AC, Benito-Martin A, Fuentes-Calvo I, Santamaria B, Blanco J, Lopez-Novoa JM, et al. TNF-related weak inducer of apoptosis (TWEAK) promotes kidney fibrosis and Ras-dependent proliferation of cultured renal fibroblast. Biochim Biophys Acta. 2013;1832(10):1832(10):744-55.

150. Sharma AK, Mauer SM, Kim Y, Michael AF. Interstitial fibrosis in obstructive nephropathy. Kidney Int. 1993;44(4):774-88.

151. Haley DP, Bulger RE. kThe aginf male rat: structure and function of the kidney. Am J Anatomy. 1983;167:1-13.

152. Sharma A, Mucino MJ, Ronco C. Renal functional reserve and renal recovery after acute kidney injury. Nephron Clin Pract. 2014;127:94-100.

153. He L, Livingston MJ, Dong Z. Autophagy in acute kidney injury and repair. Nephron Clin Pract. 2014;127:56-60

154. Heidenreich S, Tepel M, Lang D, Rahn KH, Zidek W. Differential effects of insulin-like growth factor I and platelet-derived growth factor on growth response, matrix formation, and cytosolic free calcium of glomerular mesangial cells of spontaneously hypertensive and normotensive rats. Nephron. 1994;68(4):481-8.

155. Ong ACM, Fine LG. Loss of glomerular function and tubulointerstitial fibrosis: Cause or effect? Kidney Int. 1994a;45(345-51).

156. Wensing LA, Campos AH. TBX3, a downstream target of TGF- $\beta 1$, inhibits mesangial cell apoptosis. Exp Cell Res 2014;328:340-50.

157. Sharma SK, Mauer M, Kim Y, Michael A. Interstitial fibrosis in obstructive nephropathy. Kidney Int. 1993;44:744-88. 
158. Hinz B, Gabbiani G. Fibrosis: recent advances in myofibroblast biology and new therapeutic perspectives. F1000 Biol Rep. 2010;2:78.

159. Kaissling B, Le Hir M. The renal cortical interstitium: morphological and functional aspects. Histochem Cell Biol. 2008;130:247-62.

160. Niu H, Nie L, Liu M, Chi Y, Zhang T, Li Y. Benazepril affects integrin-linked kinase and smooth muscle $\alpha$-actin expression in diabetic rat glomerulus and cultured mesangial cells. BMC Nephrol. 2014;15:135.

161. Xin C, Ren S, Eberhardt W, Pfeilschifter J, Huwiler A. The immunomodulator FTY720 and its phosphorylated derivative activate the Smad signalling cascade and upregulate connective tissue growth factor and collagen type IV expression in renal mesangial cells. Br J Pharmacol. 2006;147(2):164-74.

162. Border WA, Noble NA. Transforming growth factor beta in tissue fibrosis. NEngl J Med. 1994;331:1388-96.

163. Sharma SK, Zyyadeh FN. The transforming growth factor- $\beta$ and the kidney. Semin Nephrol. 1993(116-128).

164. Muñoz-Félix JM, González-Núñez M, López-Novoa JM. ALK1-Smad 1/5 sigbaling pathway in fibrosis development: Firend or foe? Cytokine\&Gorwth Factor Reviews. 2013;24:523-37.

165. Schnaper HW. TGF-[beta] signal transduction in chronic kidney disease. Front Biosci. 2009;14:2448-65.

166. Yeh YC. Transforming growth factor-[beta]1 induces Smad3-dependent [beta]1 integrin gene expression in epithelial-to-mesenchymal transition during chronic tubulointerstitial fibrosis. Am J Pathol. 2010;177:1743-54.

167. Kyyoshi T, Okuda S, Ando T, als. e. TGF- $\beta$ in glomerulosclerosis and interstitial fibrosis of Adriamycin nephropathy. Kidney Int. 1994;45(2):523-36.

168. Rodriguez_Peña A, Prieto M, Duwel A, als. e. Endoglin upregulation during experimental renal interstitial fibrosis in mice. Hypertension. 2002;40:713-20.

169. Isaka Y, Fujiwara Y, Ueda N, Kaneda Y, Kamada T, Imai E. Glomerulosclerosis induced by in vivo transfection of transforming growth factor-beta or platelet-derived growth factor gene into the rat kidney. J Clin Invest. 1993;92(6):2597-601.

170. Kopp JB, Factor VM, Mozes M, als. e. Angiotensin II stimulates endothelin-1 secretion in cultured rat mesangial cells. Kidney Int. 1996;42:860-66.

171. Menè P. Mesangial Cell Cultures. J Nephrol. 2001;14:198-203.

172. Meng XM, Chung AC, Lan HY. Role of the TGF-beta/BMP-7/Smad pathways in renal diseases. Clin Sci (Lond). 2013;124:243-54.

173. Meng XM, Huang XR, Xiao J, Chen HY, Zhong X, al. e. Diverse roles of TGF-beta receptor II in renal fibrosis and inflammation in vivo and in vitro. J Phatol. 2012;227:175-88. 
174. Sato M, Muragaki Y, Saika S, Roberts AB, Ooshima A. Targeted disruption of TGF-beta1/Smad3 signaling protects against renal tubulointerstitial fibrosis induced by unilateral ureteral obstruction. J Clin Invest. 2003;112:1486-94.

175. Zhong X, Chung AC, Chen HY, Meng XM, Lan HY. Smad3-mediated upregulation of miR-21 promotes renal fibrosis. J Am Soc Nephrol. 2011;22(1668-81).

176. Lan HY. Diverse roles of TGF- $\beta /$ Smads in renal fibrosis and inflammation. Int $\mathrm{J}$ Biol Sci. 2011;7(7):1056-67.

177. Gelasco AK, Raymond JR. Indoxyl sulphate induces complex redox alterations in mesangial cells. Renal Physiol. 2006;290:F1551-58.

178. Gómez-Guerrero C, Hernández-Vargas P, López-Franco O, Ortiz-Muñoz G, Egido J. Mesangial cells and glomerular inflammation: from the pathogenesis to novel therapeutic approaches. Curr Drug Targets Inflamm Allergy. 2005;4:341-51.

179. Martinez-Salgado C, Eleno N, Morales AI, Perez-Barriocanal F, Arevalo M, Lopez-Novoa JM. Gentamicin treatment induces simoultaneoues proliferation and apoptosis in rats. Kidney Int. 2004;65(2161-71).

180. Migliorini A, Ebid R, Scherbaum CR, Anders HJ. The danger control concept in kidney disease: mesangial cells. J Nephrol. 2013;26(437-449).

181. Pfeilschifter J. Mesangial cells orchestrate inflammation in the renal glomerulus. News Physiol Sci. 1994;9:271-6.

182. Ohashi R, Shimizu A, Masuda Y, Kitamura H, Ishizaki M, Sugisaki Y, et al. Peritubular capillary regression during the progression of experimental obstructive nephropathy. J Am Soc Nephrol. 2002;13:1795-805.

183. Suzuki S, Fukasawa H, Kitagawa K, Uchida C, Hattori T, Isobe T, et al. Renal damage in obstructive nephropathy is decreased in Skp2-deficient mice. Am J Pathol. 2007;171:473-83

184. Truong LD, Choi YJ, Tsao CC, Ayala G, Sheikh-Hamad D, Nassar G, et al. Renal cell apoptosis in chronic obstructive uropathy. The role of caspases. Kidney Int. 2001;60:924-34.

185. Misaki T, Yamamoto T, Suzuki S, Fukasawa H, Togawa A, Ohashi N, et al. Decrease in tumor necrosis factor-alpha receptor-associated death domain results from ubiquitin-dependent degradation in obstructive renal injury in rats. Am J Pathol. 2009;75:74-83.

186. Makino H, Sugiyama H, Kashihara N. Apoptosis and extracellular matrix-cell interactions in kidney disease. Kidney Int Suppl. 2000;77:S67-75.

187. Savill J. Apoptosis and the kidney. J Am Soc Nephrol. 1994;5:12-21.

188. Sugiyama H, Kashihara N, Makino H, Yamasaki Y, Ota A. Apoptosis in glomerular sclerosis. 49. 1996(103-11). 
189. Kato M, Yuan H, Xu ZG, Lanting L, Li SL, Wang M, et al. Role of the Akt/FoxO3a pathway in TGF-beta1-mediated mesangial cell dysfunction: a novel mechanism related to diabetic kidney disease. J Am Soc Nephrol. 2006;17:3325-35.

190. Anil Kumar P, Welsh GI, Saleem MA, Menon RK. Molecular and cellular events mediating glomerular podocyte dysfunction and depletion in diabetes mellitus. Frontiers in Endocrinology. 2014;5:Art 151.

191. Deckert T, eldt-Rasmussen B, Borch Johnsen K, Jensen T, Kofoed-Enevoldsen A. Albuminuria reflects widespread vascular damage. Thestnohypothesis. Diabetologia. 1989;32:219-26.

192. Kefalides NA. Basement membrane research in diabetes mellitus. Coll Relat REs. 1981;1:295-99.

193. Menne J, Park JK, Boehne M, Elger M, Lindschau C, Kirsch T, et al. Diminished loss of proteoglycans and lack of albuminuria in protein kinase C-alpha-deficient diabetic mice. Diabetes. 2001;53:2101-9.

194. Vernier RL, Steffes MW, SissonRoss S, Mauer SM. Heparan sulfate proteoglycan in the glomerular basement membrane in type1 diabetes mellitus. 41. 1992(1070-80).

195. Kriz W, Lemley KV. The role of the podocyte in glomerulosclerosis. Curr Opin Nephrol Hypertens. 1999;8(4):489-97.

196. Pagtalunan ME, Miller PL, Jumping-Eagle S, Nelson RG, Myers BD, Rennke HG. Podocyte loss and progressive glomerular injury in type II diabetes. J Clin Invest. 1997(99(2)).

197. Lee HS. Pathogenic role of TGF- $\beta$ in the progression of podocyte diseases. Histol Histopathol. 2011;26(1):107-16.

198. Fukuda A, Wickman LT, Venkatareddy MP, Sato Y, Chowdhury MA, Wang SQ, et al. AngiotensinII dependent persistent podocyte loss from destabilized glomeruli causes progression of end stage kidneydisease. 81. 2012(40-55).

199. Schiffer M, Bitzer M, Roberts IS, Kopp JB, Dijke P, Mundel P, et al. Apoptosis in podocytes induced by TGFbeta and Smad7. J Clin Invest. 2001;108:807-16.

200. Nam BY, Paeng J, Kim SH, Lee SH, Kim DH, Kang HY, et al. The MCP-1/CCR2 axis in podocytes is involved in apoptosis induced by diabetic conditions. Apoptosis. 2012;17:1-13.

201. Dalla Vestra M, Masiero A, Roiter AM, Saller A, Crepaldi G, Fioretto P. Is podocyte injury relevant in diabetic nephropathy?Studies in patients with type 2 diabetes. 52. 2003;1031-35. 